US Army Corps of Engineers ${ }_{\circledast}$

Engineer Research and

Development Center

\title{
Finite Element Analysis of Quoin Block Deterioration and Load Transfer Mechanisms in Miter Gates
}

Pintle and Pintle Connections

DeAnna L. Dixon and Wayne D. Hodo

May 2021

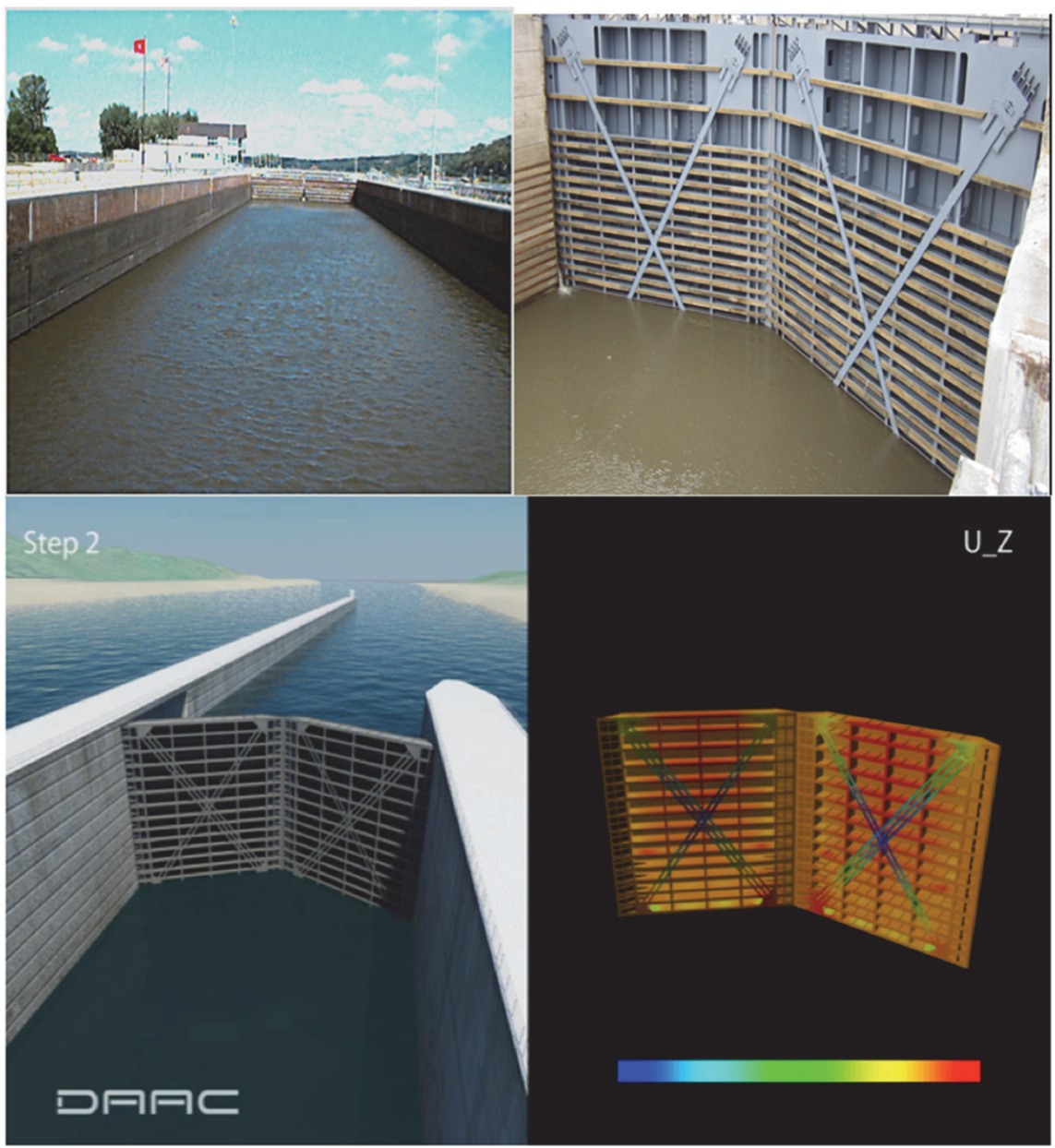


The U.S. Army Engineer Research and Development Center (ERDC) solves the nation's toughest engineering and environmental challenges. ERDC develops innovative solutions in civil and military engineering, geospatial sciences, water resources, and environmental sciences for the Army, the Department of Defense, civilian agencies, and our nation's public good. Find out more at www.erdc.usace.army.mil.

To search for other technical reports published by ERDC, visit the ERDC online library at https://erdclibrary.on.worldcat.org/discovery. 
ERDC TR-21-9

May 2021

\title{
Finite Element Analysis of Quoin Block Deterioration and Load Transfer Mechanisms in Miter Gates
}

Pintle and Pintle Connections

\author{
DeAnna L. Dixon \\ U.S. Army Engineer Research and Development Center (ERDC) \\ Information Technology Laboratory (ITL) \\ 3909 Halls Ferry Road \\ Vicksburg, MS 39180-6199 \\ Wayne D. Hodo \\ U.S. Army Engineer Research and Development Center (ERDC) \\ Geotechnical and Structures Laboratory (GSL) \\ 3909 Halls Ferry Road \\ Vicksburg, MS 39180-6199
}

Technical Report (TR)

Approved for public release; distribution is unlimited.

\footnotetext{
Prepared for This effort was partially funded under the ERDC Information Technology Laboratory Training Program. This report was used to meet my Master's degree program requirements. The research topic was developed under the purview of the USACE- Mobile District.
} 


\section{Abstract}

The U.S. Army Corps of Engineers (USACE) currently operates and maintains approximately 193 commercially active lock sites with 239 locks and dams spanning nearly 12,000 miles. These networks of water channels are used to transport 600 million tons of domestic cargo, generating $\$ 405$ billion in revenue annually. Nearly $60 \%$ of these structures in operation are over 50 years old and have reached design life. A failure of the miter gates could result in a major negative impact on the economy and on the ability to maintain flood control. Administrators need recommendations to better prioritize maintenance and repair of the USACE miter gates. This work investigated the influence of miter gate's quoin block degradation on load transfer to the pintle and/or pintle connections. Results of finite element analysis are reported for the quoin block degradation simulated levels of $0 \%, 25 \%, 50 \%$, and $75 \%$. The parametric study shows the overstressed regions are the pintle neck and bolt-hole regions. To improve pintle designs so they may better mitigate detrimental environmental based deterioration effects, this work recommends (1) increasing the thickness of the bolthole connection region and (2) adding ribbing reinforcement around the neck area of the pintle.

DISCLAIMER: The contents of this report are not to be used for advertising, publication, or promotional purposes. Citation of trade names does not constitute an official endorsement or approval of the use of such commercial products. All product names and trademarks cited are the property of their respective owners. The findings of this report are not to be construed as an official Department of the Army position unless so designated by other authorized documents. 


\section{Contents}

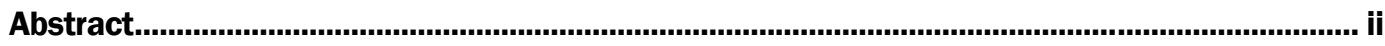

Figures and Tables.........................................................................................................................................

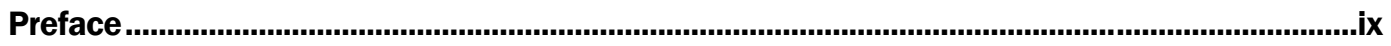

1 Introduction......................................................................................................................... 1

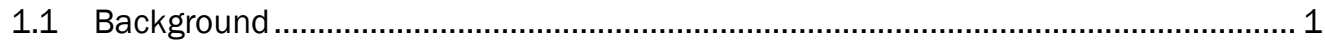

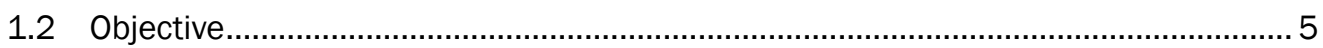

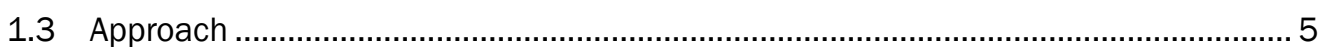

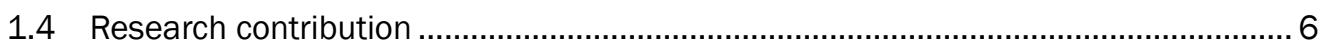

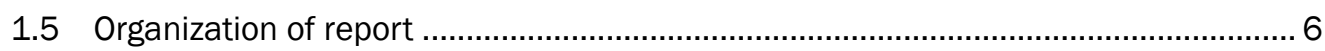

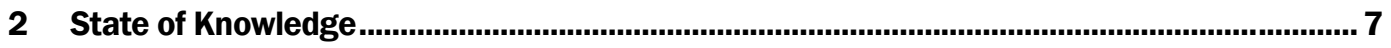

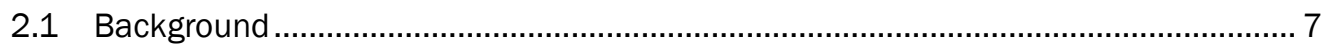

2.2 Miter gate design .............................................................................................. 7

2.2.1 Load and resistance factor design criteria (LRFD) for miter gates ............................ 7

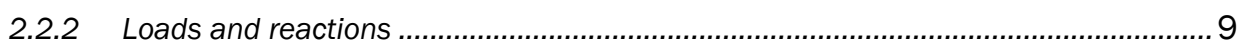

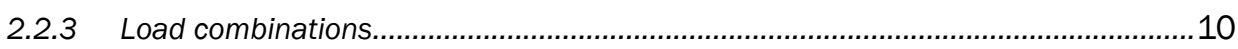

2.2.4 Pintle design .............................................................................................. 11

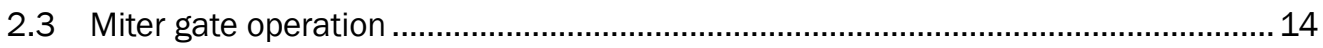

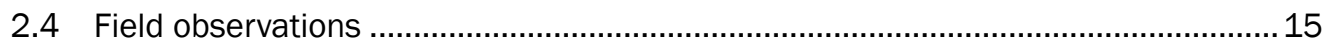

2.4.1 Background for USACE research programs...........................................................15

2.4.2 U.S. Army Engineer Research and Development Center (ERDC) and USACE Mobile District site assessment ......................................................................... 19

2.5 Deterioration prediction models for steel structures and miter gates......................24

2.6 Computational analysis of miter gates .....................................................................26

2.7 Overall state-of-knowledge summary .............................................................. 27

3 3D Finite Element Model (FEM) Development and Analysis Criteria.................................29

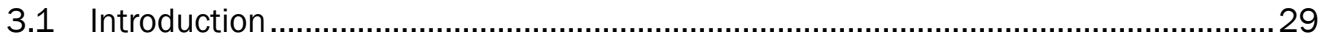

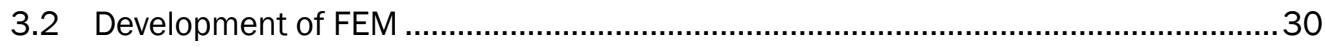

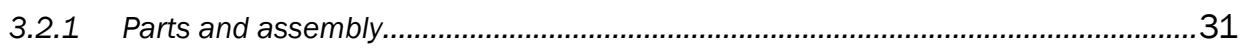

3.2.2 Finite element type and meshing....................................................................... 32

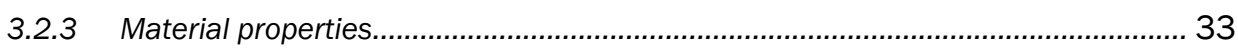

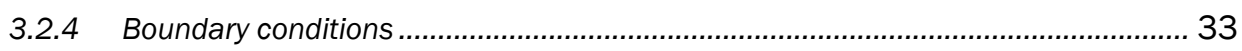

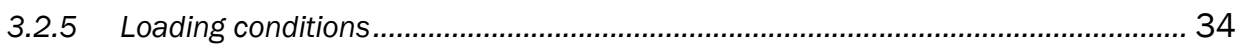

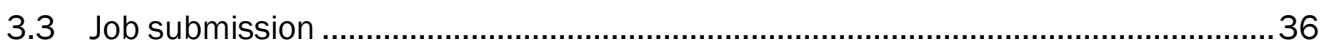

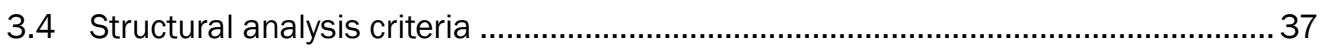

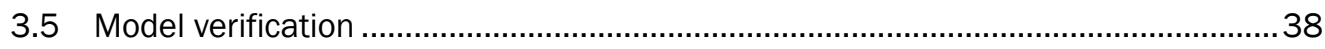

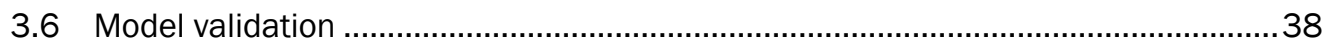

3.7 Overall computational modeling methodology summary ........................................39

4 Results of Parametric Analyses......................................................................................40

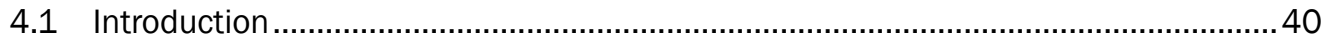


4.2 Plane view results of quoin block deterioration states............................................. 40

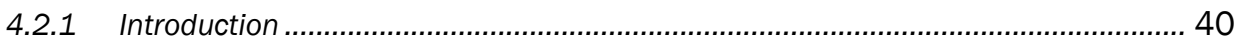

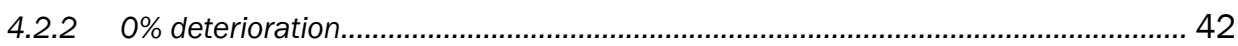

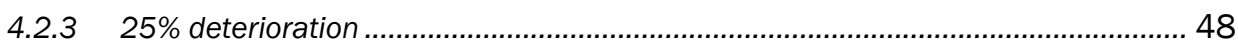

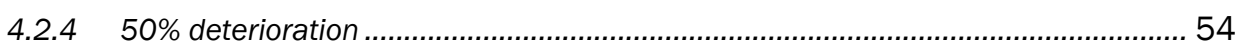

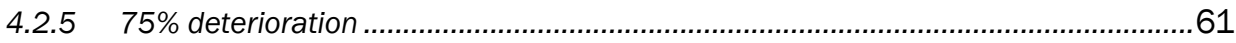

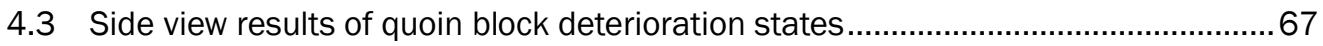

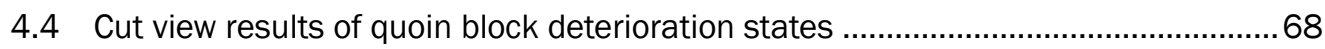

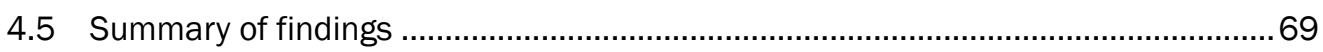

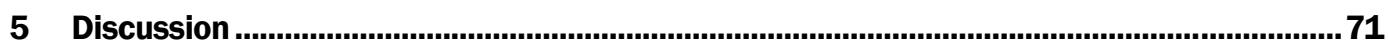

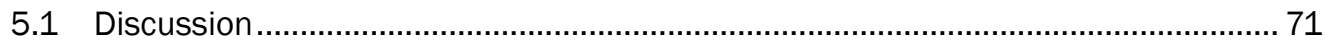

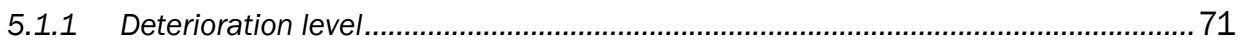

5.1.2 Predicted results versus field observations.......................................................... 72

5.1.3 Recommendations for pintle designs and retrofits.............................................. 74

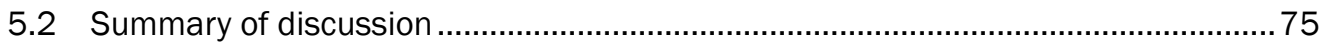

6 Summary, Conclusions, and Future Work ……...........................................................

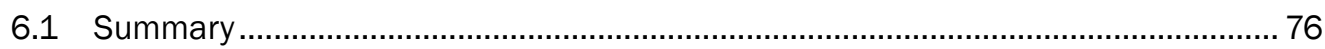

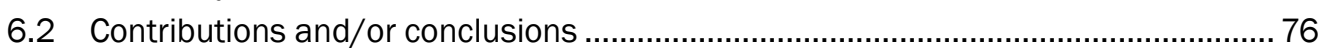

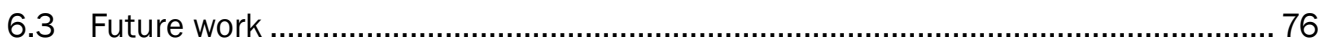

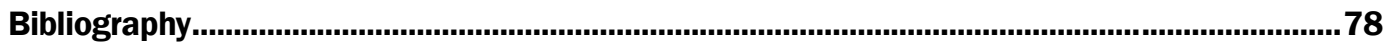

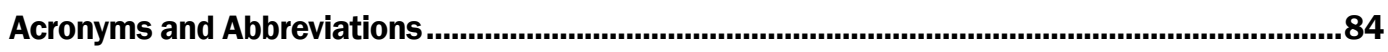

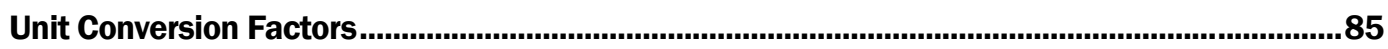

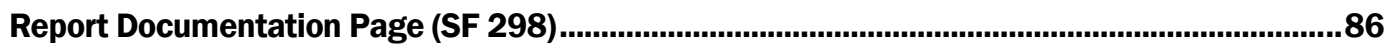




\section{Figures and Tables}

Figure

Page

1-1 Inland and intracoastal waterway system of the United States 2

1-2 Typical miter gate leaves 3

1-3 Miter gate in its closed position (mitered) 3

1-4 Miter gate open and operating 4

1-5 Quoin block deterioration (gap observed) 4

1-6 Cracking in the pintle region (left); Bolt failure in the connection of the pintle with the gate (right)

2-1 Horizontally framed miter gate in the open position (Tom Bevill lock and dam miter gate)

2-2 Illustration of intermediate diaphragms used to provide vertical support within the miter gate

2-3 Illustration of hydrostatic loads acting on a horizontally framed miter gate

2-4 Illustration of pintle parts: (a) socket, (b) pintle, (c) shoe, (d) base not shown

2-5 Finite element model (FEM) of pintle socket connected to the bottom of the last girder web with steel bolts

2-6 Schematic of forces acting on the pintle 13

2-7 Schematic of reaction forces of $\boldsymbol{R} \boldsymbol{a}$ and $\boldsymbol{R} \boldsymbol{b}$ on gate 14

2-8 Photograph of Aberdeen Lock and Dam miter gate 20

2-9 Photograph of gap observed between the quoin block and lock wall 21

2-10 Photograph of Aberdeen Lock and Dam pintle left and right with crack

2-11 Photograph of John C. Stennis Lock and Dam miter gate 22

2-12 Photograph of John C. Stennis Lock and Dam pintle with cracks 22

2-13 Photograph of Tom Bevill Lock and Dam miter gate 23

2-14 Photograph of Tom Bevill Lock and Dam pintle with cracks 23

3-1 Aerial photographic view of Lock and Dam $27 \quad 29$

3-2 Photograph of LD27 miter gate that was used for modeling 30

3-3 Schematic of LD27 miter gate that was used for modeling 30

3-4 Computational modeling and simulation flow chart 31

3-5 Miter gate model and the sub-components for the miter gate meshed with finite elements

3-6 Illustration of typical nonlinear uniaxial tensile behavior for metals represented by an assumed bilinear (elastic-perfectly plastic) 
constitutive material model

3-7 Illustration of the globally applied boundary conditions for the gudgeon pin, quoin block, and miter block

3-8 Illustration of the applied hydrostatic differential pressure loads to miter gate

3-9 Illustrates the failure envelope of the von Mises yield criterion

4-1 Degradation (boundary conditions removal) of the quoin block boundary conditions in the FEM

4-2 Location of the horizontal and vertical paths on the pintle

4-3 Contour plot showing von Mises stress and critical stress region at 0\% deterioration (plan view)

4-4 Stress plot showing von Mises stress along "Horizontal- Load Path 1" at $0 \%$ deterioration

4-5 Stress plot showing von Mises stress along “Horizontal-Load Path 2" at $0 \%$ deterioration

4-6 Stress plot showing von Mises stress along “Horizontal-Load Path 3" at $0 \%$ deterioration

4-7 Stress plot showing von Mises stress along "Horizontal-Load Path 4" at $0 \%$ deterioration

4-8 Stress plot showing von Mises stress along "Vertical Load Path 1" at $0 \%$ deterioration

4-9 Stress plot showing von Mises stress along "Vertical Load Path 2" at $0 \%$ deterioration

4-10 Stress plot showing von Mises stress along "Vertical Load Path 3" at 0\% deterioration

4-11 Stress plot showing von Mises stress along "Vertical Load Path 4" at $0 \%$ deterioration

4-12 Contour plot showing von Mises stress and critical stress region at (a) $0 \%$ and (b) $25 \%$ deterioration levels (plane view)

4-13 Stress plot showing von Mises stress along "Horizontal- Load Path 1" at $0 \%$ and $25 \%$ deterioration levels

4-14 Stress plot showing von Mises stress along "Horizontal- Load Path 2" at $0 \%$ and $25 \%$ deterioration levels

4-15 Stress plot showing von Mises stress along "Horizontal- Load Path 3" at $0 \%$ and $25 \%$ deterioration levels

4-16 Stress plot showing von Mises stress along "Horizontal- Load Path 4" at $0 \%$ and $25 \%$ deterioration levels

4-17 Stress plot showing von Mises stress along "Vertical- Load Path 1" at $0 \%$ and $25 \%$ deterioration levels 
Figure

0\% and $25 \%$ deterioration levels

4-19 Stress plot showing von Mises stress along "Vertical- Load Path 3" at $0 \%$ and $25 \%$ deterioration levels

4-20 Stress plot showing von Mises stress along "Vertical- Load Path 4" at $0 \%$ and $25 \%$ deterioration levels

4-21 Contour plot showing von Mises stress and critical stress region at (a) $0 \%$ and (b) 50\% deterioration levels (plane view)

4-22 Stress plot showing von Mises stress along "Horizontal- Load Path 1" at $0 \%$ and $50 \%$ deterioration levels

4-23 Stress plot showing von Mises stress along "Horizontal- Load Path 2" at $0 \%$ and $50 \%$ deterioration levels

4-24 Stress plot showing von Mises stress along “Horizontal- Load Path 3" at $0 \%$ and $50 \%$ deterioration levels

4-25 Stress plot showing von Mises stress along "Horizontal- Load Path 4" at $0 \%$ and $50 \%$ deterioration levels

4-26 Stress plot showing von Mises stress along "Vertical- Load Path 1" at $0 \%$ and $50 \%$ deterioration levels

4-27 Stress plot showing von Mises stress along "Vertical- Load Path 2" at $0 \%$ and $50 \%$ deterioration levels

4-28 Stress plot showing von Mises stress along "Vertical- Load Path 3" at $0 \%$ and $50 \%$ deterioration levels

4-29 Stress plot showing von Mises stress along "Vertical- Load Path 4" at $0 \%$ and $50 \%$ deterioration levels

4-30 Contour plot showing von Mises stress and critical stress region at (a) $0 \%$ and (b) 75 deterioration levels (plane view)

4-31 Stress plot showing von Mises stress along "Horizontal- Load Path 1" at $0 \%$ and $75 \%$ deterioration levels

4-32 Stress plot showing von Mises stress along "Horizontal- Load Path 2" at $0 \%$ and $75 \%$ deterioration levels

4-33 Stress plot showing von Mises stress along "Horizontal- Load Path 3" at $0 \%$ and $75 \%$ deterioration levels

4-34 Stress plot showing von Mises stress along "Horizontal- Load Path 4" at $0 \%$ and $75 \%$ deterioration levels

4-35 Stress plot showing von Mises stress along "Vertical- Load Path 1" at $0 \%$ and $75 \%$ deterioration levels

4-36 Stress plot showing von Mises stress along "Vertical- Load Path 2" at $0 \%$ and $75 \%$ deterioration levels

4-37 Stress plot showing von Mises stress along "Vertical- Load Path 3" at $0 \%$ and $75 \%$ deterioration levels

4-38 Stress plot showing von Mises stress along "Vertical- Load Path 4" at 
Figure

Page

0\% and $75 \%$ deterioration levels

67

4-39 Contour plot showing von Mises stress and stress distribution along the pintle's “X-Z" -direction at: (a) 0\%, (b) 25\%, (c) 50\%, and (d) $75 \%$ deterioration levels (side views)

68

4-40 Contour plot showing von Mises internal stress and stress distribution through the pintle's "Y-Z" -direction at: (a) 0\%, (b) 25\%, (c) $50 \%$, and (d) $75 \%$ deterioration levels (cut views)

5-1 The (a) 3D-FEM correctly predicting the exact (b) field observed cracking and crack propagating in the bolt-hole region of the pintle region for the Bevill Lock and Dam, located in the USACE Mobile District

5-2 The (a) 3D-FEM correctly predicting the exact, and (b) field observed cracking in the neck region of the pintle region for the John $\mathrm{C}$.

Stennis Lock and Dam, located in the USACE Mobile District 


\section{Preface}

The work described herein was funded by the U.S. Army Engineer Research and Development Center (ERDC). This effort was partially funded under the ERDC Information Technology Laboratory Training Program. This report was used to meet my Master's degree program requirements. The research topic was developed under the purview of the USACE-Mobile District. The research described and the resulting analyses presented herein was executed with oversight provided by my Master's Committee Chairman, Professor Phillip Gullett, at the Mississippi State University (MSU) Civil and Environmental Engineering Department. The original version of this report was submitted to MSU in partial fulfillment of the requirements for the degree of Master of Science in Civil Engineering (MSCE), December 2016.

The study was conducted by the CAD/BIM Technology Center for (ISC), of the Software Engineering Informatics Division (IS), ERDC Information Technology Laboratory (ERDC-ITL) and the Airfields and Pavements Branch (GMA), of the Engineering Systems and Materials Division (ESMD), ERDC Geotechnical and Structures Laboratoty (ERDC-GSL). At the time of publication, Ms. Mariangelica Carrasquillo-Mangual was Chief of the CAD/BIM Technology Center, and Dr., Jacqueline Pettway was Acting Chief of the Software Engineering Informatics Division. At the time of publication, Mrs. Anna Jordan was Chief of the Airfields and Pavements Branch, and Mr. Justin Strickler was Chief of the Engineering Systems and Materials Division. Ms. Patti S Duett was the Deputy Director and Dr. David A. Horner was Director of ERDC-ITL. Mr. Charles Ertle, III was the Deputy Director, and Mr. Bart Durst was Director of ERDC-GSL.

COL Teresa A. Schlosser was Commander of ERDC, and Dr. David W. Pittman was the Director. 
THIS PAGE INTENTIONALLY LEFT BLANK 


\section{Introduction}

\subsection{Background}

The U.S. Army Corps of Engineers (USACE) currently operates and maintains approximately 193 commercially active lock sites with 239 locks and dams. Corps lock sites provide access to navigation channels that span nearly 12,000 miles of inland and intracoastal waterways (Figure 1-1) (USACE 2013). The U.S. inland waterway system's locks and dams are very important to the transportation of agricultural and industrial goods (McAllister and Ellingwood 2001). The U.S. waterway system transports more than half of the nation's grain and oilseed exports, about $20 \%$ of the coal for utility plants, and about 22\% of domestic petroleum (Grier 2009, Padula et al. 2010). This network of water channels transports 600 million tons annually of domestic cargo such as raw materials, liquid, and bulk primary products (e.g., coal, petroleum, sand, cement, processed metals, etc.). The Mississippi River generates $\$ 405$ billion in revenue annually (Cullen 2015).

The large hydraulic steel miter gate structures are critical components for this system's water locks, which help regulate water flow and provide controlled access to navigable rivers. Maintaining miter gate operation is critical as nearly $60 \%$ of these structures in operation are over 50 years old and have reached their design life (USACE 2013). A failure of the miter gates could cause the locks to be inoperable, result in river traffic delays that would cause significant negative impacts on the economy (billions of dollars in lost revenue), and compromise the ability to maintain flood control, which could result in unwanted inland flooding, damage to residential and commercial property, and loss of life.

One of the largest expenditures for locks and dams is the maintenance and repair of miter gates. Field inspection reports provide evidence of fatigue cracking and/or corrosion deterioration of the miter gates (Estes et al. 2004). In September 2013 field inspections were conducted of the Tombigbee River miter gates. The observed damages were shown to repeatedly occur in the pintle and pintle connection region. USACE engineers suspected the damage might have been caused by quoin block deterioration. 
Figure 1-1. Inland and intracoastal waterway system of the United States.

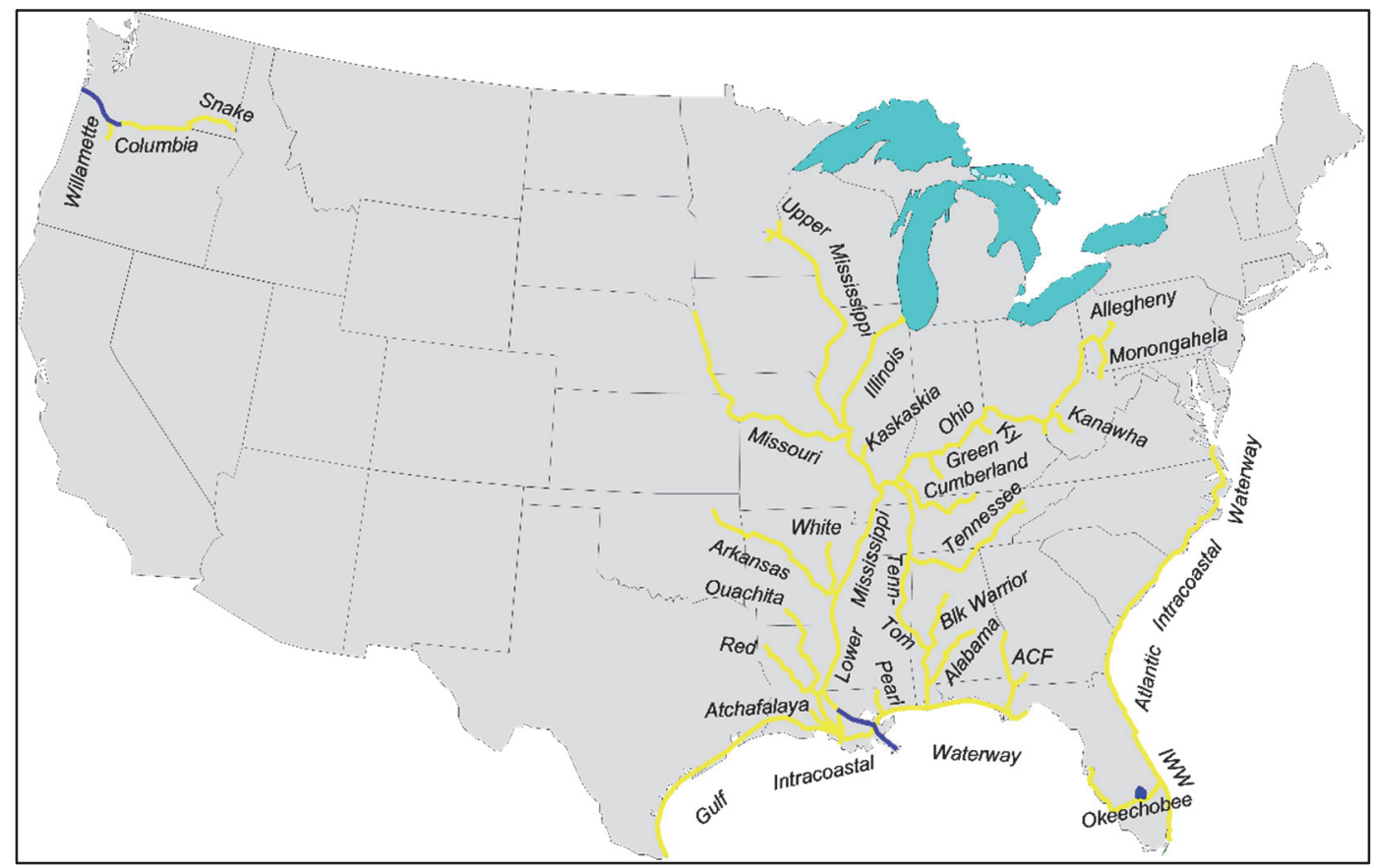

Source: Grier (2009).

A typical miter gate (Figure 1-2) consists of two leaves that operate by swinging about their supports at the concrete lock wall and by meeting at a 30-deg angle when closed (mitered) (Figure 1-3) (Estes et al. 2004). The quoin block (Figure 1-4), a vertical rectangular block located on the quoin end of the miter gate, has a convex surface, and the wall quoin (located on the lock wall) has a concave surface. The quoin block sets in the wall quoin and makes complete contact. In the September 2013, field observations indicated the quoin block had deteriorated and had very little contact with the wall quoin (Figure 1-5). Because the quoin block is the most critical load bearing structural component, the USACE implemented a quality control and quality assurance (QC/QA) plan to closely monitor any deterioration that may occur during installation and operation of the miter gate. However, despite the strict QC/QA measures, a sufficient characterization of the potential effects of deterioration on the gate operation and longterm performance was lacking. 
Figure 1-2. Typical miter gate leaves.

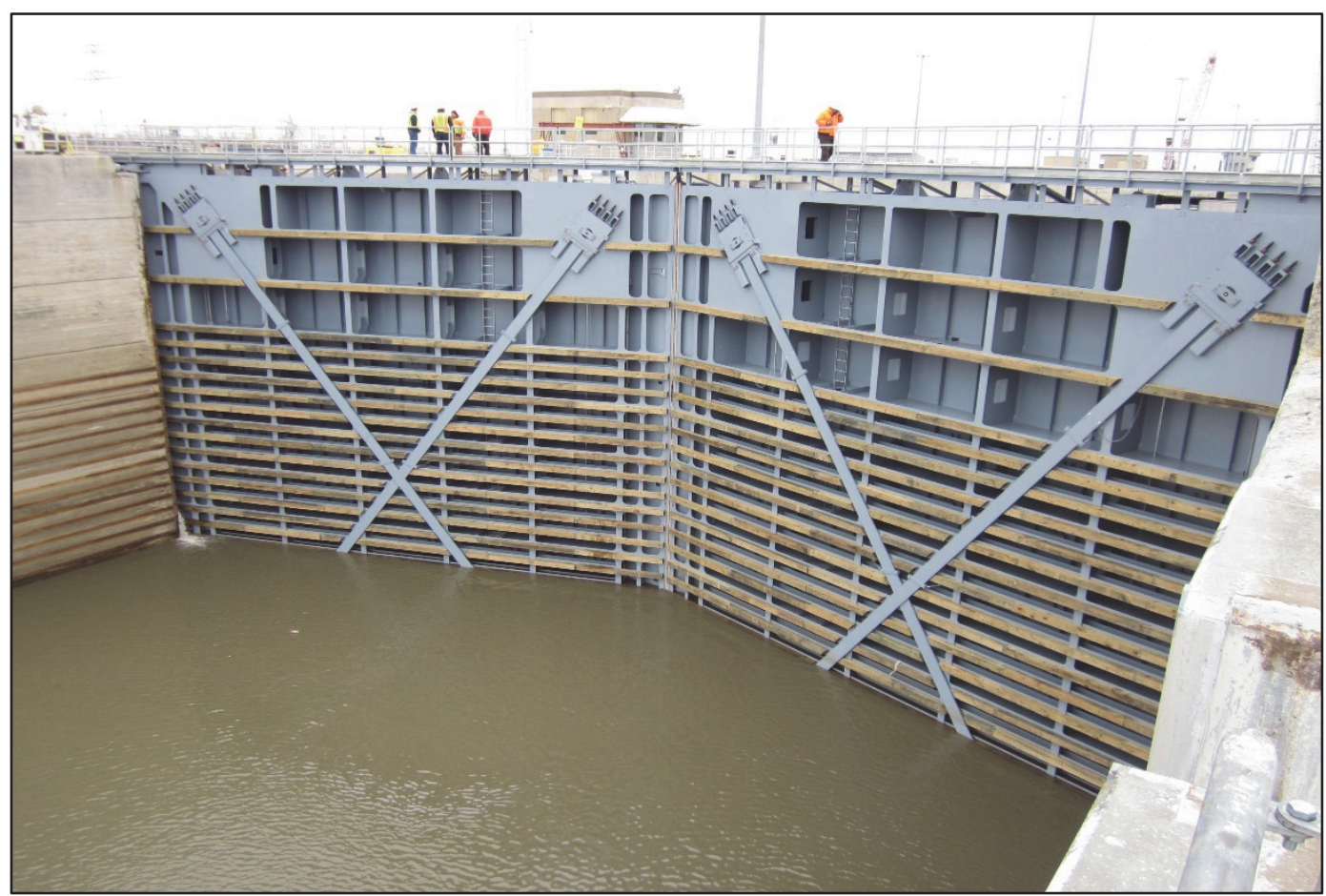

Source: USACE District, St. Louis (2013).

Figure 1-3. Miter gate in its closed position (mitered).

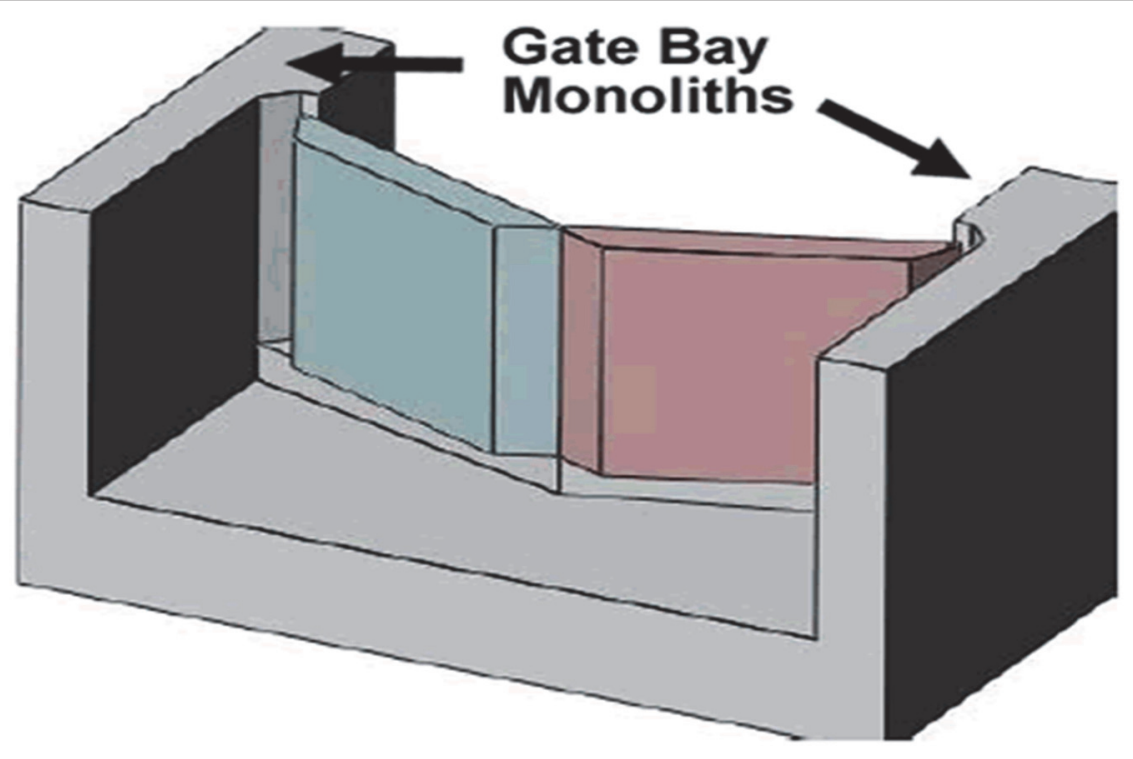

Closed holding water

Source: USACE (2008a). 
Figure 1-4. Miter gate open and operating.

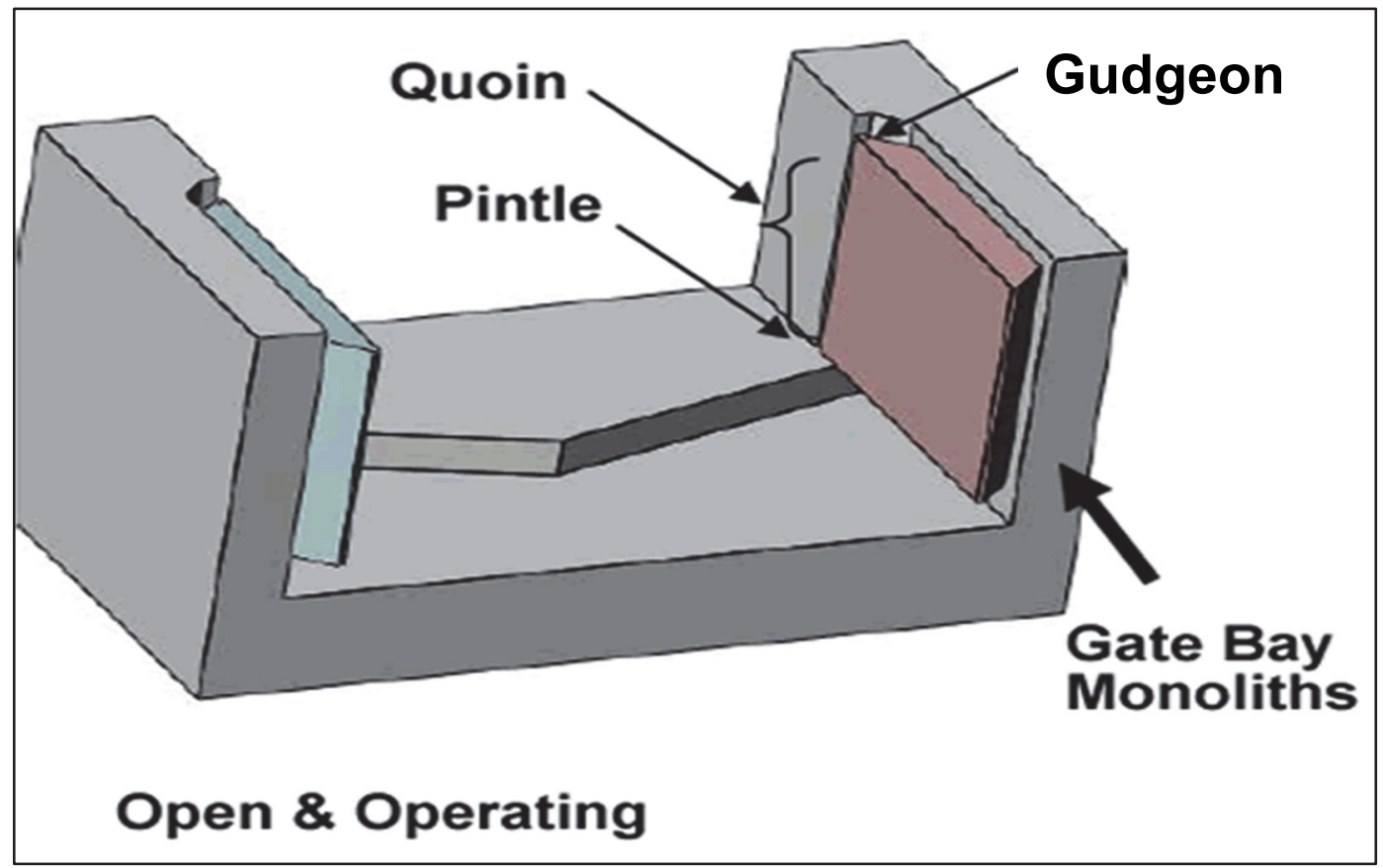

Source: USACE (2008b).

Figure 1-5. Quoin block deterioration (gap observed).

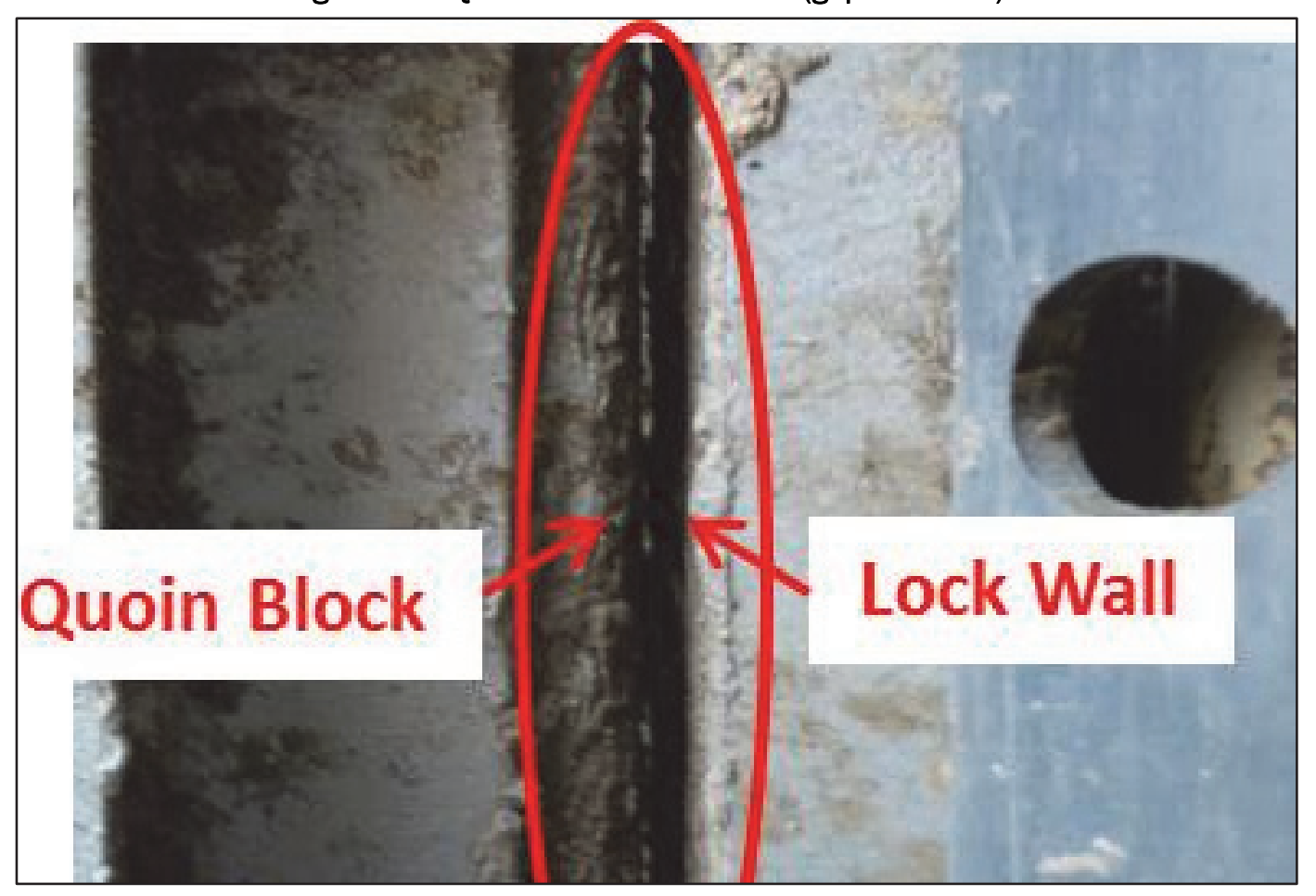




\subsection{Objective}

The objective of this investigation was to determine the influence quoin block deterioration and loss of lock wall contact has on load transfer to the pintle (component that the gate pivots on) and pintle connections. The pintle is thought to be the most important structural component mainly affected by quoin block deterioration. ${ }^{*}$ Damage to the pintle may lead to premature loss of operational capacity and overall performance of the miter gate. The hypothesis $(H)$ is when the quoin block deteriorates and loses contact with the lock wall, the miter gate adds excessive loads to the pintle region, which leads to accelerated cracking and failure of its components (Figure 1-6).

Figure 1-6. Cracking in the pintle region (left); Bolt failure in the connection of the pintle with the gate (right).

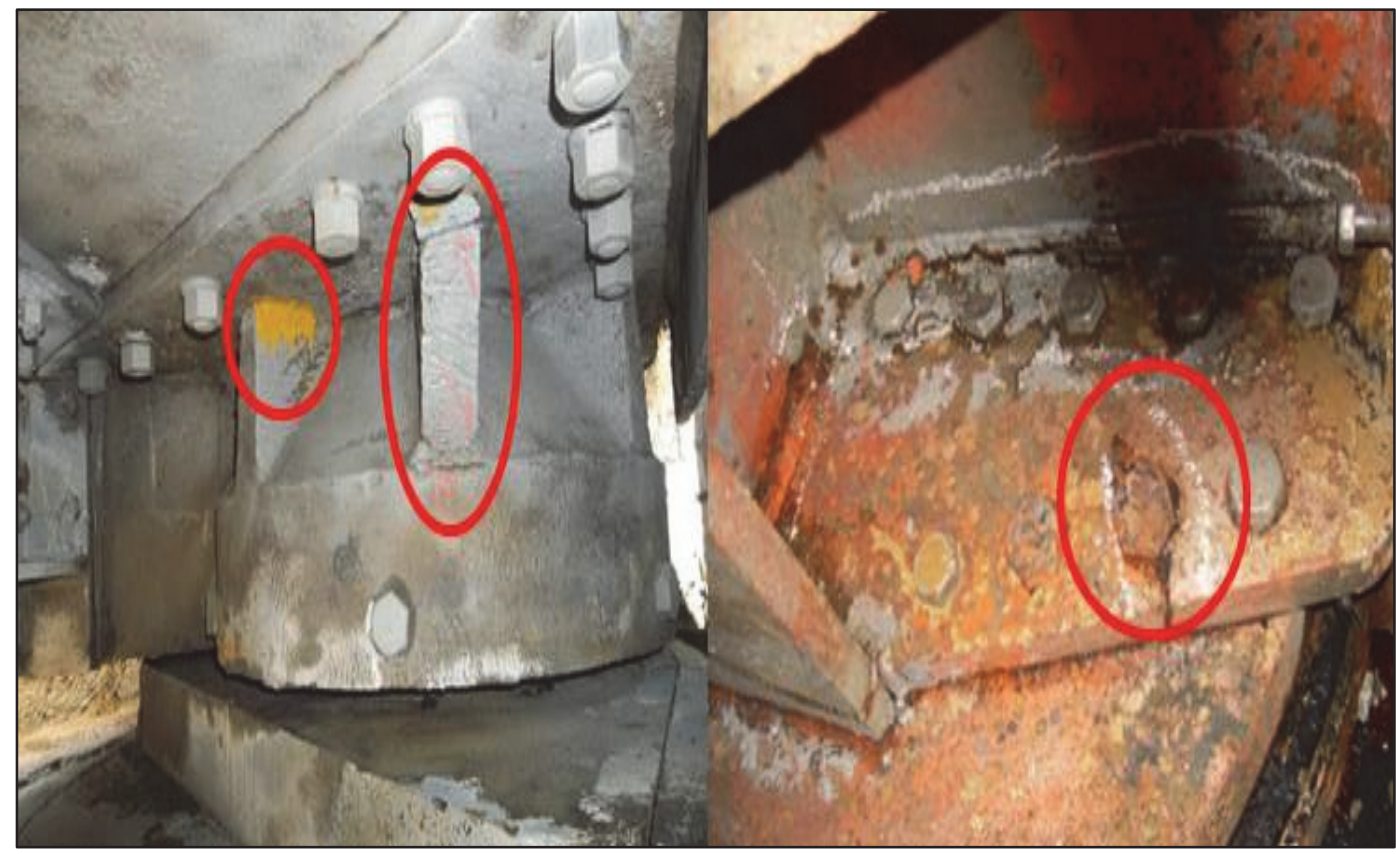

\subsection{Approach}

A three dimensional (3D) finite element model (FEM) is representative of the in-service miter gate structures used in the United States was developed. The Lock and Dam 27 (LD27) miter gate located in Granite City, Illinois, was modeled. The LD27 gate was chosen because USACE provided the as-built drawings, technical specifications, and the design report. Finite element analysis (FEA) was used to quantify the effects of quoin block

* U.S. Army Engineer Research and Development Center (ERDC). 2013. Internal Memorandum. 
deterioration between the lock wall and miter gate as a function of stress level changes occurring in the pintle region. The approach used in this investigation was:

1. Finite element simulations were conducted at $0 \%, 25 \%, 50 \%$, and $75 \%$ quoin block deterioration levels so that the stress state in the pintle and pintle connectors could be analyzed.

2. The results from the simulated parametric stress analysis were then compared to the load and resistance factor design (LFRD) based design for LD27 pintle to the von Mises yield stress criterion.

\subsection{Research contribution}

The understanding of how deterioration affects miter gates is vital to USACE. The deterioration of a miter gate's elements can threaten its operation and potentially cause undesired costly catastrophic damage to adjacent river connected communities. This unique study developed and provided representative FEM of the in-service miter gate structures used in the United States. Furthermore, the numerical analysis provided a sufficient method for evaluating the pintle designs by evaluating quoin block deterioration and load transfer in the assembled components.

\subsection{Organization of report}

Chapter 2 of this report provides a detailed overview of the current state of knowledge for the design, operation, inspection, and monitoring of miter gates. Chapter 3 describes the 3D FEM development and analysis criteria. Chapter 4 discusses the simulation results for the parametric analysis of quoin block deterioration and load transfer in the pintle and pintle connections. Chapter 5 discusses specific questions raised by the hypothesis, model prediction comparisons to previous field inspection observations, and recommended design modifications. Chapter 6 summarizes the contributions and conclusions drawn from this investigation and makes recommendations for future work. 


\section{State of Knowledge}

\subsection{Background}

USACE has the responsibility for operating and maintaining United States' 193 commercially navigable waterways, which contain 239 locks and dams (USACE 2013). A large number of the locks are opened and closed by miter gates. Miter gates have several different purposes, e.g., they form a damming surface across the lock chamber, they serve as guard gates for filling and emptying the lock chamber, and they provide access from one lock wall to another (Riveros 1995).

\subsection{Miter gate design}

In the United States, locks are designed with double-leaf miter gates that allow the water level in the lock chamber to coincide with the upper and lower approach channels. Miter gates are either horizontally or vertically framed. Horizontally framed miter gates provide greater structural capacity, greater rigidity, better resistance to barge impact, and are significantly lower in cost than vertically framed gates. For these reasons, USACE exclusively uses horizontally framed miter gates (Riveros 1995). A horizontally framed miter gate (Figure 2-1) consists of a skin plate supported with horizontal girders. The horizontal members are supported by the vertical quoin block at one end and the vertical miter block at the other end. The quoin block secures the gate to the concrete wall. The miter block on the opposite end makes contact at a 30-degree angle with the opposite miter gate leaf's miter block. Figure 2-2 shows the intermediate diaphragms that provide additional vertical supports within the miter gate for reinforcing the girder's stiffness in accordance with EM-1110-2-2703 (HQUSACE 1994).

\subsubsection{Load and resistance factor design criteria (LRFD) for miter gates}

USACE uses the LRFD approach in accordance with EM 1110-2-2105 (HQUSACE 1993) and American Institute of Steel (AISC) code (AISC 2001). The LRFD does not consider dynamic loading conditions directly. Instead, the LFRD accounts for the external dynamic forces acting on the structure by limiting the structure's load carrying capacity, providing a suitable safety factor. 
Figure 2-1. Horizontally framed miter gate in the open position (Tom Bevill Lock and Dam miter gate).

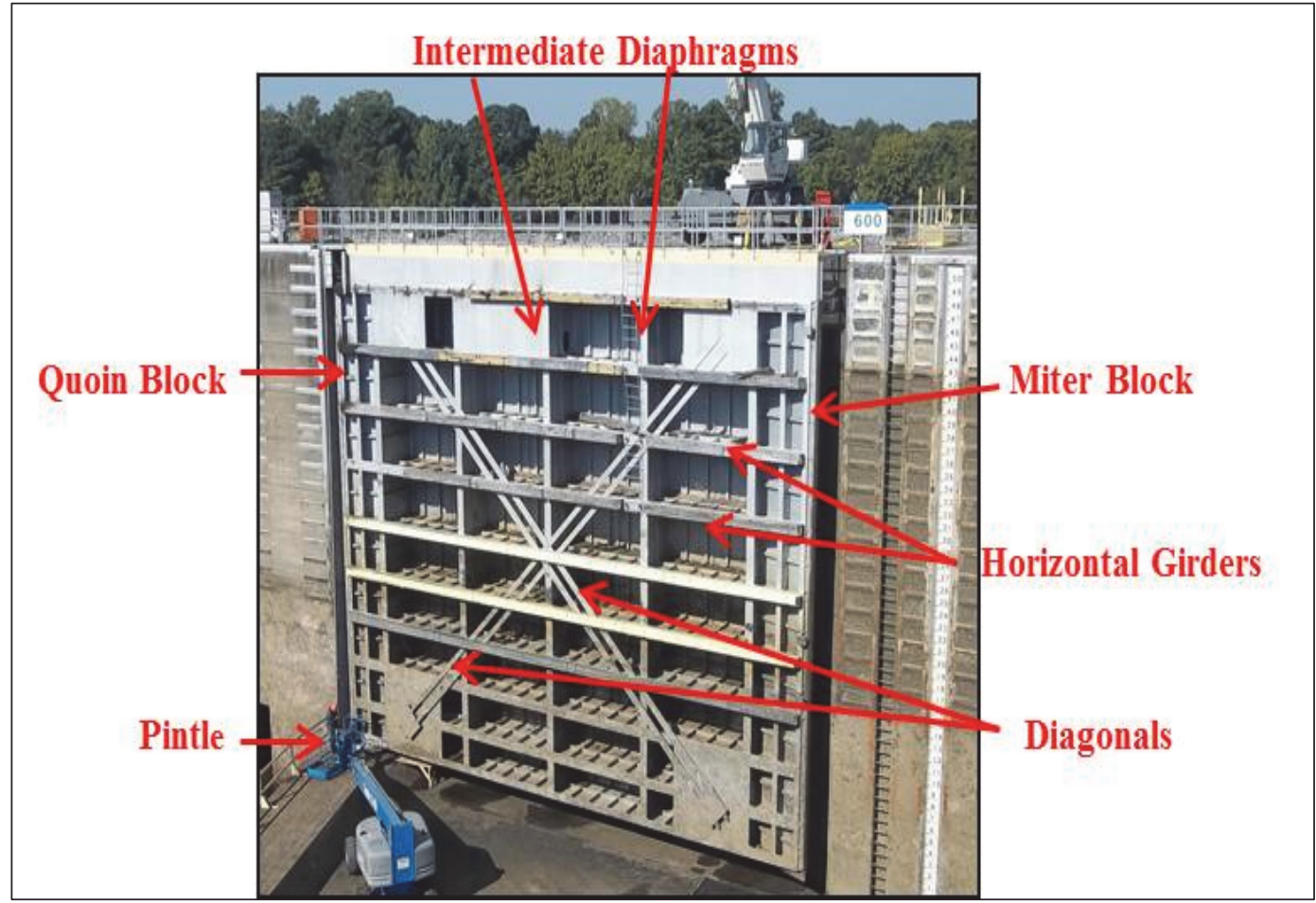

Figure 2-2. Illustration of intermediate diaphragms used to provide vertical support within the miter gate.

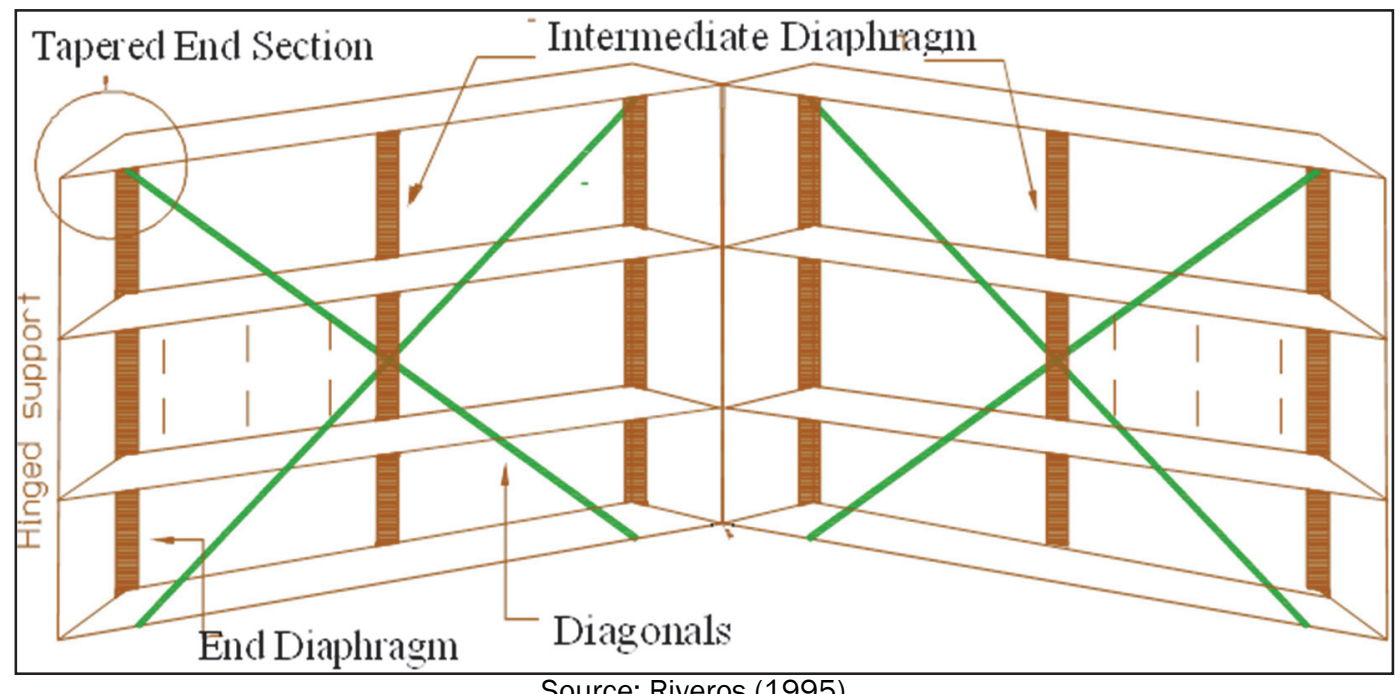

Source: Riveros (1995).

The LRFD is a method of proportioning structures so the predefined stress state is not exceeded when fully loaded. The LRFD method has two main advantages over the Allowable Stress Design (ASD) method. The first advantage of LRFD is one does not have to assume linearity between load and force or force and stress in a limit state stress analysis. The second advantage is the 
LRFD method allows multiple load combination factors to be used to make up for the degree of uncertainty of different loads. The LRFD criteria provide a more uniform reliability in the EM-1110-2-2105 (HQUSACE 1993) design process. The as-built designs for the LD27 miter gate were based on the EM 1110-2-2105 before the 2014 specification update.

\subsubsection{Loads and reactions}

Loads included in the design of miter gates are gravity $(W)$, hydraulic $\left(H_{s}\right)$, operating $(Q)$, barge impact $(I)$, and earthquake loads $(E)$. The reactions of the gates are divided into two categories: when the gate is open and has no water load or when the leaves are mitered and supporting the full hydrostatic load in accordance with EM 1110-2-2703 (HQUSACE 1994). The current study considered only gravity and hydraulic loads. Barge impact, earthquake, and operating loads do not contribute to environmental based deterioration of the hydraulic steel structures (HSS). Investigating non-environmental based deterioration is outside the scope of the current study and will not be discussed in further detail.

\subsubsection{Gravity loads (W)}

Gravity loads consist of the dead load (D), ice loads $(C)$, and/or mud loads $(M)$ based on site-specific conditions.

\subsubsection{Hydraulic loads $\left(H_{s}\right)$}

Hydraulic loads consist of static water loads on the gate produced by the pool differential or temporal hydraulic loads (Figure 2-3). The temporal hydraulic load, $H_{t}$, is equal to $1.25 \mathrm{ft}$ of head as specified in Paragraph 3-9 of EM 1110-2-2703 (HQUSACE 1994). The temporal hydraulic loads are temporary changes in water level resulting in a differential water level on opposite sides of a lock gate. This may be caused by over-travel of water in the valve culvert during filling or emptying, wind waves, ship waves, propeller wash, etc. The hydrostatic load, $H_{s}$, is determined based on site-specific conditions for upper and lower pool elevation. 
Figure 2-3. Illustration of hydrostatic loads acting on a horizontally framed miter gate.

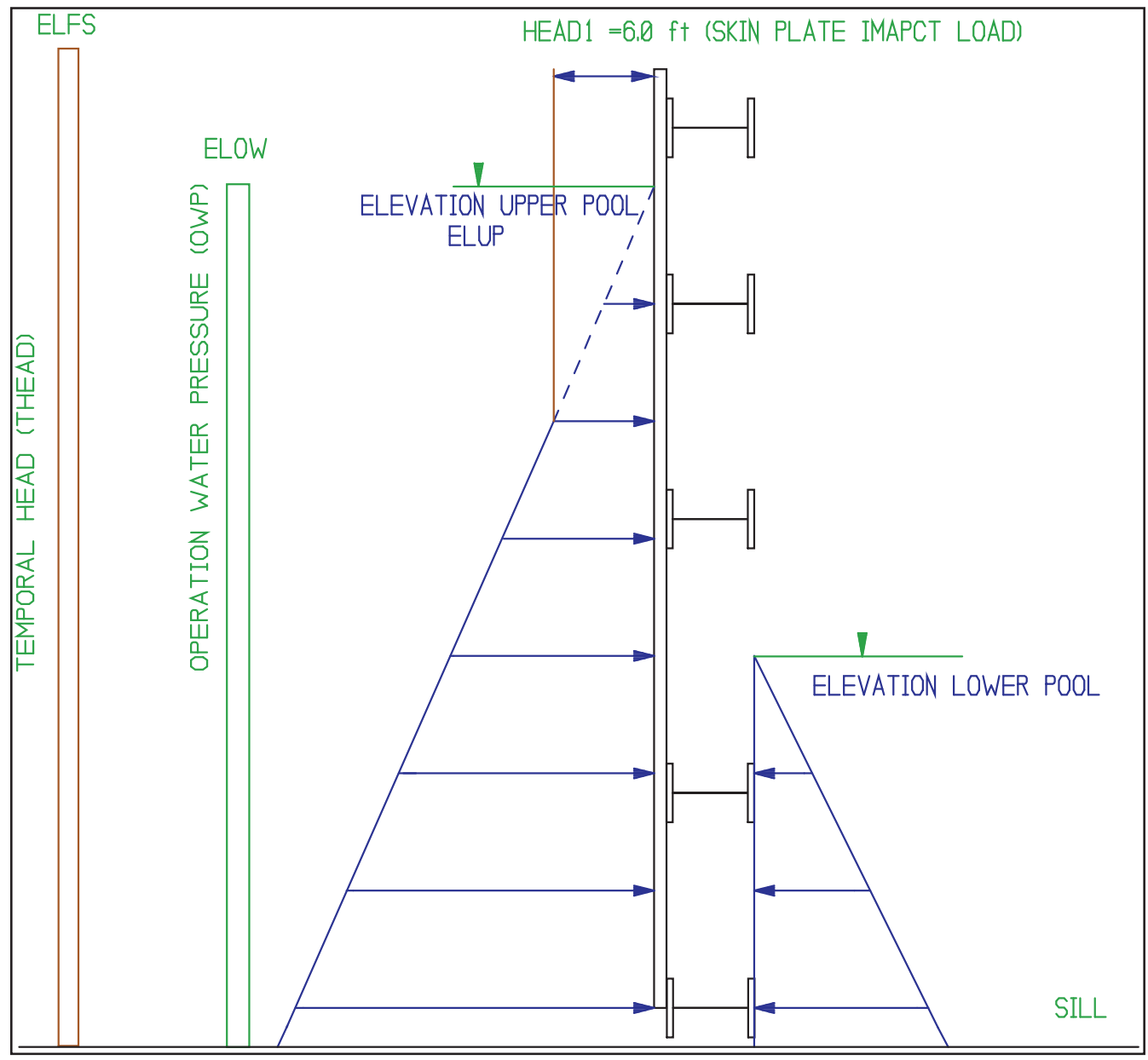

Source: Riveros (1995).

\subsubsection{Load combinations}

The load case for this study was determined using EM 1110-2-2105 (HQUSACE 1993), which specifies that miter gates should have design strengths at all sections equal to the required strengths calculated for the factored load forces in the following load combinations:

$$
H_{s}=1.2 D+1.6(C+M)+1.0 H_{t}
$$

where

$$
\begin{aligned}
D & =\text { dead load } \\
C & =\text { ice load } \\
M & =\text { mud load } \\
H_{S} & =\text { hydrostatic load } \\
H_{t} & =\text { temporal hydraulic load. }
\end{aligned}
$$




\subsubsection{Pintle design}

The pintle assembly is currently designed according to EM 1110-2-2703 (HQUSACE 1994). The assembly supports the dead weight of the miter gate that is made up of four major pintle parts: (a) socket, (b) pintle, (c) shoe, and (d) base (Figure 2-4).

Figure 2-4. Illustration of pintle parts: (a) socket, (b) pintle, (c) shoe, (d) base not shown.

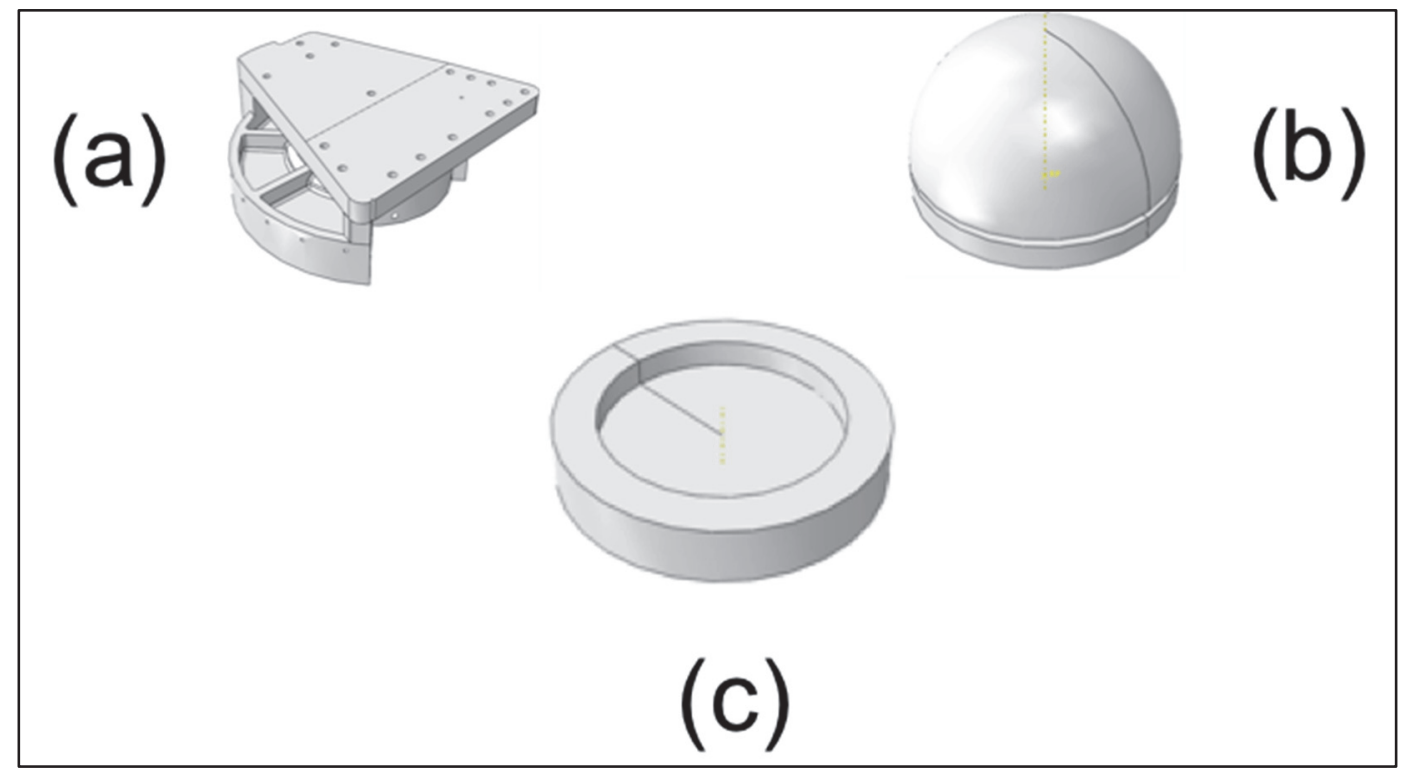

Source: ERDC-ITL-Computational Analysis Branch.

The pintle socket is made of cast steel and is connected to the bottom of the last girder web with steel bolts (Figure 2-5). The bolts are designed to carry the gate's shear reaction force. For an additional safety factor, a thrust plate is welded under the bottom girder web with a milled contact surface between the plate and pintle socket. The plate size is designed to be at least $1 \frac{1 / 4-i n}{}$. thick and 12 in. wide with a length as required by the girder web. The socket covers the bushing that fits over the pintle ball. An allowable bearing stress of 1,500 psi is desirable but may not be practical. The use of an automatic greasing system enables a higher bearing stress, which should not exceed 2,500 psi. 
Figure 2-5. Finite element model (FEM) of pintle socket connected to the bottom of the last girder web with steel bolts.

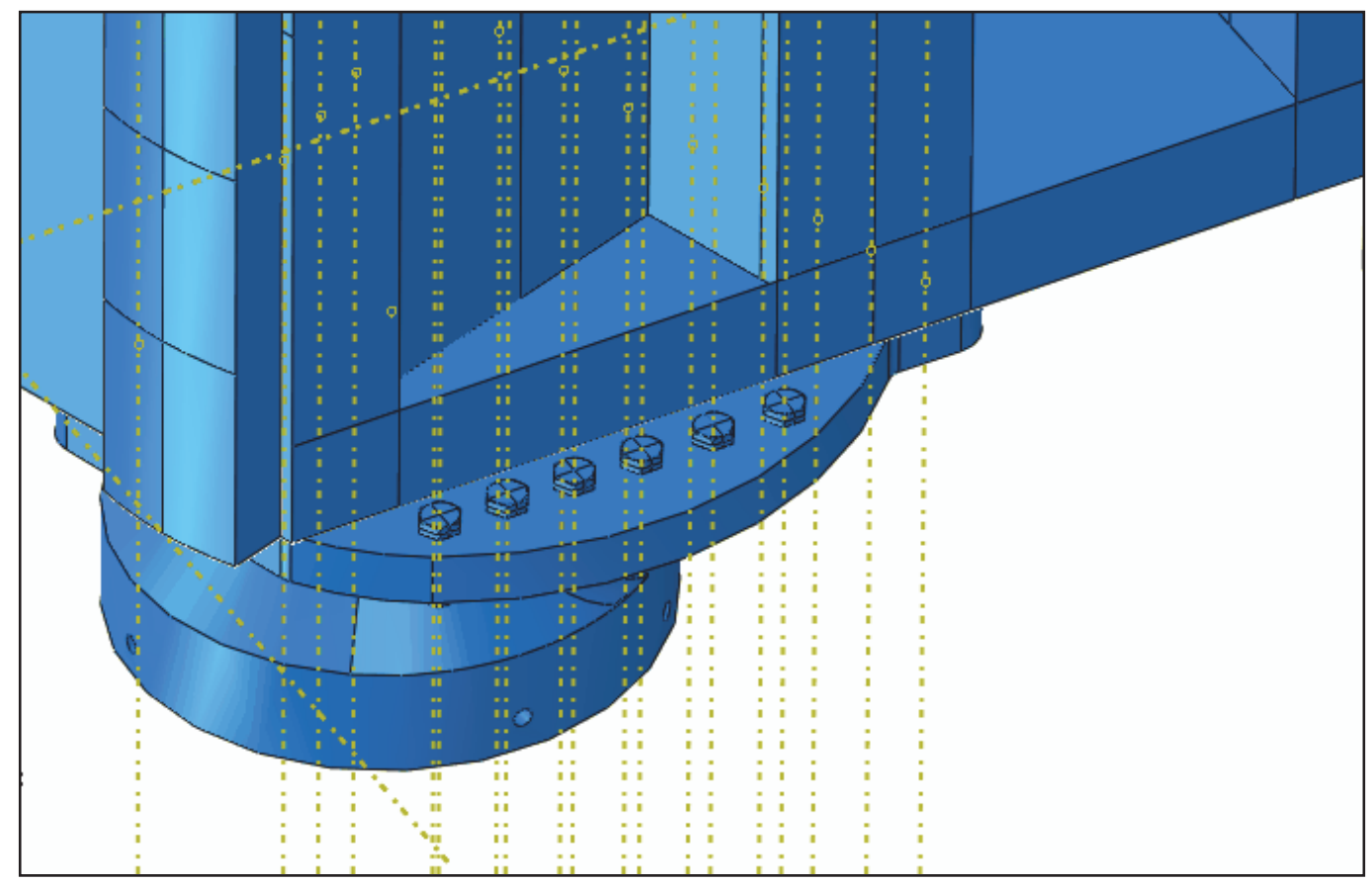

The top-bearing surface has the shape of a half sphere, and the bottom shaft is cylindrical-shaped. The pintle is generally made of alloy steel with nickel content and has a 10- to 20-in. diameter. The LD27 pintle has a 22-in. diameter. The structural member is made from alloy steel to mitigate the environmental corrosion effects often caused by salt or brackish water.

The pintle base is designed so there will be a compressive force under the base. The compressive force on the concrete can vary from a maximum at the top surface to a minimum at the bottom surface. The horizontal force exerted on the pintle causes an overturning moment. The load combinations that make up the total horizontal forces are of hydrostatic and miter gate leaf loads. The vertical reaction force can be determined from the angle the resultant force makes with the horizontal force and the eccentric loading distance. Figure 2-6 illustrates the loads that act on the member. 
Figure 2-6. Schematic of forces acting on the pintle.

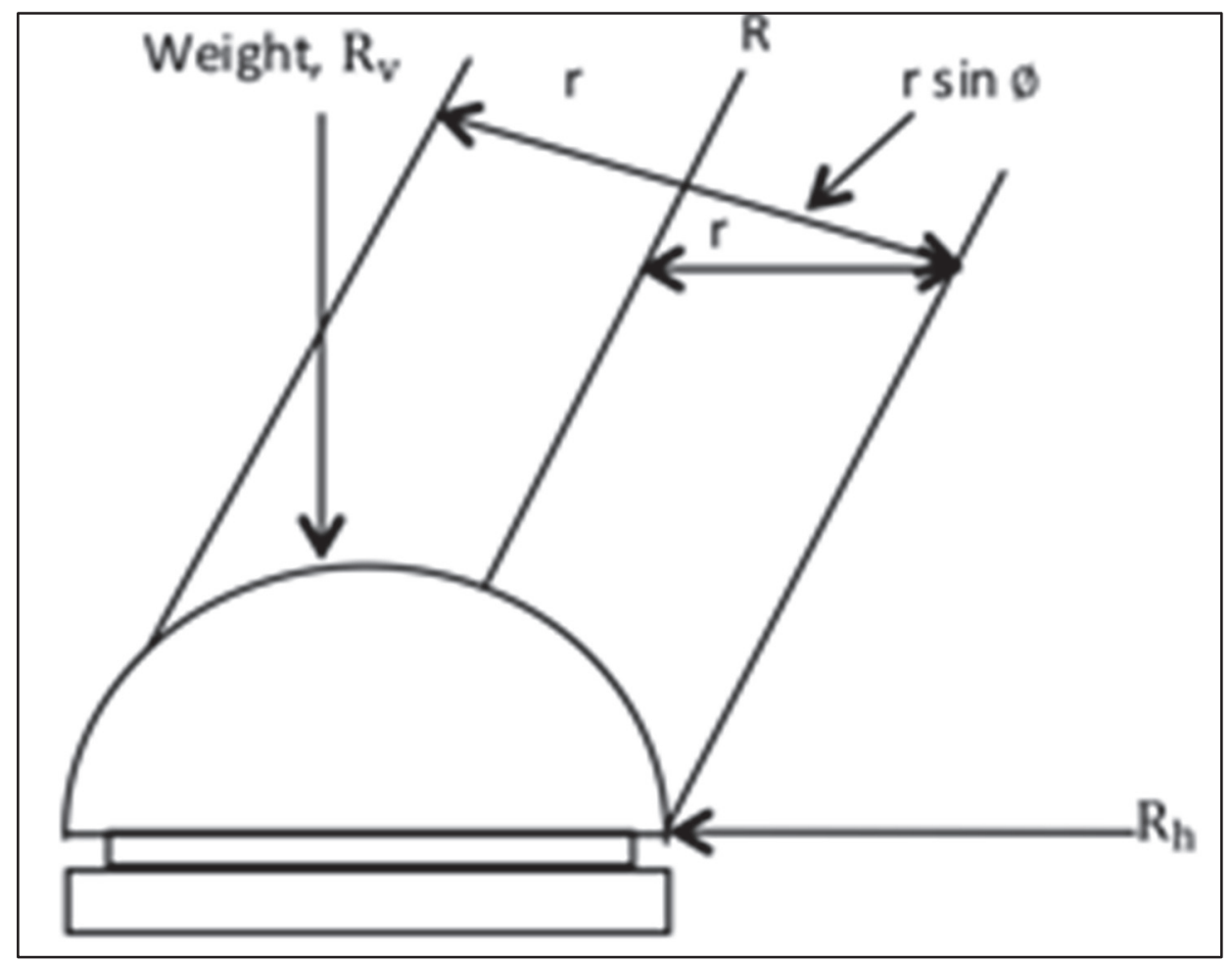

The $R_{v}$ is the service vertical reaction at the pintle base, $R_{h}$ is the service horizontal reaction, and $\mathrm{R}$ is the resultant service reaction at the pintle base. $\mathrm{W}_{\mathrm{T}}$ is the dead weight of the leaf, and $\mathrm{R}_{\mathrm{h}}$ is the resultant of the $R_{a}$ and $\mathrm{R}_{b}$ (Figure 2-7).

where

$$
\begin{aligned}
R_{a}= & \frac{w_{T} \times h}{V} \\
w_{T}= & \text { dead weight of leaf } \\
\mathrm{h}= & \text { length of leaf minus distance from contact to pintle divided by } 2 \\
\mathrm{~V}= & \text { vertical distance between gudgeon pin reaction and pintle } \\
& \text { reaction } R_{b}=\frac{w_{T} \times d}{V} \\
\mathrm{~d}= & \text { distance from center of gravity of leaf to center line of pintle. }
\end{aligned}
$$


Figure 2-7. Schematic of reaction forces of $\boldsymbol{R}_{a}$ and $\boldsymbol{R}_{b}$ on gate.

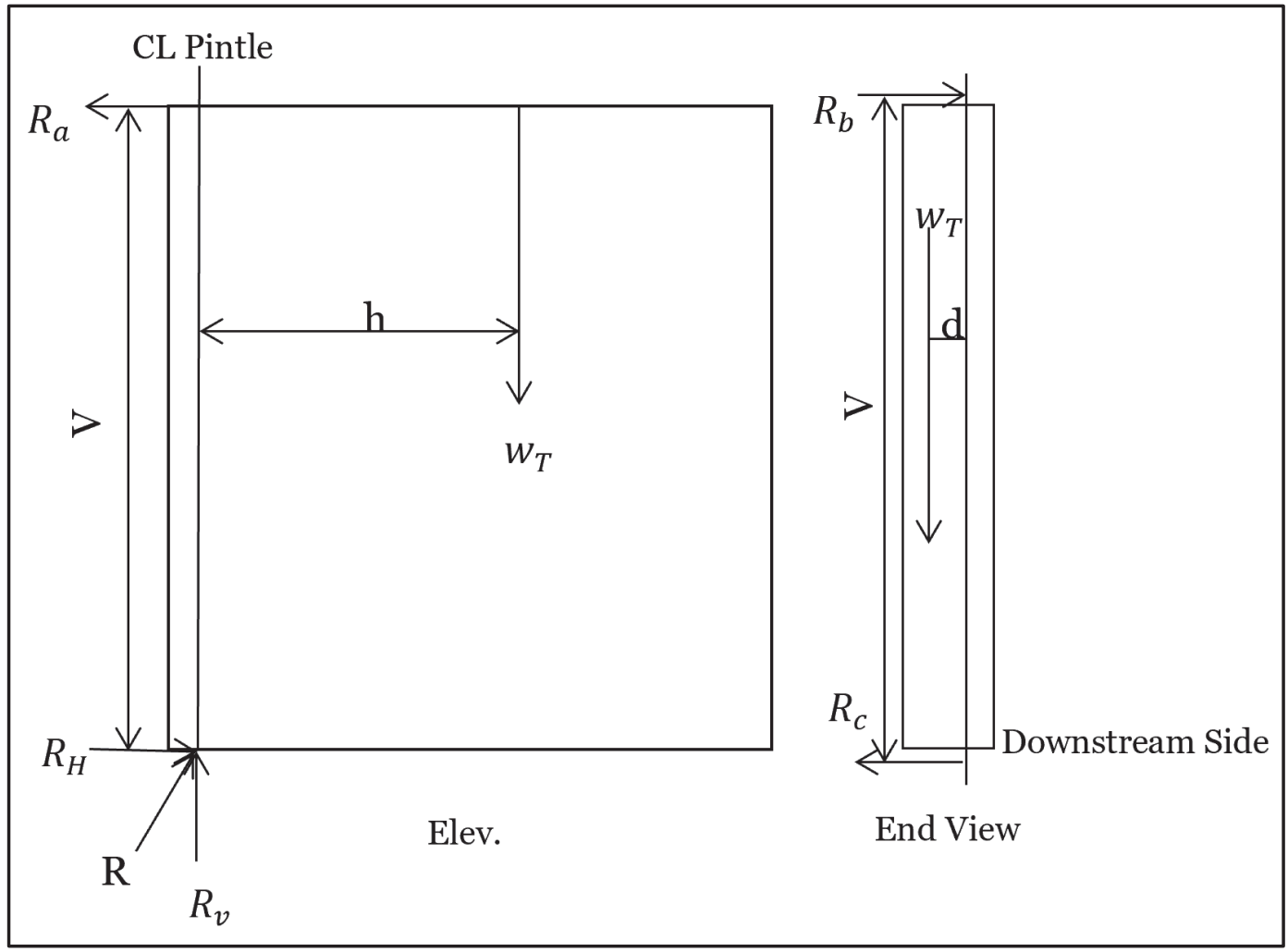

\subsection{Miter gate operation}

During the lock operation, the gate opens from its free-hanging condition to the mitered (closed) operating condition, where the gate's arch action through the girders transmits hydrostatic pressure loads into the lock walls. When the miter gates open and close, they push or pull through the water with a hydraulically actuated strut arm attached at the top of the gate. The eccentric loading caused by the strut arm adds additional forces to the submerged surfaces from the movement through the water. The forces cause torsional loads to develop in the gate. Per ETL 1110-2-566 (HQUSACE 2010), diagonal braces are attached across the gate to help resist these torsion type loads and to negate "sagging" at the miter end under the dead weight of the gate.

The pintle assemblies used for horizontally framed miter gates are either fixed or floating. The assembly for LD27 is floating. The pintle is set into a cast steel shoe with a shear key to prevent the pintle from turning in the shoe. The shoe is not fastened to the base, allowing the gate leaf to move outward in case of debris between the quoin and wall quoin. 


\subsection{Field observations}

\subsubsection{Background for USACE research programs}

There have been several implementations of programs through the years to assist in detecting, operating, and rehabilitating miter gates. The Repair, Evaluation, Maintenance, and Rehabilitation (REMR) Research Program was established to identify and develop effective and affordable technology for maintaining and extending the service life of existing Corps civil works structures (McCleese 2000). The Navigation Systems Research Program (NAVSYS) was developed to integrate tools and methods to help with the planning, design, construction, and management of present and future lock and dam systems. These research programs have successfully identified the need to properly maintain miter gates to ensure effective operation.

\subsubsection{Repair, Evaluation, Maintenance, and Rehabilitation (REMR) research program}

The REMR Research Program was conducted in two phases to identify and develop innovative ways for maintaining the U.S. lock and dam systems. Phase I began in fiscal year 1984 (FY84) and was completed in FY89. The success of Phase 1 allowed the opportunity for Phase 2, which was initiated in FY91 and completed in FY98. The REMR Research Program made use of strain gauge instrumentation data to detect any changes in structural behavior on lock gates. The strain gauge instrumentation was placed on the main structural elements (girders, beams, quoin block, and/or diaphragms). The instrumentation data were compared to analytical data. Four lock gates were tested, and all exhibited unexpected structural behavior, as further described below in greater detail (Commander et al. 1992a, 1992b, 1993, and 1994).

Field experiments and analytical studies were conducted for a miter gate leaf at the Emsworth Lock and Dam (Commander et al. 1992b). Strain gauge instrumentation was recorded at 32 locations for two loading conditions, varying head differential (difference in upper pool elevation and lock chamber water elevation), and during gate operation. During the head differential test, large strains were measured near the diagonal member connections (downstream flanges of the top girder, vertical girder, quoin girder, and miter girder) at very low head differential. The strain data functioned in a highly nonlinear manner versus the expected near-linear behavior. During the gate operation test (in which the gate was opened 
and closed), zero strain was recorded at one of the diagonal members. This was unusual behavior because significant torsional forces are applied to the leaves as they swing through the water and because the diagonals provide most of the torsional resistance. This observation called for an inspection of the diagonal member, which revealed it was completely loose and was void of any pretension. The leaf was warped such that the bottom girder was not fully in contact with the bottom sill, due to the loss of diagonal pretension. The occurrence of large strains at low differential head was due to the torsional deformation as the increasing head differential load pushed the bottom girder back against the sill (Commander et al. 1994).

A vertical lift gate at Lock 27 was also instrumented with strain gauges and then monitored. Field data and analysis results were both used to determine important aspects of the loading and response behavior. Through analysis of field data, a structural deficiency was identified, and unknown boundary conditions and loading were assessed by comparing analytical and measured strain data (Commander et al. 1994). Strain gauge instrumentation was placed at 60 locations on the gate as the leaf was lifted to apply vertical load and as the lock chamber was emptied and filled to vary the head differential. The instrumentation measurements obtained from the head differential test indicated bending behavior of the horizontal girders. Strain values on the upstream girder flanges were in compression. The direction of bending was such that the hydraulic pressure must have been greater on the upstream face of the gate than on the downstream face. The strain gauge reading indicates the seal between the gate leaf and the upstream sill was inoperative.

It was later found the seal had been removed several years prior. When there is no seal, the hydrostatic pressure distribution on the gate leaf is significantly different from that of a leaf with a seal. Strain data collected from the vertical load tests showed the gate was resting on the bottom sill. The computed and measured strains indicated the bottom girder was not fixed, but some resistance was added by friction along the bottom sill. The analytical model was used to determine the horizontal resistance along the bottom of the sill by approximating with a series of linear elastic springs a process also known as the Prony series method (Carriere and Moses 1992). The spring stiffness was determined through an iterative process in which the stiffness was varied until the analytical results compared reasonably with the strain measurements. The results showed that the bottom sill was 
providing horizontal resistance to the gate leaf, and an approximate linear value of the resistance was obtained.

At Lock and Dam 26, a vertical lift gate was instrumented with strain gauges to assess structural damage (Commander et al. 1994). During a field visual inspection, a crack was identified at a welded connection between a diaphragm flange and a girder flange. The strain gauges were placed in the vicinity of a crack to determine how the local damage may affect the gates operation. The analytical data obtained from the strain gauge instrumentation indicated significant tensile stresses in the diaphragm flange (crack location) under vertical loading. Excessive shear deformation of the gate under vertical loading caused high tensile stresses. An increase in localized tensile stresses is an indication that cracking will occur in the structural member (Boresi et al. 2003).

Strain gauge instrumentation was also installed at Red River Lock and Dam No. 1 miter gate at 32 locations (Commander et al. 1993). The upper six horizontal girders and the upper portions of the vertical diaphragms were instrumented. Strain inducers were located symmetrically about the center of the leaf with three of the girders being instrumented at quarter points along their lengths. Strain measurements were recorded during the head differential and gate operating (opening and closing) loading conditions. Results showed no structural deficiencies.

However, irregular boundary conditions were detected at low levels of head differential. The behavior measured at the miter ends of the gate showed a change in boundary conditions occurred with increasing head differential. This was believed to have happened because some of the girders were not fully mitered (when the gates are closed and making full contact) with their respective counterparts before the application of the hydrostatic load. This would result in small gaps between the miter ends of the girders for low head differential loads. The change in boundary conditions would occur as the head differential load increased enough to force the miter ends of the girders together. The effect of the gaps between the horizontal girder contact points was notable because of the significantly low load. The presence of the small gaps is relatively insignificant from a structural standpoint since the gates close as the load increases. The measured behavior was important for this study because unexpected strain histories were identified, and the cause was investigated by simulating the deficiency analytically (Commander et al. 1994). 
The overall findings of the REMR study indicated the strain gauge instrumentation could detect structural deficiencies. However, strain gauge instrumentation on only the major structural elements of the gate at 32 locations may not be sufficient to locate and quantify structural deficiencies. In addition, instrumentation gauges were not able to discern what led to the structural deficiencies (ex., barge impact or environmental effects). To accurately assess damage, at least one cross-section of every major structural element should be instrumented. Conversely, the addition of instrumentation was thought to be excessive, impractical, and costly.

\subsubsection{Naval System (NAVSYS) research program}

The purpose of the NAVSYS Research Program is to develop and integrate tools, techniques, and methods that expedite the planning, design, construction, and management of present and future lock and dam systems (Hite et al. 2006). Under the program, the Structural Health Monitoring and Analysis in Real Time of Lock Gates (SMART Gate) database was developed to use strain gauge sensors to monitor real-time damage and long-term deterioration (Hite et al. 2006, Chang and Kopsaftopoulos 2015). The SMART Gate web application is an automatic structural health monitoring (SHM) tool to ensure the operational safety and effective maintenance of lock gates. Strain gauge instrumentations are strategically installed on the structures and are interfaced to data loggers. The data is transmitted from the structure to a Microsoft SQL Server database via the USACE Corpsnet.

Also, the Navigation Structures Inventory Management System (NAVSIMS) was developed under the NAVSYS Research Program. The objective of NAVSIMS is to maintain a central repository used to access pertinent information regarding inspection, reporting, and evaluation system for Hydraulic Steel Structures (HSS). Furthermore, NAVSIMS was established to systematically identify, document, and track deficiencies (Sauser and Riveros 2009). NAVSIMS is a web accessible database tool developed to provide field inspection reports and gate operation histories on HSS (NAVSIMS). As a result of the NAVSYS Research Program, the SMART Gate and NAVSIMS database tools provide detailed requirements so USACE Divisions and Districts can perform needed maintenance and SHM of the lock and dam systems (Barker 2012).

USACE identified an increased need for a structural rating classification criterion that provides a standardized protocol for consistently collection, inspection frequency, and assessing inspection data across USACE district 
offices. An engineering manual was developed to meet the demands of the district offices. An Inspection, Evaluation, and Repair System of Hydraulic Steel Structures manual was developed to provide an organized approach to identifying, documenting, and tracking deficiencies in miter gates, per EM 1110-2-6054 (HQUSACE 2001). The structural rating criteria ensured each member of a miter gate is listed along with its function. Additionally, the specific type of deficiency, such as corrosion, cracks, and member damage, is recorded with a detailed description. The conditions state rating system is used to describe the deterioration of HSS. The HSS condition state uses a rating system from 1 to 5 , in which a rating of 1 indicates the structure is in excellent condition, and a rating of 5 indicates the structure has failed. Influence factors are also considered to describe conditions affecting structural behavior. Influence factors are also rated from 1 to 5 , where a rating of 1 indicates a benign influence, and a rating of 5 indicates a severe influence.

NAVSIMS provides USACE with the means to store inspections, drawings, and other data pertaining to the structure. After each field inspection, the reports are uploaded to the NAVSIMS web site for long-term SHM. Each lock and dam is now associated with USACE Divisions and Districts responsible for maintenance and operation. Included in the database are maps of all the lock and dams in the United States. NAVSIMS provides a capability for predicting the future condition of the HSS under USACE authority. Also available is a graphing tool that displays the deterioration curve of the structure and develops an inspection report.

\subsubsection{U.S. Army Engineer Research and Development Center (ERDC) and USACE Mobile District site assessment}

As a result of the REMR and NAVSYS Inspection and Sensor health monitoring research programs, USACE Districts were made aware there might be issues with the in-service miter gates quoin block, pintle, and pintle connectors. In September 2013, the Mobile District and U.S. Army Engineer Research and Development Center (ERDC) researchers were tasked with conducting independent inspections of the miter gates' critical structural members for the lock gates along the Tombigbee River. The lock and dam gate sites inspected were Aberdeen, John C. Stennis, and Tom Bevill. 


\subsubsection{Aberdeen Lock and Dam}

The Aberdeen Lock and Dam (Figure 2-8) is located on the Tombigbee River in Monroe County near Aberdeen, MS. It is horizontally framed with 10 girders and 3 intermediate diaphragms. The quoin block was observed not contacting the lock wall (Figure 2-9), and cracks were detected in the pintle region (Figure 2-10).

Figure 2-8. Photograph of Aberdeen Lock and Dam miter gate.

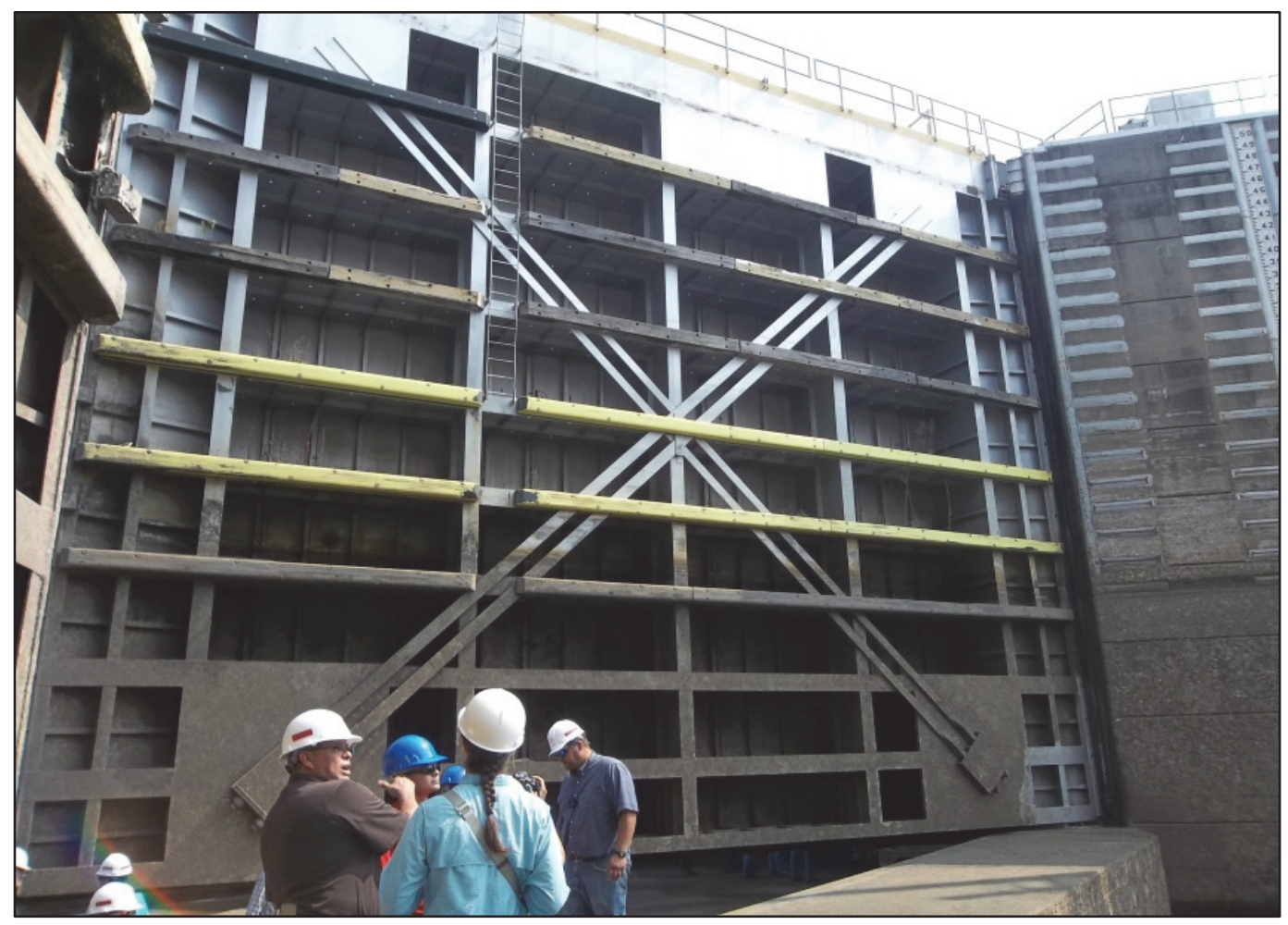


Figure 2-9. Photograph of gap observed between the quoin block and lock wall.

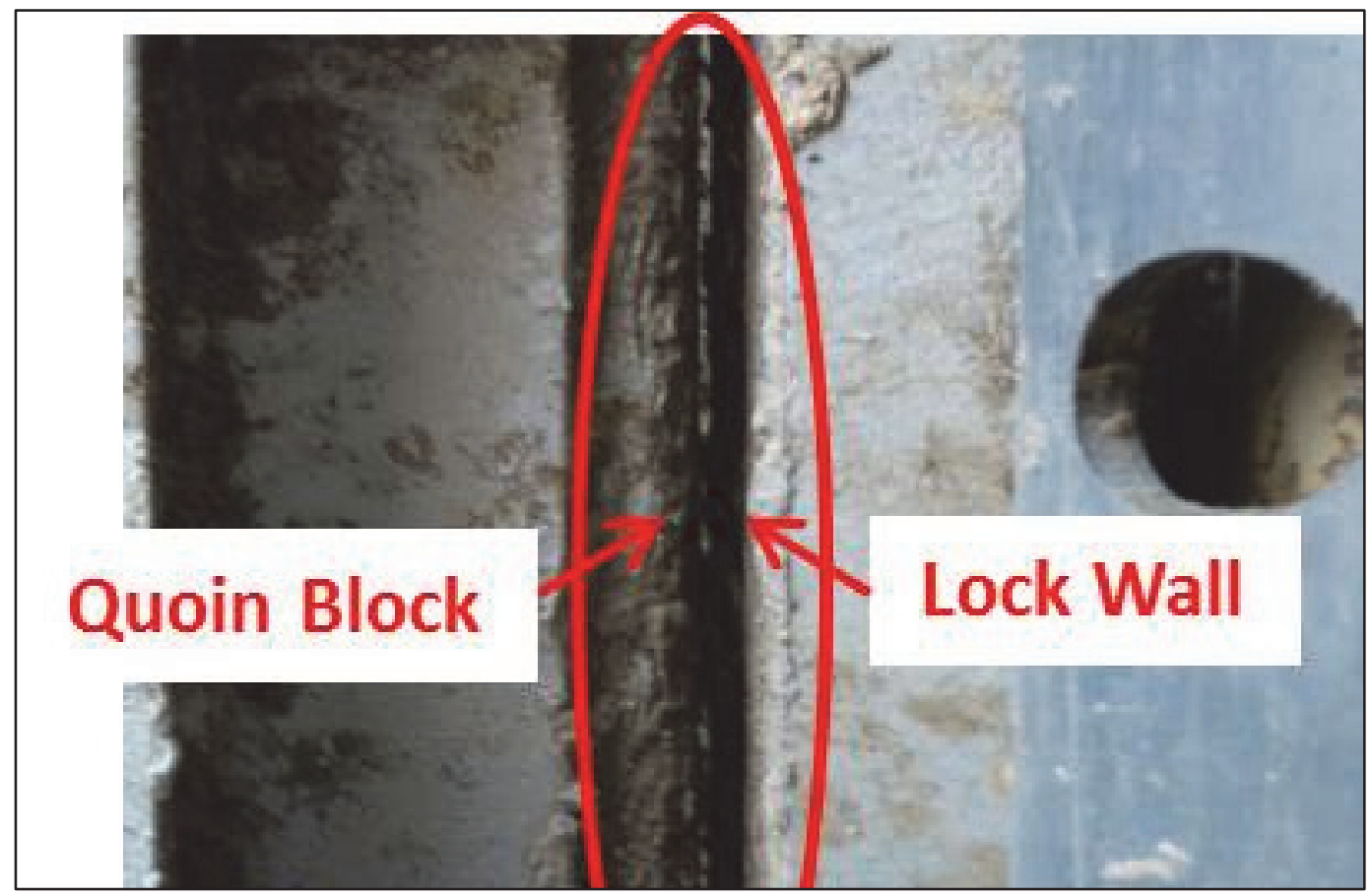

Figure 2-10. Photograph of Aberdeen Lock and Dam pintle left and right with crack.

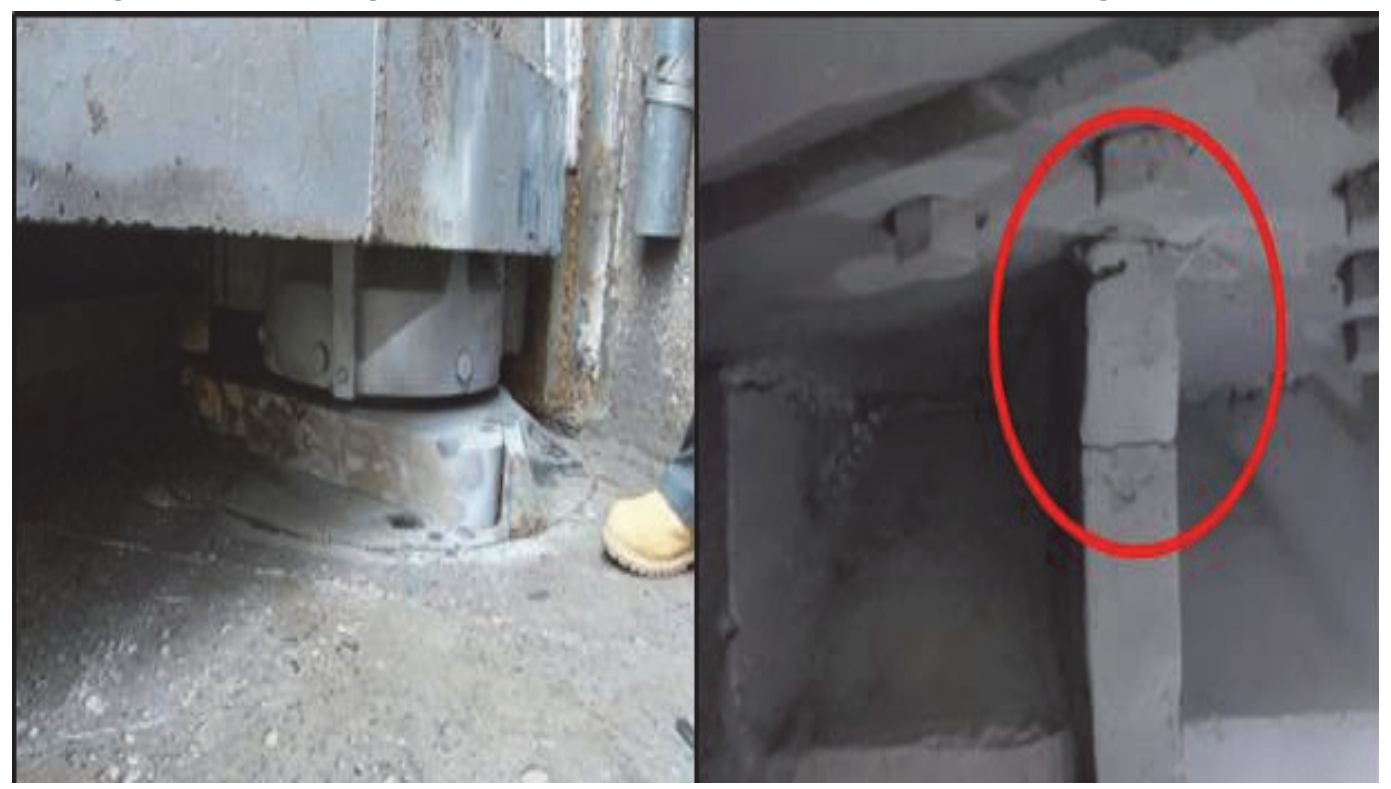

\subsubsection{John C. Stennis Lock and Dam}

The John C. Stennis Lock and Dam (Figure 2-11) is located on the Tombigbee River in Lowndes County near Columbus, MS. It is horizontally framed with 10 girders and three intermediate diaphragms. There were gaps between the quoin block and lock wall and cracks in the pintle region (Figure 2-12). 
Figure 2-11. Photograph of John C. Stennis Lock and Dam miter gate.

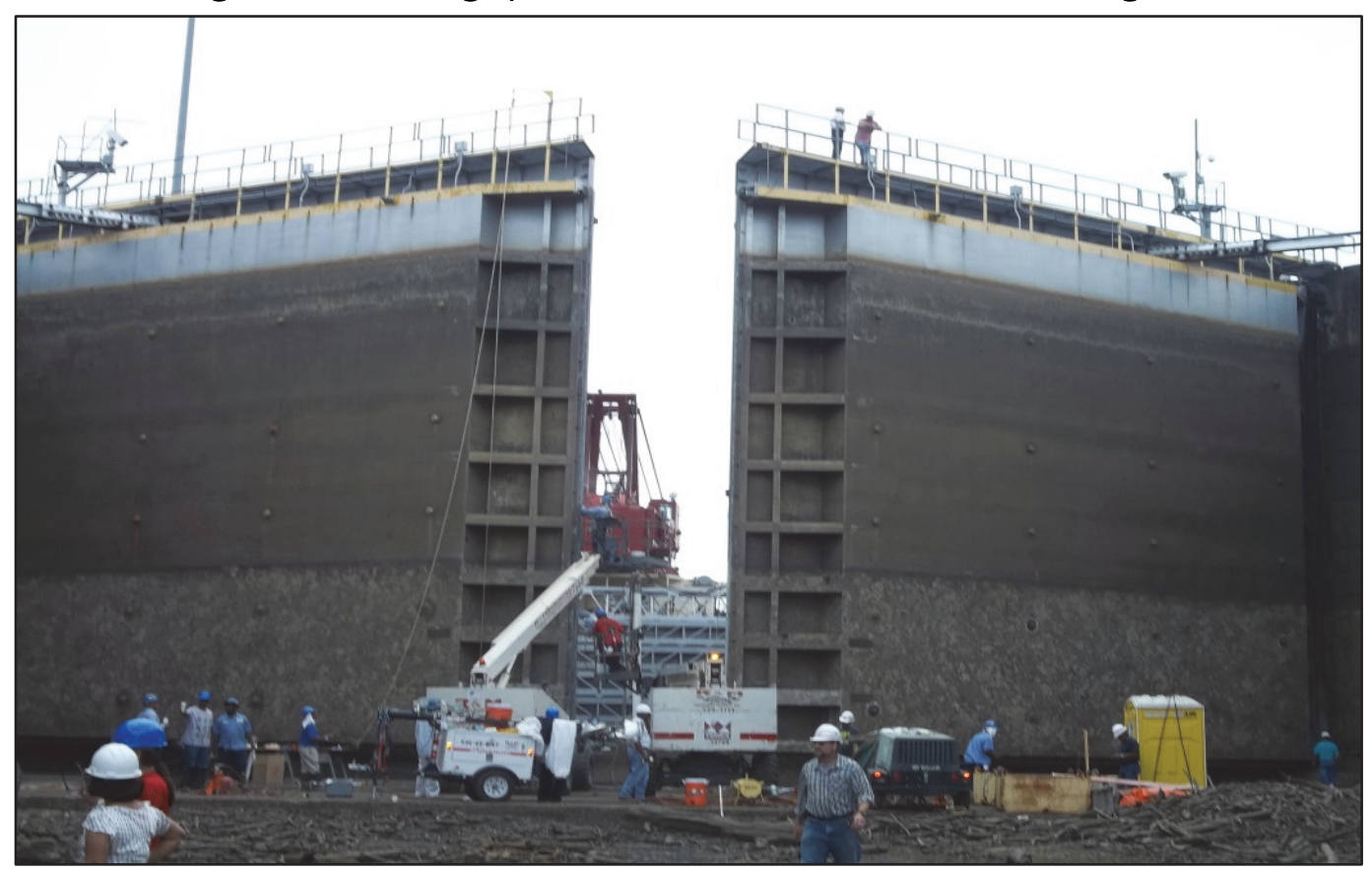

Figure 2-12. Photograph of John C. Stennis Lock and Dam pintle with cracks.

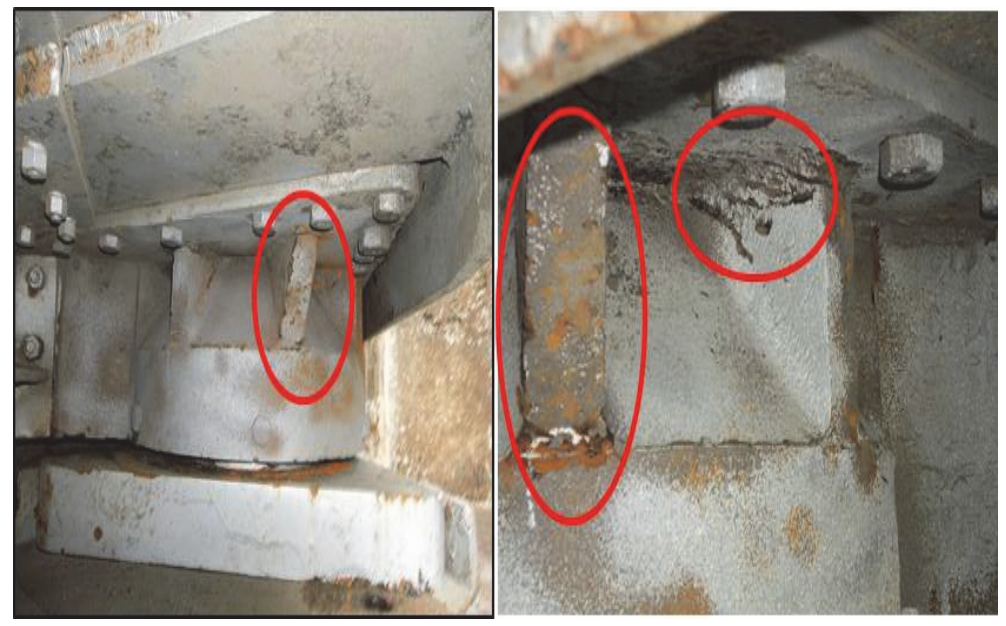

\subsubsection{Tom Bevill Lock and Dam}

The Tom Bevill Lock and Dam (Figure 2-13) is located on the Tombigbee River in Pickens County near Pickensville, AL. It is horizontally framed with 10 girders and three intermediate diaphragms. Quoin block deterioration was observed, causing a gap between the quoin block and lock wall, and cracks were detected in the pintle region (Figure 2-14). 
Figure 2-13. Photograph of Tom Bevill Lock and Dam miter gate.

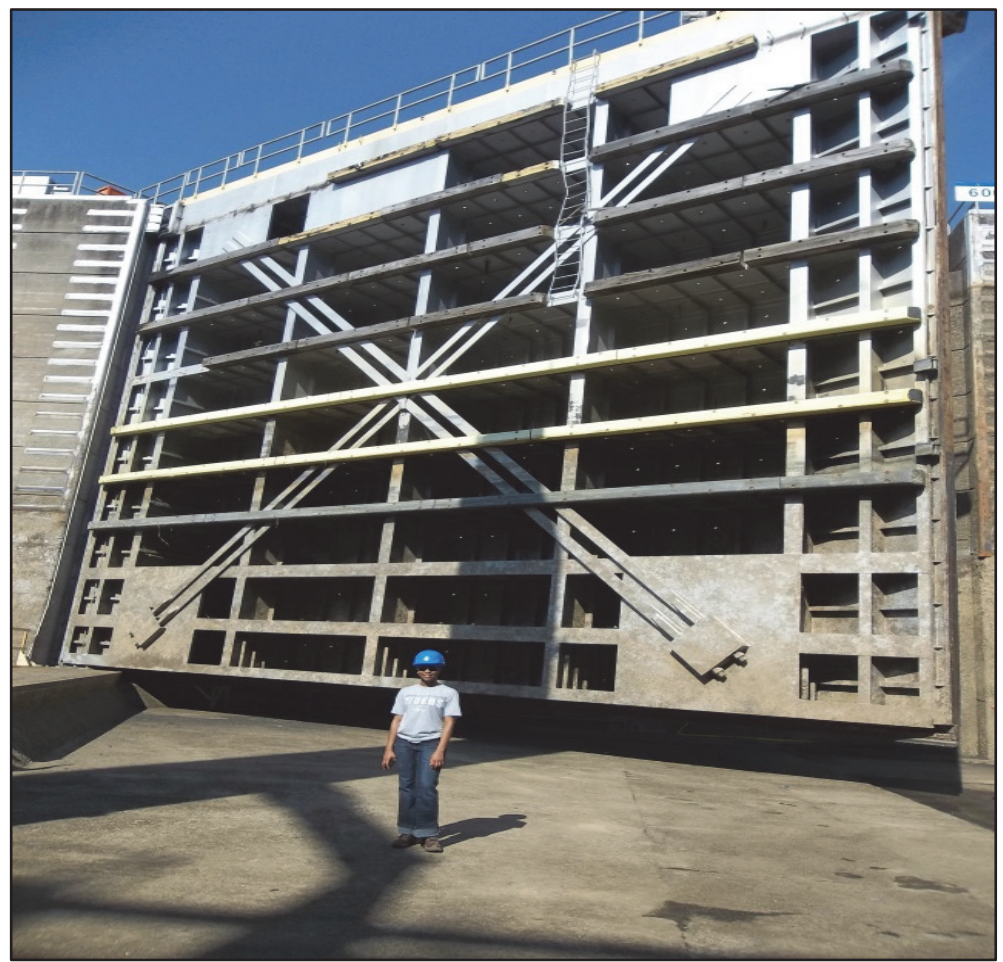

Figure 2-14. Photograph of Tom Bevill Lock and Dam pintle with cracks.

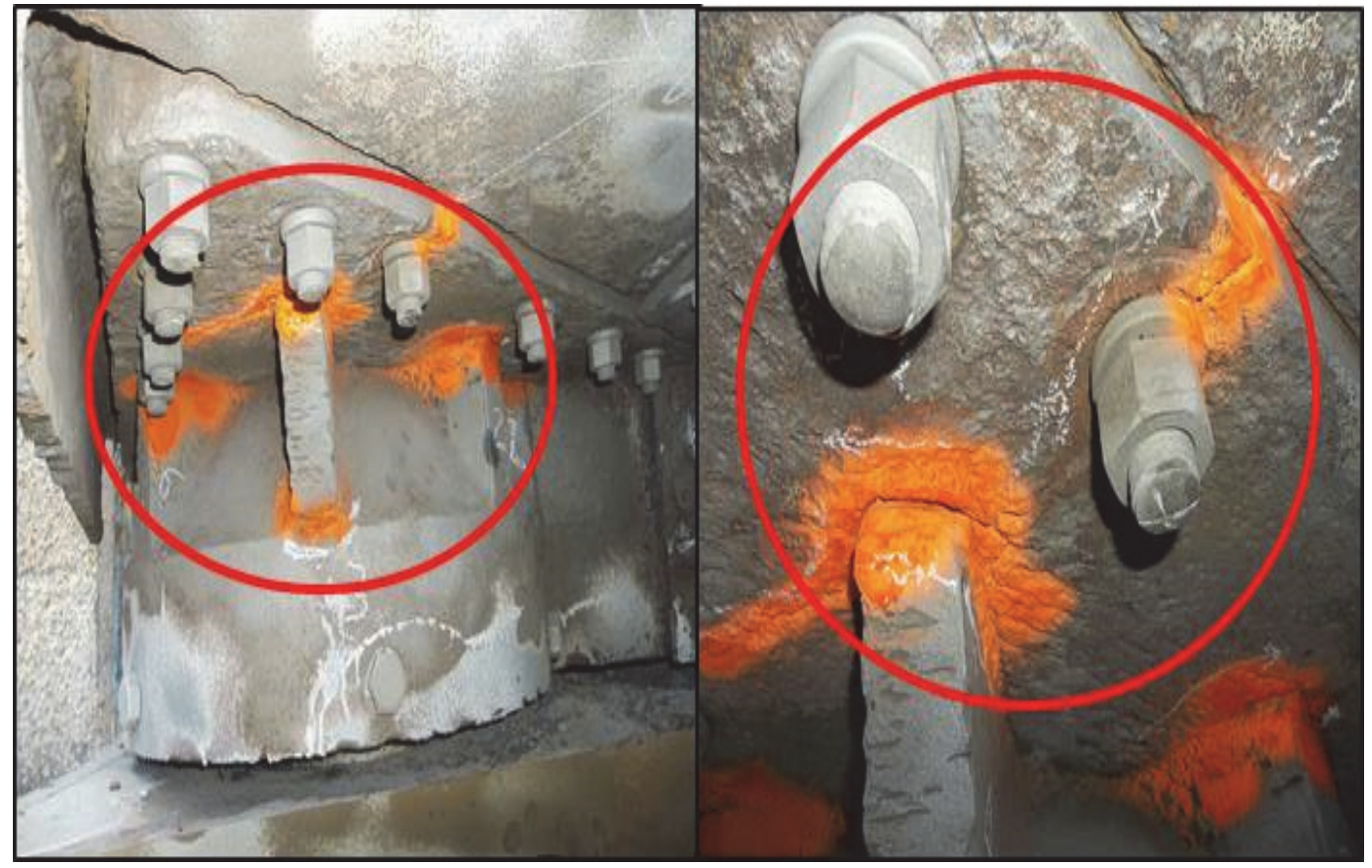

\subsubsection{Findings from field inspections}

The findings from the inspections revealed the structural defects and deterioration in the quoin block were mainly due to environmental corrosion 
and the water's hydrostatic force. The inspectors also believed the quoin block deterioration may be causing structural overload in the pintle region. The field inspection of the three lock and dam sites discussed above provides an observation-based hypothesis that quoin block deterioration may be related to the pintle damage.

As a result, the USACE Mobile District has determined there is a need to reevaluate the pintle design for the Tombigbee River miter gates. This investigation is vital to USACE to determine how load transfer affects the pintle and its connections due to quoin block deterioration. The three cases selected seem to be representative of damage observed for most in-service miter gates used along the Mississippi River's lock and dam system. Furthermore, deterioration is a major expenditure for USACE, and it is essential to study and to better understand the mechanical performance of miter gates. The next two sections discuss the reported use of finite element modeling and analytical methods that have been used to evaluate the effects deterioration has on steel structures and miter gates. Also, note that the available literature is sparse in the open public domain as it pertains to FEM of hydraulic gate structures operating on waterways.

\subsection{Deterioration prediction models for steel structures and miter gates}

Deterioration models have been developed in an effort to maintain and predict the life expectancy of miter gates. Riveros and Arredondo (2014) developed a mathematical linear deterioration model. Estes et al. (2004) developed a mathematical logarithmic deterioration model.

The Riveros and Arredondo (2014) study used data provided by the New York State Department of Transportation (NYDoT). The condition state data was based on steel bridge elements of over 80 years of inspections. The data was applicable because steel miter gates and steel bridges have the same deterioration effects. The Markov Chain deterioration prediction model was used. When applying the Markov Chain process, the following assumptions and observations are to be made. First, the deterioration process is continuous in time. To render a structure discrete in time, the condition is analyzed at specific periods. These periods correspond to periodic and detailed inspections. Second, the condition of a structure can have an infinite number of condition states; however, miter gates have a finite set of 1 to 5 condition states, where 1 is perfect condition and 5 is failure. Finally, the future of a miter gate depends only on its current condition. 
Fluctuations in the NYDoT steel bridge data occurred between 30 and 40 years because the data represents the average condition state of many elements. Condition state values at 10-year intervals were calculated using a linear regression equation to eliminate fluctuations and make the data manageable. The values were used as the average condition state at each interval. The Weibell distribution and Latin Hypercube Simulation generated synthetic random condition state values to represent a range of condition states at each 10-year interval. The transition probabilities were calculated using the condition state values. The Markov Chain process is then applied to generate a deterioration model. The results of the deterioration model and actual data showed a good correlation between the two. The deterioration model indicated the condition states reach State 2 at approximately 35 years and State 3 at 75 years. The measured field data indicates the condition states reach State 2 at 36 years and State 3 at 73 years.

Estes et al. (2004) addresses how visual condition index (CI) inspections can be used to update the reliability of a miter gate. A time-dependent reliability analysis of Lock and Dam 12 was used to predict how the structure will perform over its operational life. A miter gate is usually divided into three environmental zones: the atmospheric zone, where the gate is only exposed to air; the splash zone, where the gate is exposed to both water and air as the water in the lock chamber is raised and lowered; and the submerged zone, where the gate remains underwater. Estes et al. (2004) considered corrosion deterioration in the splash and atmospheric zones of the miter gate. The following deterioration model was developed based on results from corrosion tests of bare steel under simulated splash zone conditions and steel coupon tests in a variety of environments:

$$
\begin{gathered}
\log C=\log 23.4+0.65 \log t+\varepsilon_{c} \\
\log C=\log 148.5+0.903 \log t+\varepsilon_{c}
\end{gathered}
$$

where

$$
\begin{aligned}
\mathrm{C}= & \text { thickness loss due to corrosion }(\mu \mathrm{m}) \\
\mathrm{t}= & \text { time (years) } \\
\varepsilon_{c}= & \text { uncertainty factor with a mean of o and standard deviations of } \\
& 0.219 \text { and } 0.099 \text { for atmospheric and splash zone, respectively. }
\end{aligned}
$$


The steel thickness loss was predicted by the deterioration models based on 1998 inspection data over a 10-year span. The results show that the atmospheric deterioration model offers a good representation of what is happening in the splash zone. The splash zone model overestimated the severity of the corrosion.

The research discussed above indicates the need for the understanding of deterioration and how it affects miter gates. The two research efforts presented the idea of using deterioration models to maintain and predict the life of a miter gate. The research projects lacked investigation of the change in structural capacity of miter gates due to deterioration.

\subsection{Computational analysis of miter gates}

USACE has used computational analysis in an effort to detect and study deterioration on miter gates. Commander et al. (1994) used an integrated experimental and analytical approach to determine the presence of structural deficiencies without prior knowledge of damage (Commander et al. 1994). Field tests from strain gauge instrumentation were used to measure the structural response, and a simple FEM was used to represent the response. A two-dimensional finite element grid model, developed from an in-house code, was used to simulate damage to match strain gauge readings for the vertically framed Emsworth miter gate and the horizontally framed Hollis Locks and Dam miter gate. Various degrees of damage were simulated by reducing the Young's Modulus, $E$. This approach represented the presence of a crack or deterioration of a structural element. The location of the reduced $E$ was only limited to the main structural elements (girders, beams, or diaphragms). An optimization process was used to determine the effect of damage. The optimization process was proven to be successful for locating and evaluating damage; however, there were limitations for using it as an automated procedure for structural evaluation. The simulated damage only highlighted localized damage (cracks) by some unconformable mechanisms or cause.

Riveros et al. (2009) used a 3D finite element method employing the commercially available ABAQUS code to address how quoin block deterioration creates an increase in stress in various areas of miter gates. A FEM of a miter gate was developed to conduct a parametric analysis of various degrees of quoin block deterioration. When the gate is closed, the water level in the upstream face of the gate is the maximum head, and the water level in the downstream face of the gate increases to reach the upstream level. A total of 
10 steps was used to represent the filling of the lock chamber. Each step represented an increase in the water level of the downstream side of the gate. In the final step, the hydrostatic pressure in the upstream surface of the gate is balanced with the downstream water pressure. Boundary conditions were removed at $75 \%$ the height of the quoin block from top to bottom, 50\% from top to bottom, $25 \%$ from top to bottom, $75 \%$ the height of the quoin block from bottom to top, $50 \%$ from bottom to top, $25 \%$ from bottom to top, $50 \%$ of the height from the center, $25 \%$ from the center, no boundary conditions, and full boundary conditions.

It was found, when the quoin block is deteriorated from top to bottom and the center is compared to full boundary conditions, an increase in stress was observed in the pintle zone. In the case of quoin block deterioration from the bottom to top, stresses increase in the area of the gate where deterioration is occurring. Riveros et al. (2014) introduces the idea that quoin block deterioration causes increase stress concentration in the pintle region of miter gates. However, the preliminary FEA does not quantify to what extent the pintle region is most adversely affected (ex., pintle surface, pintle ball, pintle connection sites).

\subsection{Overall state-of-knowledge summary}

Operating and maintaining miter gates are an important parts of the USACE mission. Maintaining the miter gates operation is vital for the trade industry, for port facilities, and for the safety of the adjacent river communities. Through the years there have been inspection, sensor-based health monitoring research programs implemented in support of the USACE mission. Still needed is a means to understand how deterioration affects the structural capacity of the gate while in service.

Field investigations have shown deterioration occurs in the quoin block and cracking in the pintle structural member. The assumption is axial loads that should transfer in the lock wall diminish when the quoin block deteriorates, resulting in an increase loading in the pintle region. As previously explained above by Estes et al. (2004) and Riveros and Arredondo (2014), the environmental deterioration effects can reasonably be captured by systematically removing boundary conditions. However, how increasing load affects the loading capacity of the miter gate and its connecting structural members is incompletely understood. The results of this work will provide essential information to help improve existing retrofits and future redesign to better mitigate the effects of detrimental deterioration; this 
outcome will help USACE administrators better prioritize repairs. It is likely that gates with greater deterioration will require relatively frequent maintenance and repair. The next Chapter describes the 3D FEM development and analysis criteria. 


\section{3D Finite Element Model (FEM) Development and Analysis Criteria}

\subsection{Introduction}

A 3D FEM was developed so that an in-service operating miter gate could be sufficiently represented. The model was based on the Mississippi River LD27 miter gate design. The LD27 is located on the Chain of Rocks Canal in Granite City, IL, approximately 10 miles from St. Louis, MO. The lock was originally constructed between 1947 and 1953. There are two locks at the site: the main, 1200- $\mathrm{ft}$ chamber and an auxiliary, 600-ft chamber (Figure 3-1). The miter gate at the downstream end of the main $1200 \mathrm{ft}$. chamber had been in service since 1953 and was approaching the end of its design life.

Figure 3-1. Aerial photographic view of Lock and Dam 27.

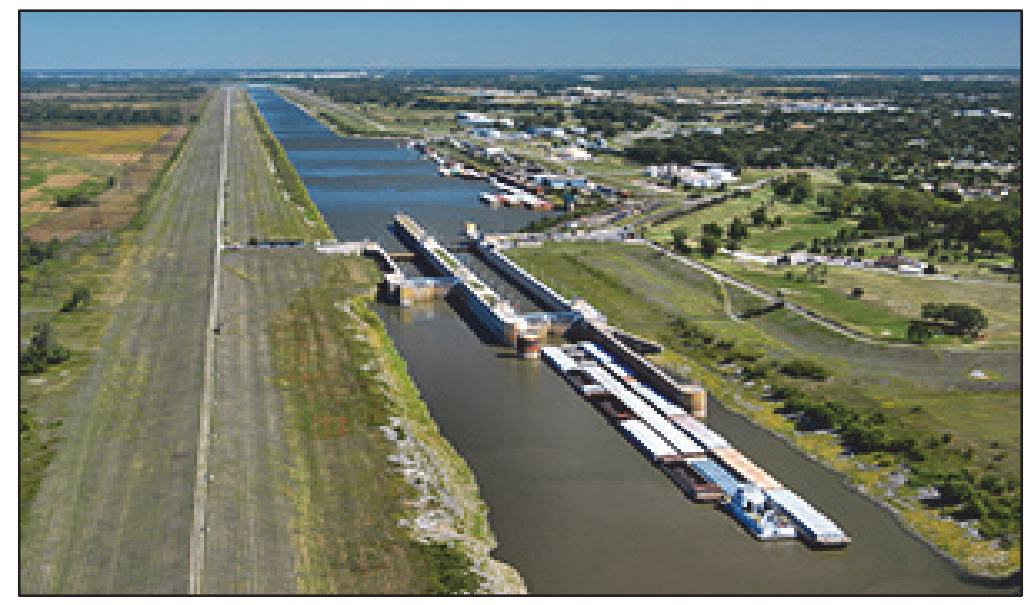

Source: USACE St. Louis District.

In August 1996, several design modifications were made for the gate, which were constructed the following year. From 1996 to 2012, lock closures were occurring frequently due to emergency repairs performed on the miter gate. The repairs were related to girder flange fatigue cracking and failure of the new diagonals. Due to the severity of the issues, the St. Louis District decided it would be more economical to replace the gate than to do extensive repairs to the 57-year old gate. The replacement was completed in 2013 (Figure 3-2). The current in-service LD27 miter gate, which is $735 \mathrm{in}$. wide and 834 in. tall, has 13 horizontal girders and four intermediate diaphragms (Figure 3-3) (Jacob Engineering Group 2010). 
Figure 3-2. Photograph of LD27 miter gate that was used for modeling.

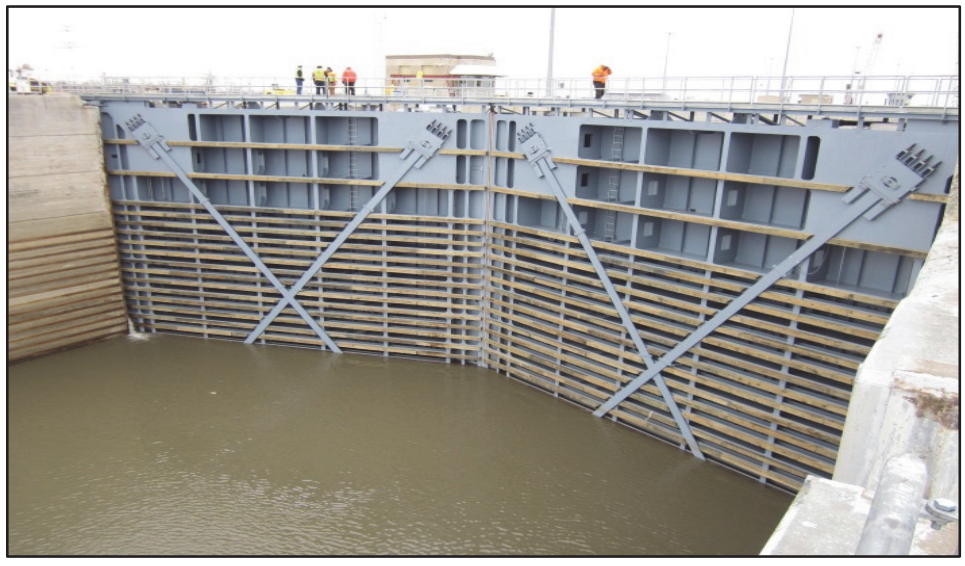

Source: USACE St. Louis District.

Figure 3-3. Schematic of LD27 miter gate that was used for modeling.

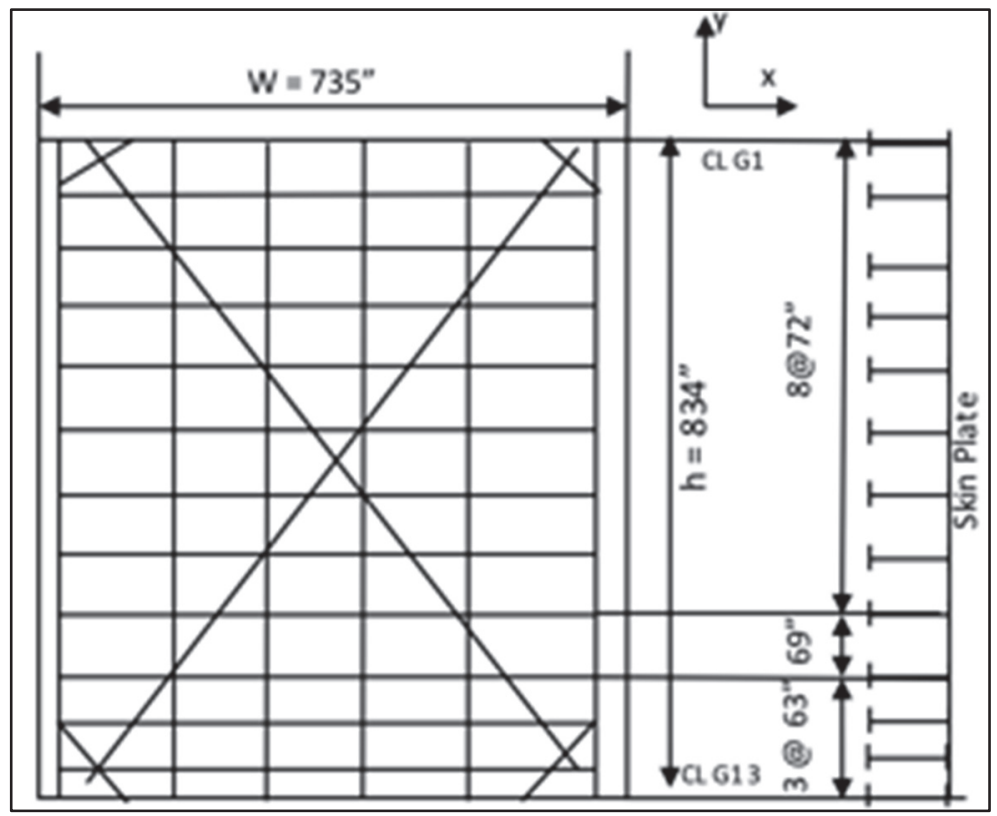

\subsection{Development of FEM}

The commercially available finite element software, ABAQUS CAE v6.13, was used to conduct a parametric analysis of the miter gate. The purpose of the parametric analysis was to provide a phenomenological understanding of how quoin block deterioration may affect the pintle's load-carrying capacity. Figure 3-4 shows a flowchart that outlines the processes routinely used for FEM development (Fish and Belytschko 2008). The details for the model's parts creation, assembly, meshing, assignment of material properties, boundary conditions, loads, job submission, verification, and validation are described below. 
Figure 3-4. Computational modeling and simulation flow chart.

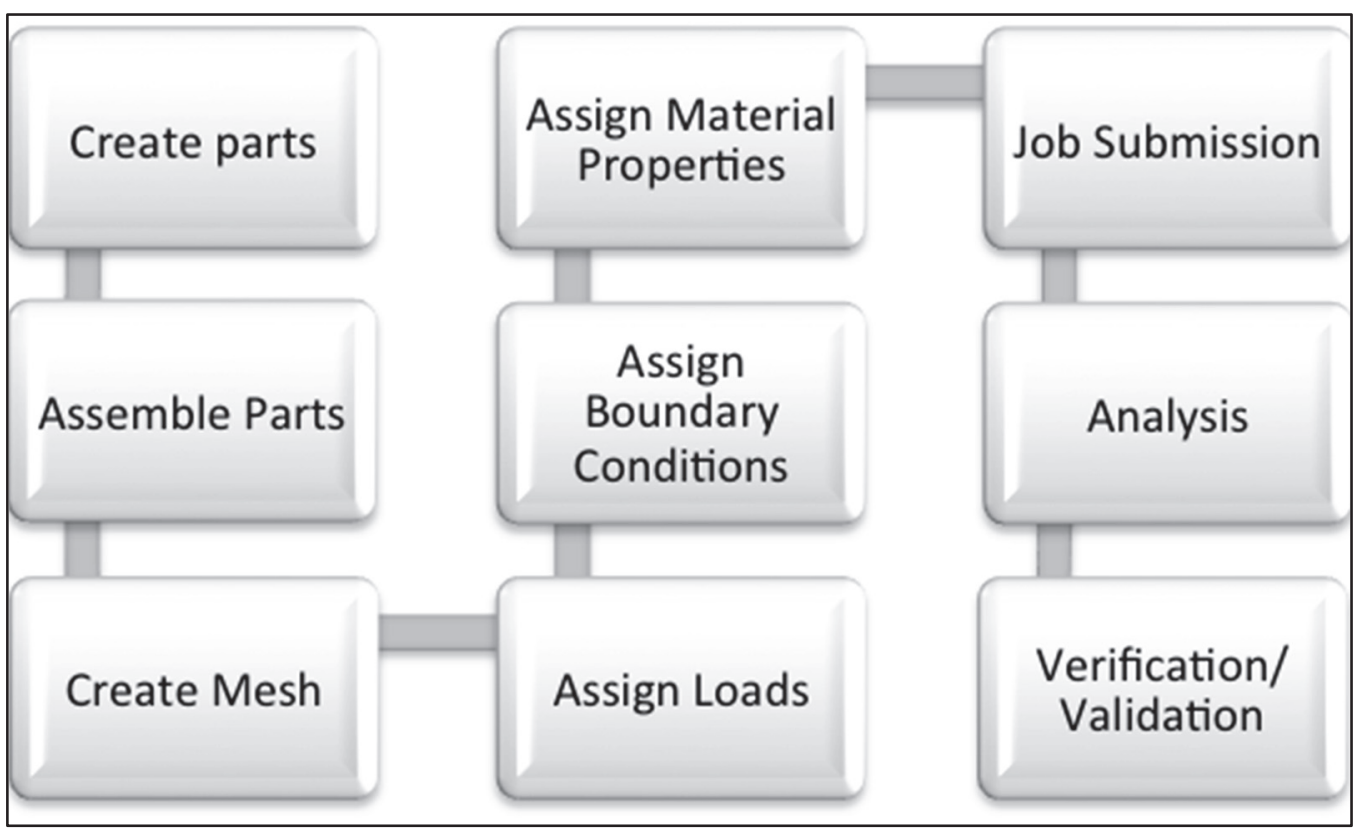

\subsubsection{Parts and assembly}

The model is based on the 2010 miter gate design drawings provided by the U.S. Army Corps of Engineers St. Louis District, MO. The 3-D hydraulic steel structural model (Figure 3-5) was assembled from miter gate, quoin block, miter block, pintle, and pintle bolt parts that were created using the ABAQUS CAE module.

Figure 3-5 also shows the sub-components for the miter gate that include the skin plate, intercostals, horizontal girders, tapered end section, end diaphragms, thrust diaphragms, quoin and miter posts, and diagonals. Tie constraints were created to connect the miter block, quoin block, pintle, and bolts to the gate. The bolts' tie constraints were applied between the bolts' stem and the pintle holes. The tie constraints allowed the application of the pretension loading of the bolts. A surface-to-surface contact interaction was used to connect the top of the pintle with the bottom surface girder web and the head of the bolts to the top surface to the bottom web. 
Figure 3-5. Miter gate model and the sub-components for the miter gate meshed with finite elements.

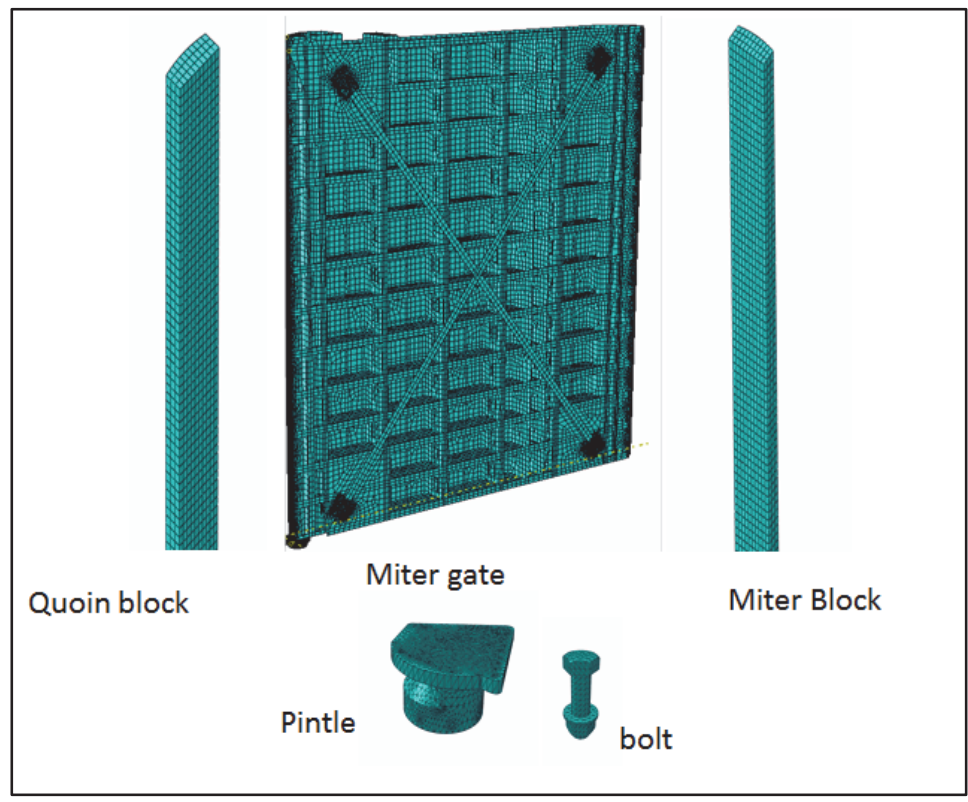

\subsubsection{Finite element type and meshing}

The components that make up the miter gate were meshed as $3-\mathrm{D}$ generalpurpose deformable shells with six degrees of freedom per node with reduced integration ( $\mathrm{S}_{4} \mathrm{R}$ and $\mathrm{S} 3$ ) elements types (Systèmes 2013). The miter gate consists of quadrilateral and triangular element shapes needed to mesh the complex geometry. The miter block and quoin block were modeled as 3-D general-purpose deformable hexahedral solids with three degrees of freedom per node with reduced integration (Element type C3D8R) (Systèmes 2013). Additionally, the pintle socket and the pintle bolts were modeled as 3-D general-purpose deformable tetrahedral solids with three degrees of freedom (Element type $\mathrm{C}_{3} \mathrm{D} 10$ ). A mesh convergence was conducted to assist in the mesh refinement and optimal resolution. Table 3.1 lists the mesh characteristics used in terms of number of elements, nodes, and seed size for each element type.

Table 3.1. Mesh characteristics.

\begin{tabular}{|l|c|c|c|}
\hline Part & \# of Elements & \multicolumn{1}{l|}{ Nodes } & Seed Size \\
\hline Miter Gate & $\approx 2.2$ million & $\approx 2.2$ million & 1 \\
\hline Bolt & $\approx 100,000$ & $\approx 165,000$ & 0.1 \\
\hline Pintle & $\approx 120,000$ & $\approx 180,000$ & 1 \\
\hline Miter Block & $\approx 25,000$ & $\approx 40,000$ & 1 \\
\hline Quoin Block & $\approx 25,000$ & $\approx 40,000$ & 1 \\
\hline
\end{tabular}




\subsubsection{Material properties}

The hydraulic structure used steel properties throughout. Table 3.2 lists the properties for the steel, A27 Grade 70-40 Class 2 (ASTM 2013). A linear elastic constitutive model was applied to the miter gate, quoin block, miter block, and bolts with a modulus of elasticity of $30 \times 10^{6} \mathrm{psi}$, Poisson's ratio of 0.3 , and mass density of $0.00073 \frac{\mathrm{lb}-\mathrm{s}^{2}}{i{ }^{4}}$. The plastic material data consisted of yield stress 40,000 psi at a strain of o and a yield stress of 70,000 psi at a strain of 0.2187 on the pintle.

Table 3.2. Material properties for the steel, A27 Grade 7040 Class 2.

\begin{tabular}{|l|c|}
\hline Material Property & Value \\
\hline Tensile Strength, Yield (psi) & 40,000 \\
\hline Tensile Strength, UTS (psi) & 70,000 \\
\hline Elongation (\%) & 22 \\
\hline Modulus of Elasticity (psi) & $30 \times 10^{6}$ \\
\hline Mass Density $\left(\frac{l b-s^{2}}{i n{ }^{4}}\right)$ & 0.00073 \\
\hline Poisson's Ratio & 0.3 \\
\hline Source: ASTM Standard A27/A27M (2013). \\
\hline
\end{tabular}

A bilinear elastic-plastic material (idealized) model was assigned to the pintle, which allowed a failure analysis in the critical member to be conducted. The assumption of the constitutive model is the uniaxial tensile response for metal material will yield in a bilinear (elastic-perfectly plastic) manner as opposed to the nonlinear manner as shown by the illustration in Figure 3-6. Therefore, the true stress-strain response predicted by the model will tend to be an underestimated material strength in the initial post-yield behavior for the pintle.

\subsubsection{Boundary conditions}

The boundary conditions were applied using a global coordinate system. The global coordinate system is defined by 1, 2, 3 planes that represent the $\mathrm{X}, \mathrm{Y}, \mathrm{Z}$ directions. The gudgeon pin, quoin block, and miter block were restrained in the 1, 2 plane, whereas the pintle was restrained in the 1, 2, 3 planes (Figure $3-7$ ). 
Figure 3-6. Illustration of typical nonlinear uniaxial tensile behavior for metals represented by an assumed bilinear (elastic-perfectly plastic) constitutive material model.

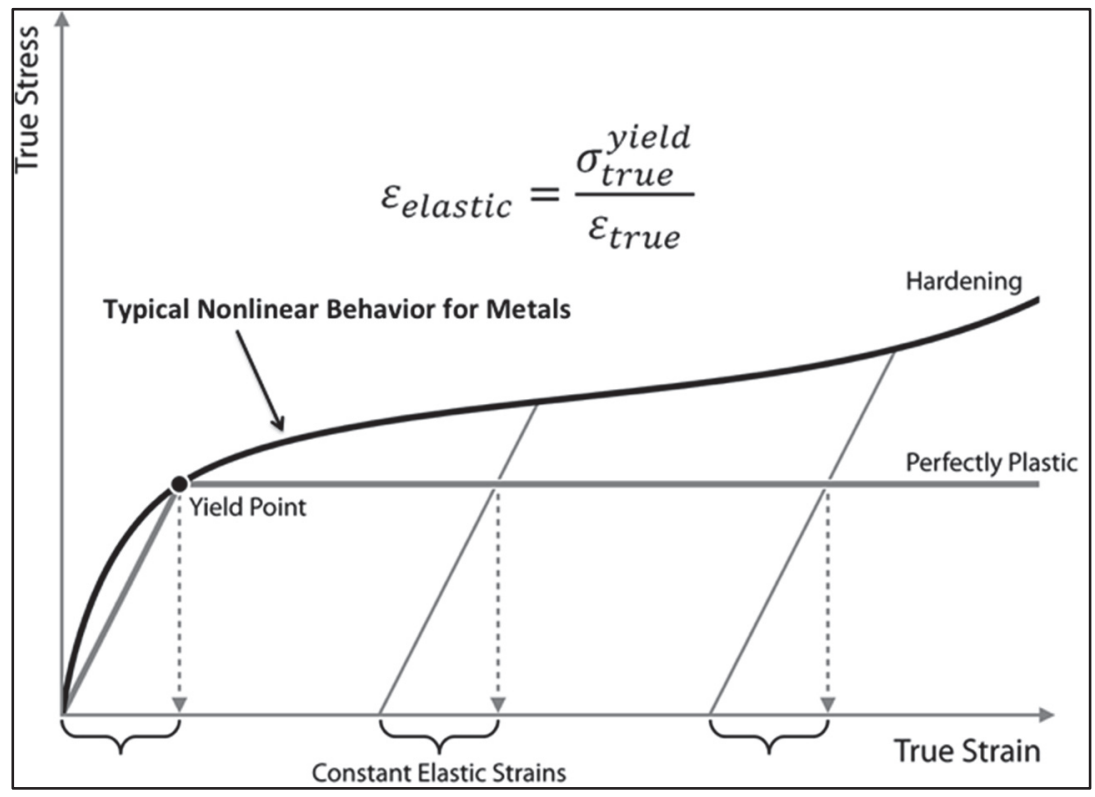

Source: Dowling (1999).

Figure 3-7. Illustration of the globally applied boundary conditions for the gudgeon pin, quoin block, and miter block.

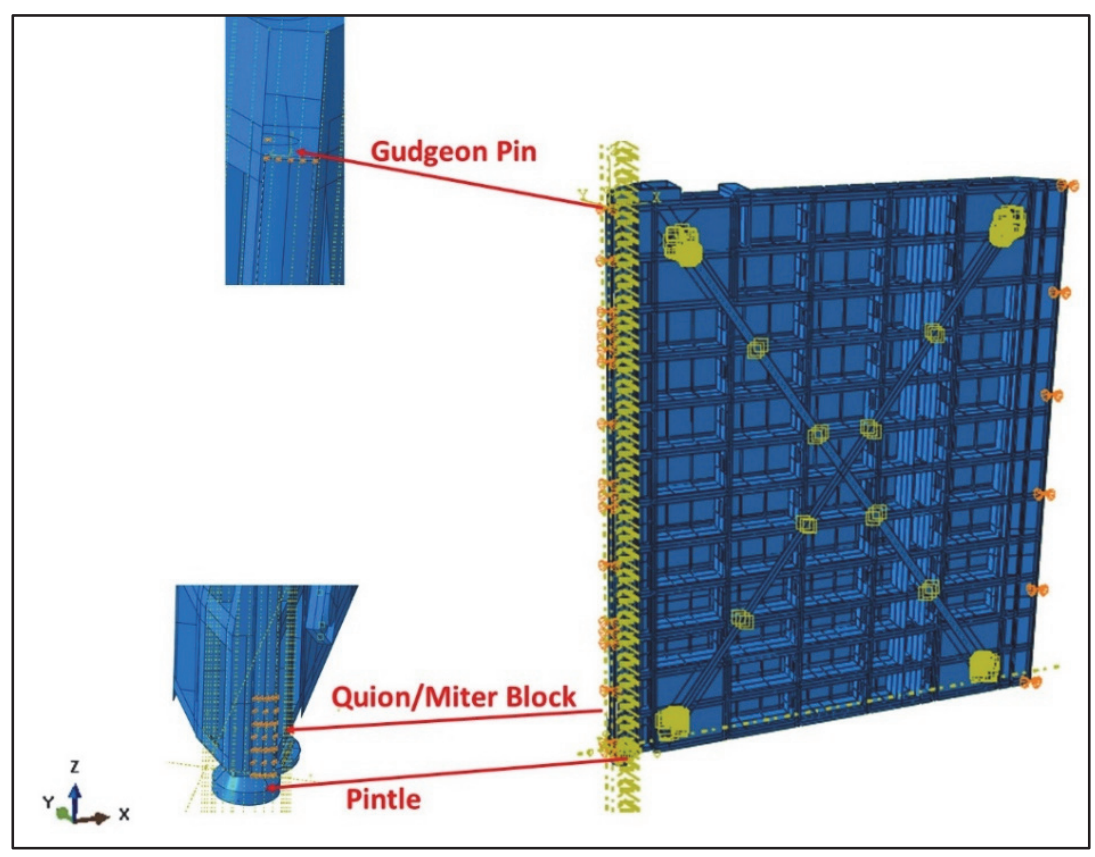

\subsubsection{Loading conditions}

Hydrostatic, thermal, and dead loads were applied to the model. The dead load, diagonals pre-stressing and bolts pre-tensioning, and hydrostatic pressure induced by the upper and lower pool define the loads boundary 
conditions. A hydrostatic pressure was applied so the submerged condition for the gate could be simulated. For this analysis, the maximum hydrostatic pressure was applied to the gate. The pressure was applied as differential pressures that represent both the upstream and downstream fully submerged levels. The maximum hydrostatic pressure applied to the downstream was $8.02 \mathrm{psi}$. The maximum hydrostatic pressure applied to the upstream was $17.55 \mathrm{psi}$. Therefore, the maximum differential pressure applied to the gate was 9.53 psi (Figure 3-8). It is believed cracking in the pintle and quoin block deterioration will occur due to the maximum hydrostatic case, as described in ETL 1110-2-566 (HQUSACE 2010).

Figure 3-8. Illustration of the applied hydrostatic differential pressure loads to miter gate.

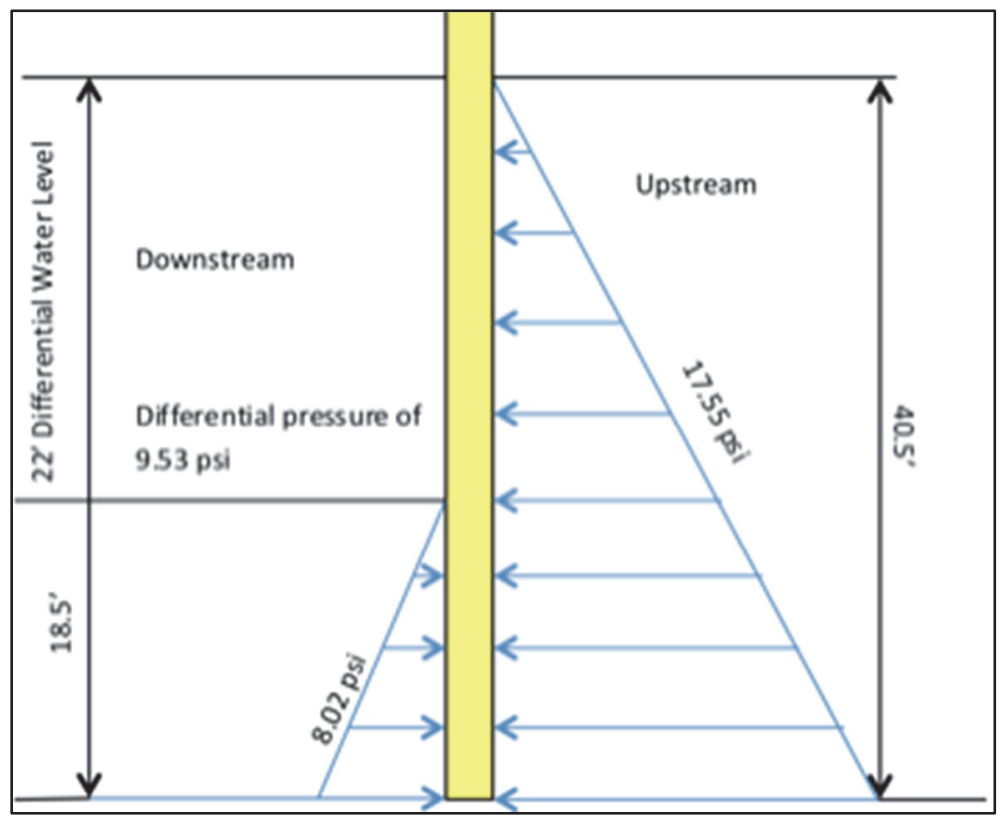

Next, a bolt load was applied to develop pretension loading in the bolts to simulate the tightening forces. The tension in the bolt was applied across the cross-section surface in the middle of the bolt stem. The bolt load was determined using the recommendation provided in the AISC Guide to Design Criteria for Bolted and Riveted Joints (Kulak et al. 2001). The value for bolt loads tensile applied load was 87,500 psi and is the tensile capacity median value of 75,000 to 100,000 psi (ASTM Standard F593-B), which was obtained from the ASTM F593-13a (2014). A thermal gradient $(\Delta T)$ of the diagonals was used to simulate the effect of the diagonal prestressing in the FEM. Equation 3 was used to determine the appropriate pre-stress tensile load as a function of temperature. Riveros et. al. (2009) provides further details on applying pre-stress tensile loads to the diagonals. The temperatures were determined from the pre-stress (positive 
diagonal 15,800 psi; negative diagonal 10,210 psi) values listed in the LD27 Miter Gate Design Calculations provided by USACE St. Louis District. The temperatures used for the positive and negative diagonals were $81^{\circ} \mathrm{F}$ and $52.4^{\circ} \mathrm{F}$, respectively.

$$
\begin{gathered}
\sigma=-E \alpha(\Delta T) \rightarrow \Delta T=\frac{P}{E \alpha} \\
\Delta T_{p}=\frac{15,800 p s i}{\left(30 \times 10^{6}\right)\left(6.5 \times 10^{-6} \frac{i n}{i n}^{\circ} \mathrm{F}\right)}=81.0^{\circ} \mathrm{F} \\
\Delta T_{n}=\frac{10,210 p s i}{\left(30 \times 10^{6}\right)\left(6.5 \times 10^{-6} \frac{i n}{i n}^{\circ} \mathrm{F}\right)}=52.4^{\circ} \mathrm{F}
\end{gathered}
$$

After thermal conditioning, the gate's dead load was applied. The dead load was defined by the gravity load. A gravity load of $386.4 \frac{\mathrm{in} \text {. }}{\mathrm{s}^{2}}$ was applied in the Z-direction of the miter gate assembly.

\subsection{Job submission}

The following sections discuss the steps used for submitting the job for simulation. Also discussed are the steps used to deteriorate the quoin block. The data obtained from the simulation was used to obtain the stress state acting on the structure when the quoin block is deteriorating.

The 3D numerical model of the LD27 miter gates simulates the operating conditions. Six steps were required to perform the numerical experiments:

1. Initial Step: This step was automatically created by ABAQUS commercial software. The software allows the user to define boundary conditions, predefined fields, and interactions that are applicable at the initialization of the simulation. The boundary conditions of the miter and quoin blocks, pintle, and gudgeon are defined in this step.

2. Gravity: The gravity load only was applied in this step.

3. NoDetero\%: This step simulated the quoin block in perfect condition. Next, Steps 4 - 6 describe the deterioration of the quoin block by the removal of boundary conditions so the $3 \mathrm{D}$ stress state can be calculated in the pintle region. 
4. Deter25\%: This step simulated the deterioration of the quoin block at $25 \%$ the height of the block from bottom to top.

5. Deter5o\%: This step simulated the deterioration of the quoin block at $50 \%$ the height of the block from bottom to top.

6. Deter $75 \%$ : This step simulated the deterioration of the quoin block at $75 \%$ the height of the block from bottom to top.

\subsection{Structural analysis criteria}

Since the miter gate is assembled using several structural components with varying geometries and subjected to a multiaxial stress state, it will exhibit nonlinear behavior post-yield. As a result, the selection of the appropriate analysis criteria is needed to adequately describe the post-yield response exhibited by the gate structure. By understanding the post-yield behavior, the inelastic (permanent deformation) can be sufficiently determined. Fortunately, with ductile metals the post-yield inelastic behavior is fairly well-understood and has often been examined using the Distortional Energy Density (von Mises) Criterion (Boresi et al. 2003). The von Mises criterion uses a cylinder that circumscribes the Tresca hexagon to define the yield surface for three-dimensional stress state, as described in Equation 4 and Figure 3-9 (Boresi et al. 2003)

$$
f=\frac{1}{6}\left[\left(\sigma_{1}-\sigma_{2}\right)^{2}+\left(\sigma_{2}-\sigma_{3}\right)^{2}+\left(\sigma_{3}-\sigma_{1}\right)^{2}\right]-\frac{1}{3} Y^{2}
$$

where

$$
\begin{aligned}
\sigma_{1}, \sigma_{2}, \sigma_{3} & =\text { general stresses in the reference }(\pi \text {-plane }) \\
Y & =\text { is the yield surface. }
\end{aligned}
$$


Figure 3-9. Illustrates the failure envelope of the von Mises yield criterion

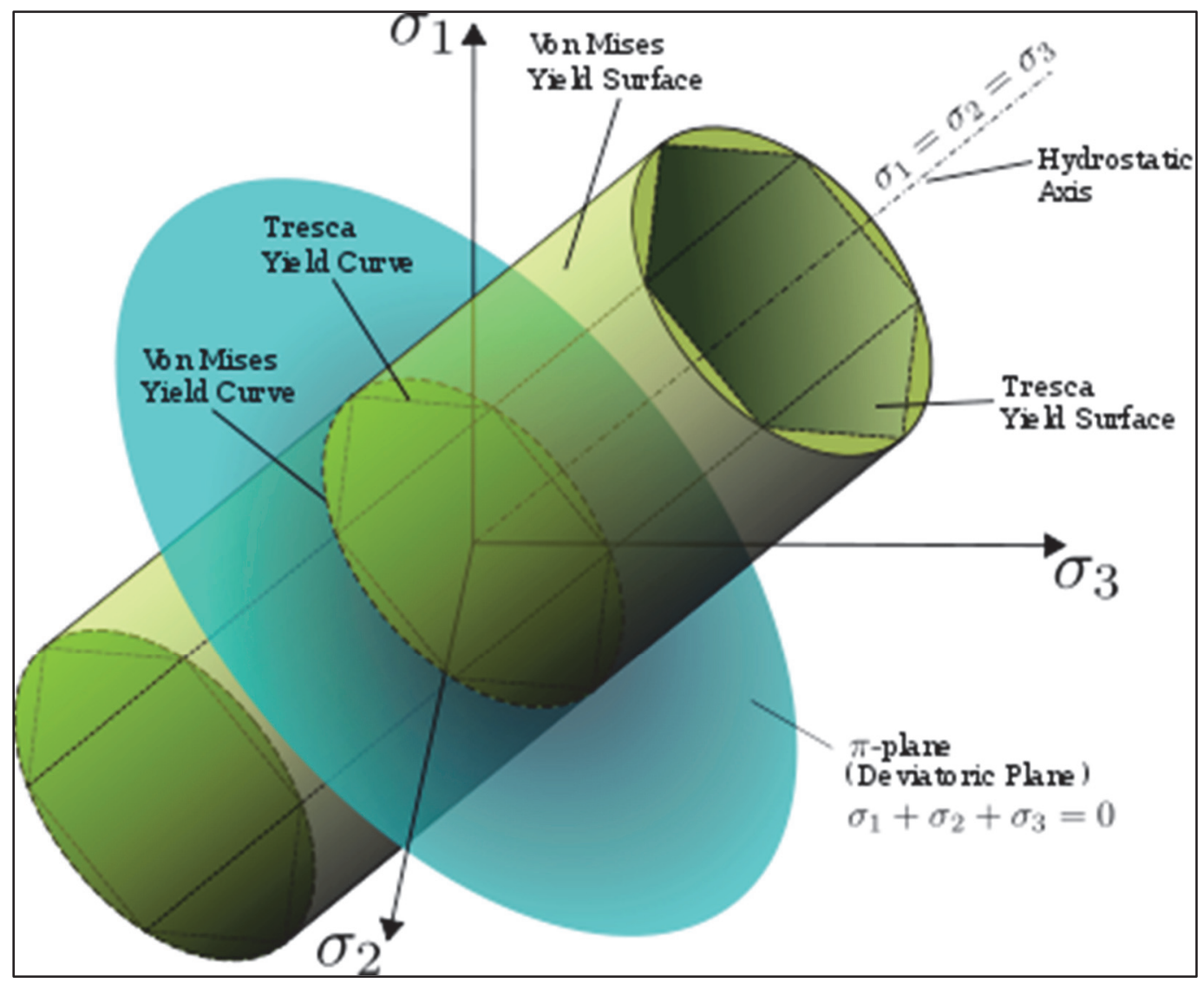

Source: $\underline{\text { http://www.engineersedge.com/ material_science/von_mises.htm. }}$

\subsection{Model verification}

Model verification was performed to compare the hand calculated miter gate loading condition forces to the FEM loading condition forces. Springs were added to the miter gate model to control movement in the gate. The Hooke's law equation ( $\mathrm{F}=\mathrm{kx}$ ) was used to adjust the $\mathrm{k}$-value until it was equivalent to the calculated reaction forces. The reaction forces generated in the model were very low when compared to hand calculated reaction forces listed in the engineer design documents provided for LD27. Further research is needed so adequate model verification techniques can be used for miter gates and other HSSs that exhibit nonlinear behavior.

\subsection{Model validation}

The simulations from the model were validated phenomenologically. Since the model could not be reasonably verified, the simulated predictions were compared with the yield limit for steel and with the visual field inspections conducted. Comparisons of predicted stress levels with that of measured 
stresses from the field instrumented miter gates could not be made because of the issues previously discussed in Chapter 2, section 2.4.1.1, "Repair, Evaluation, Maintenance, and Rehabilitation (REMR) research program." Furthermore, to effectively use field instrumentation data for model comparisons, the structural members must be instrumented immediately after fabrication, and limited data collection must be acquired during the miter gate construction assembly phase so that the initial stress state can be determined. Quantifying the initial internal stress state of the gate allows the data to be normalized correctly and thereby allows for reasonable comparisons to be made between the instrumentation data and model simulations.

\subsection{Overall computational modeling methodology summary}

The 3-D FEM was developed so that an in-service operating miter gate could be sufficiently represented. The computational methodology was developed to provide a systematic approach to investigating the effects of quoin block deterioration and loss of lock wall contact on load transfer to the pintle and pintle connections. Chapter 4 provides the results of the simulations. 


\section{Results of Parametric Analyses}

\subsection{Introduction}

A parametric analysis was conducted to determine the effect quoin block deterioration has on the miter gate's pintle. As described in Chapter 1, the quoin block (Figure 1-4) is located on the quoin end of the miter gate. The quoin block sets in the wall quoin, making complete contact when the gate is closed. Recent field observations indicate the quoin block has deteriorated and makes very little contact with the wall quoin. The hypothesis $(H)$ is that, when the quoin block deteriorates at the wall's boundaries, the axial load is no longer applied to the gate's central axis. As a result of the eccentric loading condition, the load transfer is intended to occur with the wall diminishes and may cause a stress increase in the pintle region. If the stress in the region exceeds the design limit, the miter gate structure may not meet its prescribed design and/or operational life expectancy.

The results for the von Mises predicted stresses in the pintle region were compared to the yield stress of 40,000 psi and the material's ultimate stress of 70,000 psi, which was obtained from the AISC code table of properties for steel grade A27 Grade 70-40 Class 2 (AISC 2001). Results are reported for the quoin block degradation (boundary conditions removal) levels of $0 \%, 25 \%$, $50 \%$, and $75 \%$ of the height of the block from bottom to top (Figure 4-1). The degradation of the quoin block boundary conditions was accomplished by removing the restraints in the 1,2 direction. The remainder of this chapter presents the results for the effects deterioration has on stress redistribution in the pintle member, using both cross-sectional contours and stress path analysis techniques.

\subsection{Plane view results of quoin block deterioration states}

\subsubsection{Introduction}

This section provides the results of the parametric analyses on the top surface of the pintle. The top surface is in the 1, 2 (X, Y) direction, as shown in Figure 4-2. The results were analyzed using the contour plots generated from ABAQUS. The contour plots gave an overall depiction of how the stress redistribution evolved. Additionally, the contour plots were used to identify the overstressed areas in the pintle globally. 
Figure 4-1. Degradation (boundary conditions removal) of the quoin block boundary conditions in the FEM.

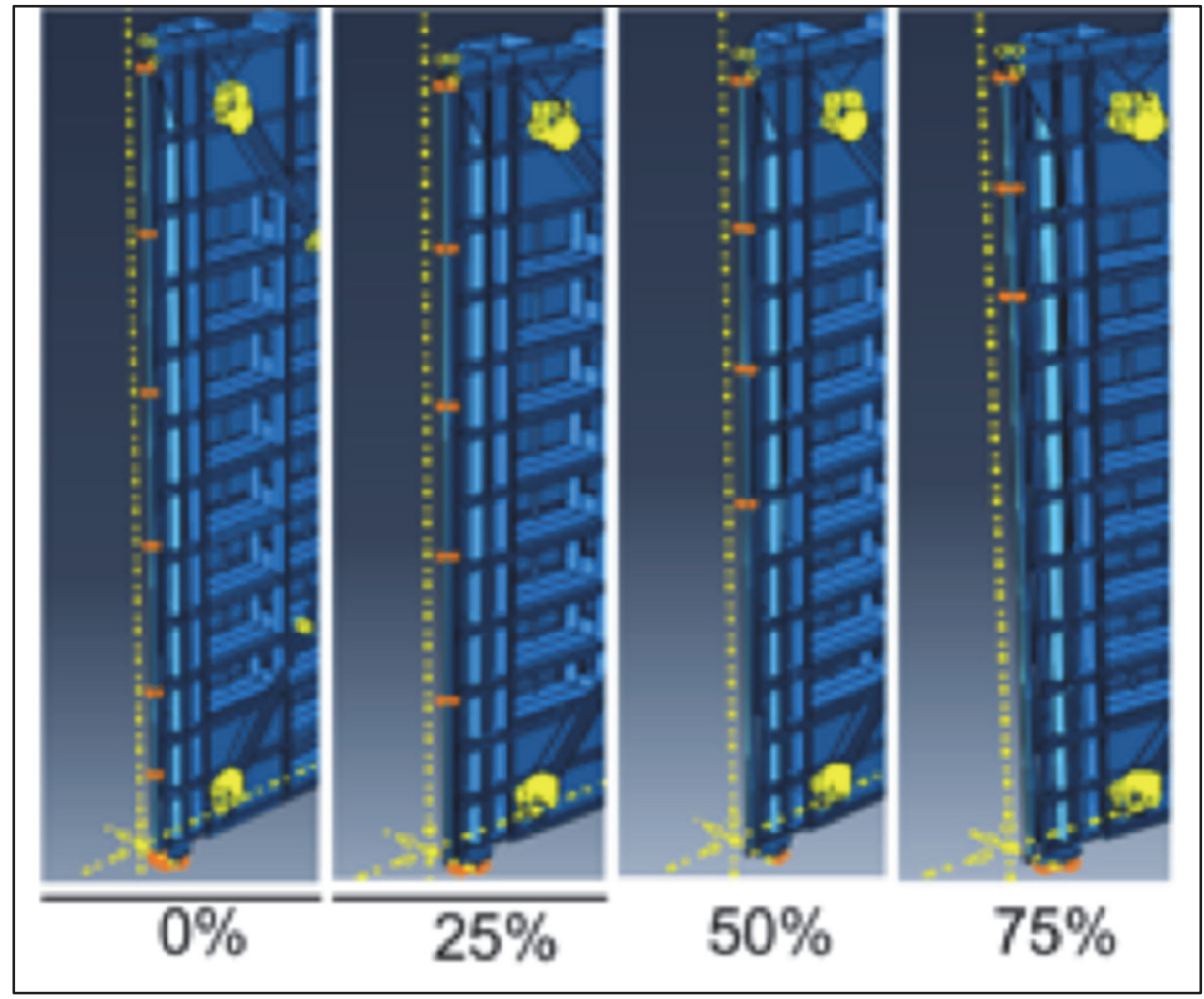

Figure 4-2. Location of the horizontal and vertical paths on the pintle.

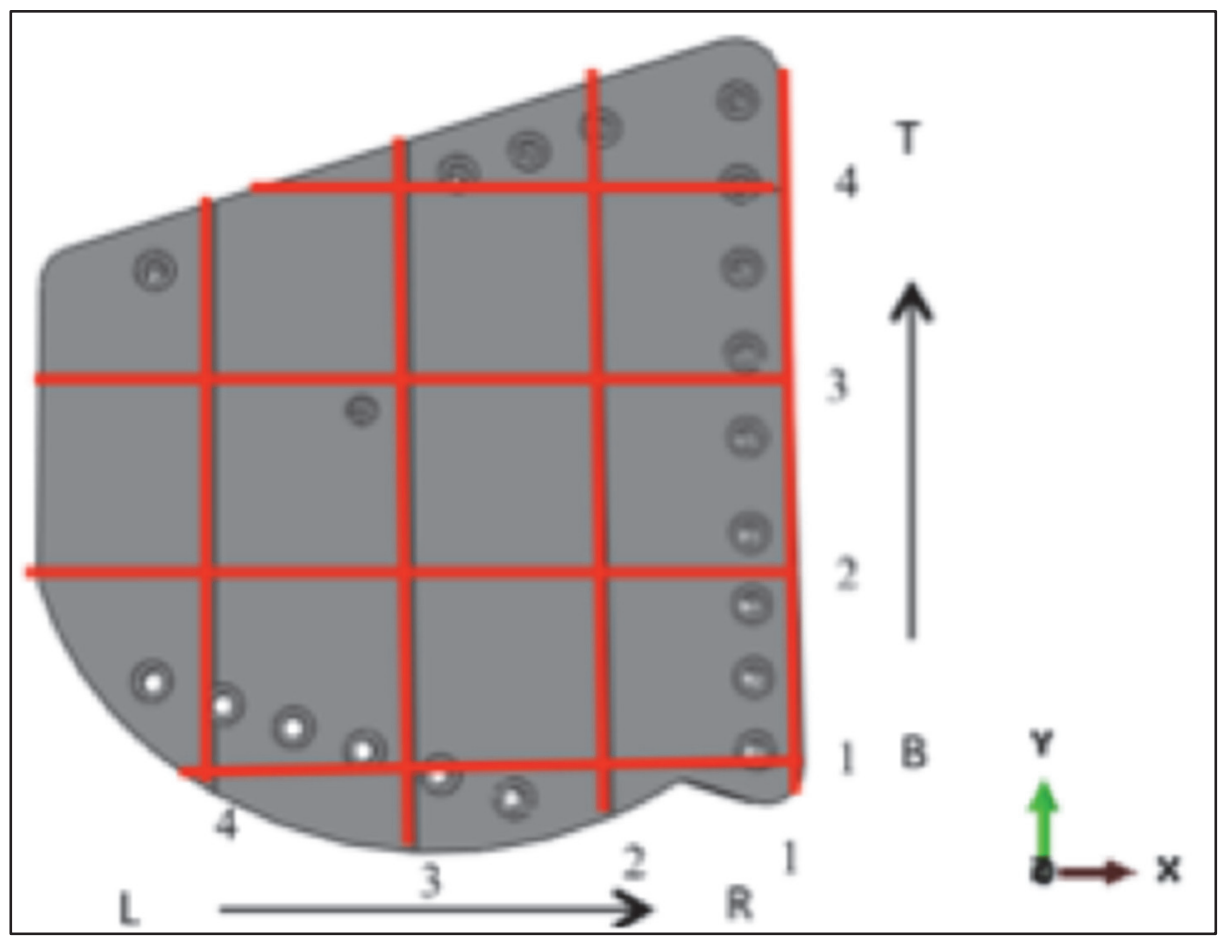


To further quantify the local critical regions, stress paths were created horizontally (right-to-left) and vertically (bottom to top) along the pintle's surface (Figure 4-2). However, the distances used to describe the stress states are horizontally (left to right) and vertically (bottom to top) along the surface.

\subsection{2 $0 \%$ deterioration}

The contour and stress plots in Figures 4-3 and 4-4, respectively, show the von Mises stresses along the "Horizontal-Load Path 1" for $0 \%$ deterioration. The observed increase seems to be occurring from left to right. The stress increase is due to the path taken along the bolt-hole region. A bolthole passes through the stress path at $10 \mathrm{in}$. and $30 \mathrm{in}$. The predicted von Mises stresses show from left to right [0-30) in. that yielding does not occur. However, from distances [30-32) in., yielding occurs. The maximum von Mises stress exceeded yield by $14 \%$ at 30 in. for the stress path.

The stress path plotted in Figure 4-5 shows the von Mises stresses along the "Horizontal-Load Path 2" for $0 \%$ deterioration. The observed increase seems to be occurring from left to right. It is very likely the stress increase is due to the path taken along the bolt-hole region. There is a bolt-hole near the stress path at $37 \mathrm{in}$. The predicted von Mises stresses show that, from left to right [0-37) in., yielding does not occur; however, at 38 in., yielding occurs. The von Mises stress exceeded yield by $2 \%$ at 38 in. for the stress path.

The stress path plotted in Figure 4-6 shows the von Mises stresses along the "Horizontal-Load Path 3" for o\% deterioration. The observed increase seems to be occurring from left to right. The stress increase is due to the path taken along the bolt-hole region. A bolt-hole is near the stress path at 37 in. The predicted von Mises stresses show from left to right that yielding does not occur.

The stress path plotted in Figure 4-7 shows the von Mises stresses along the "Horizontal-Load Path 4" for $0 \%$ deterioration. The predicted von Mises stresses show a stress increase from left to right; however, yielding does not occur. The stress increase is due to the path taken along the bolthole region. A bolt-hole passes through the stress path at 25 in. 
Figure 4-3. Contour plot showing von Mises stress and critical stress region at $0 \%$ deterioration (plan view).

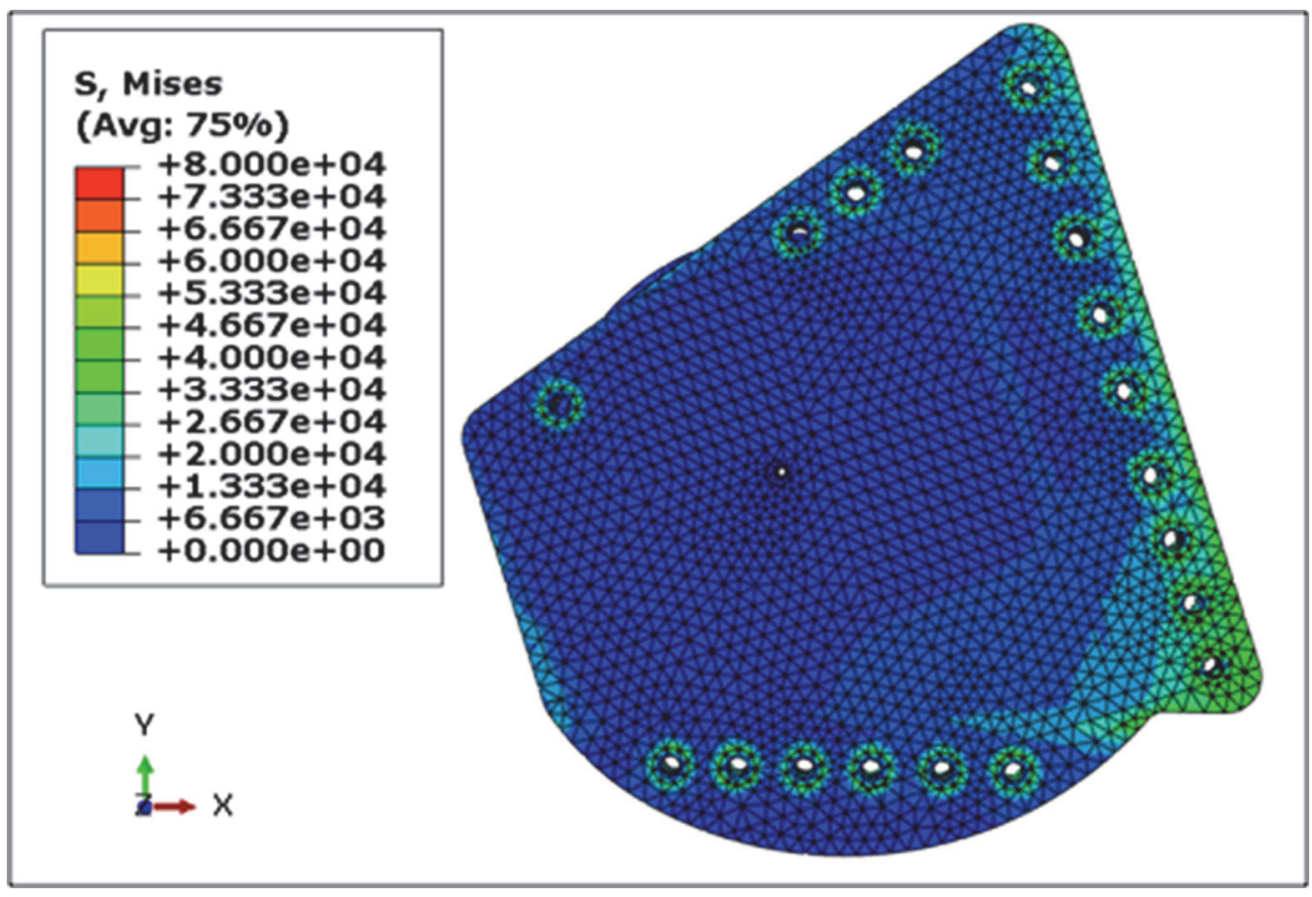

Figure 4-4. Stress plot showing von Mises stress along "Horizontal- Load Path 1" at 0\% deterioration.

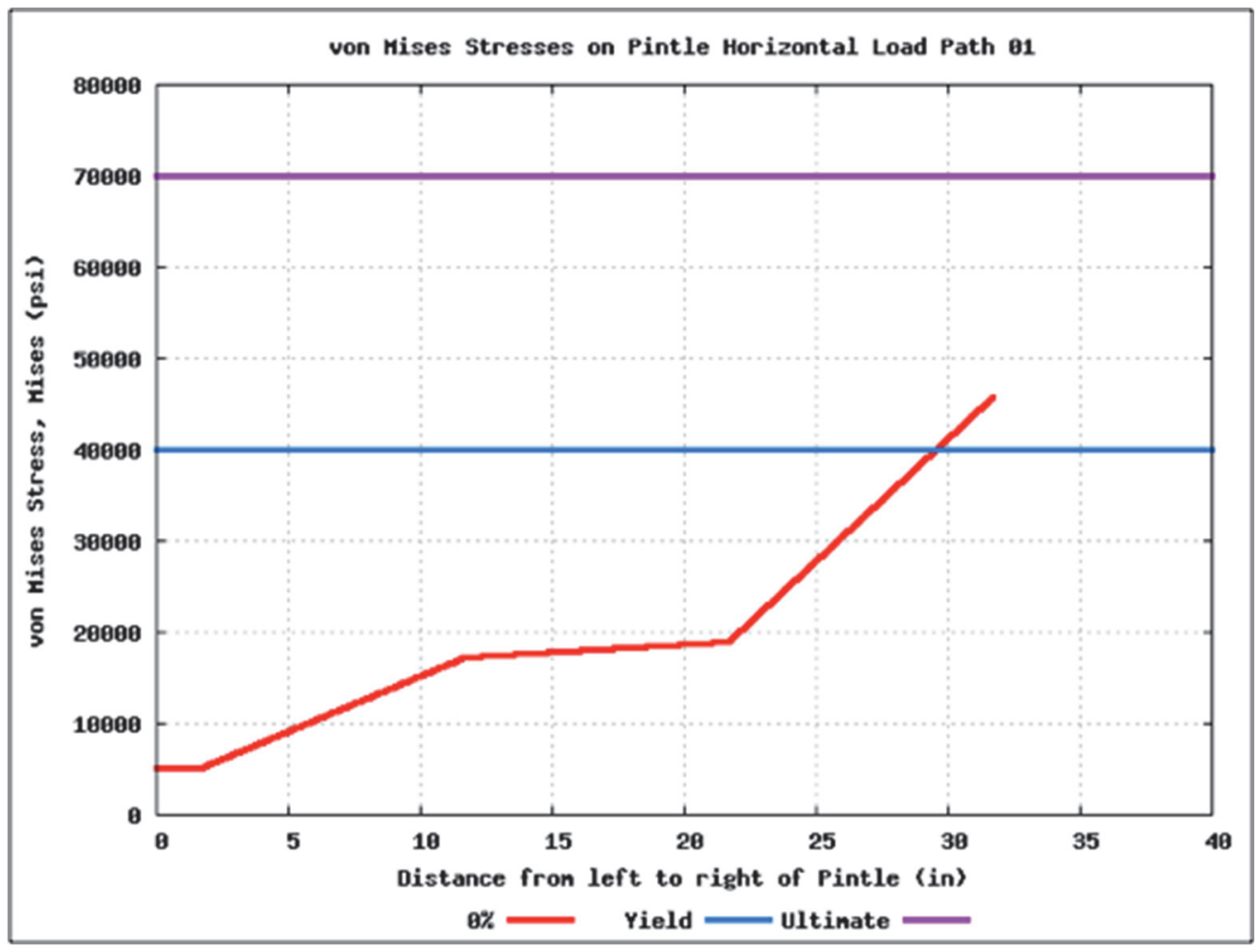


Figure 4-5. Stress plot showing von Mises stress along "Horizontal-Load Path 2" at $0 \%$ deterioration.

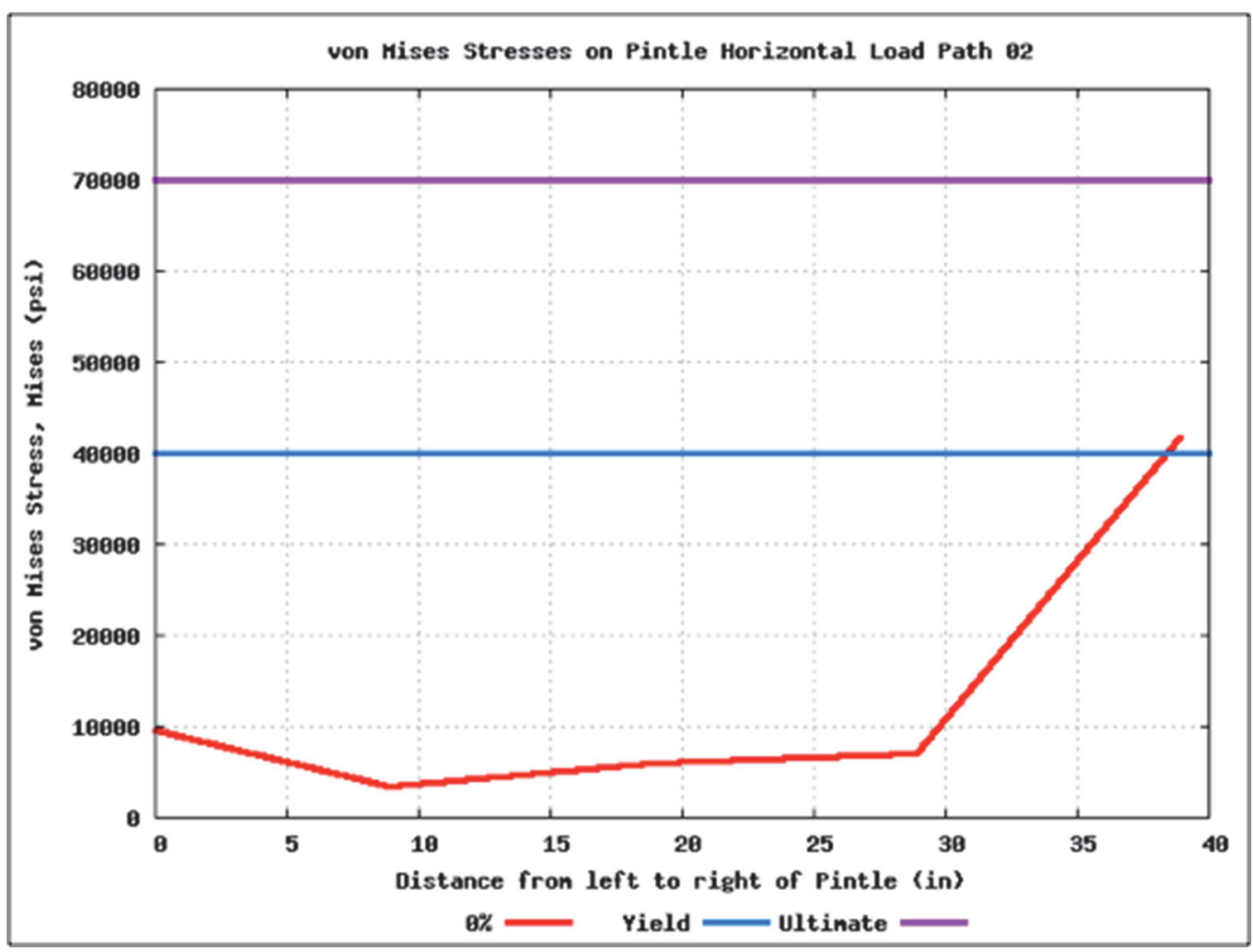

Figure 4-6. Stress plot showing von Mises stress along "Horizontal-Load Path 3" at $0 \%$ deterioration.

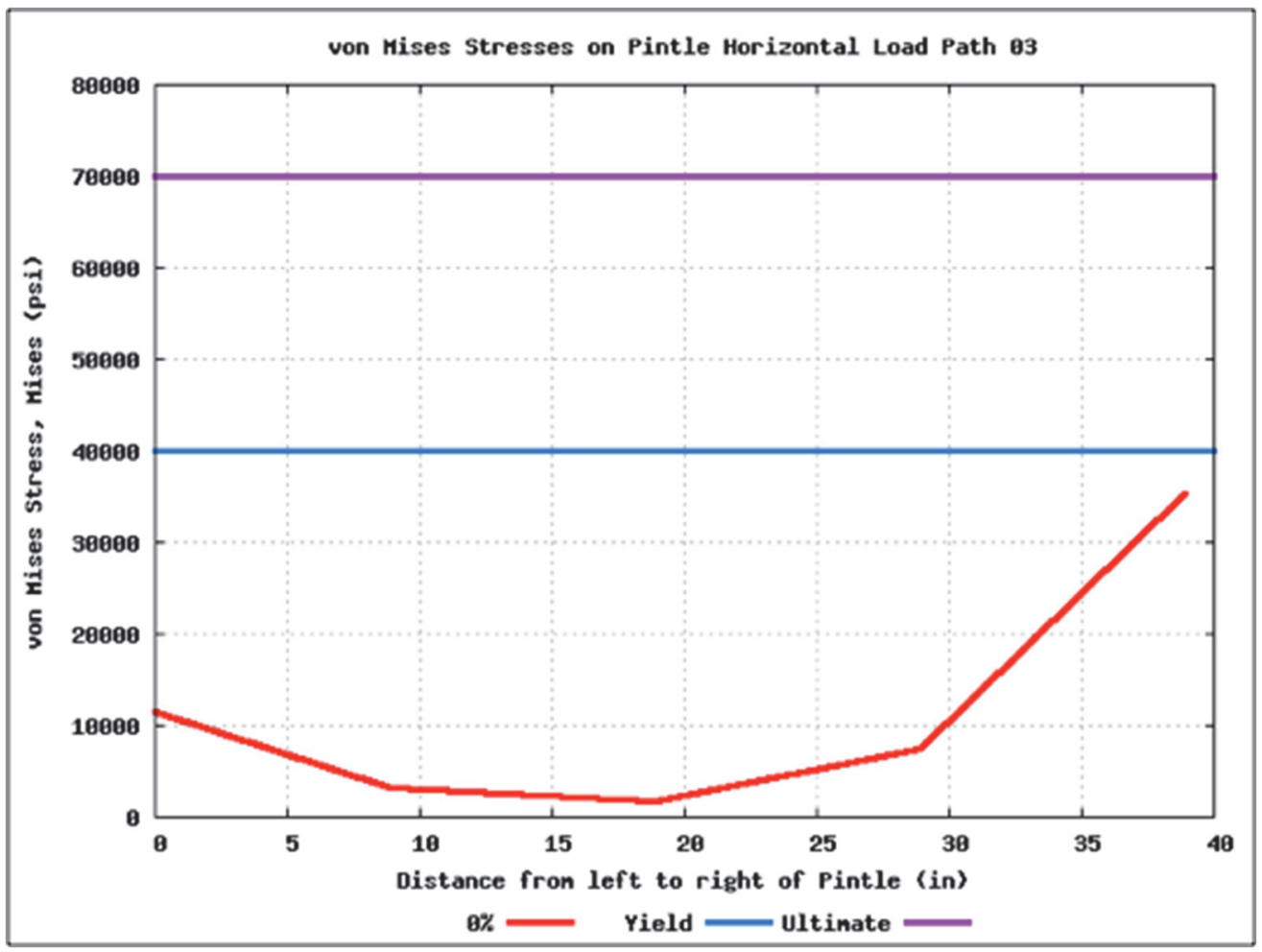


Figure 4-7. Stress plot showing von Mises stress along "Horizontal-Load Path 4" at $0 \%$ deterioration.

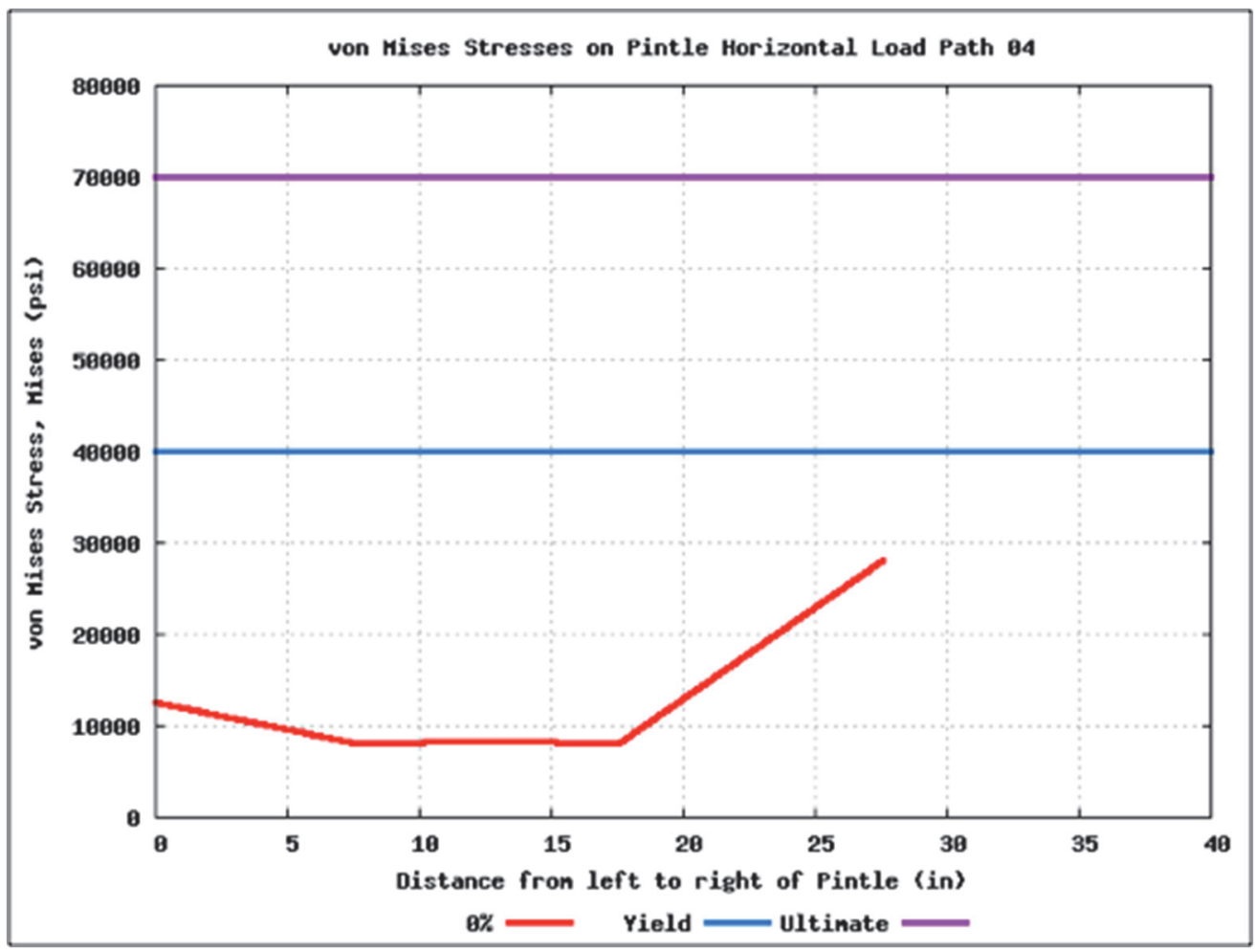

The stress path plot in Figure 4-8 shows the von Mises stresses along the "Vertical Load Path 1" for 0\% deterioration. The predicted von Mises stresses showing yielding initially occurs at o to $12 \mathrm{in}$. from bottom to top. More than likely, the initial yielding at the location is due to the path taken along the bolt-hole region. The bolt-holes are near the entire length of the stress path. The von Mises stress exceed yield by $14 \%$ at $\mathrm{o}$ in. for the stress path. From distances [12-35) in., yielding does not occur. The von Mises stress exceed yield by $8 \%$ at 36 in. for the stress path.

The stress path plotted in Figure 4-9 shows the von Mises stresses along the "Vertical Load Path 2" for o\% deterioration. Initially, the stresses start off high and decrease with consistency until 30 in. along the path. Then, there is a slight increase. It is very likely the stress increase at the location is due to the path taken along the bolt-hole region at $\mathrm{o}$ and $30 \mathrm{in}$. The predicted von Mises stresses show from bottom to top [0-36) in. that yielding does not occur. 
Figure 4-8. Stress plot showing von Mises stress along "Vertical Load Path 1" at 0\% deterioration.

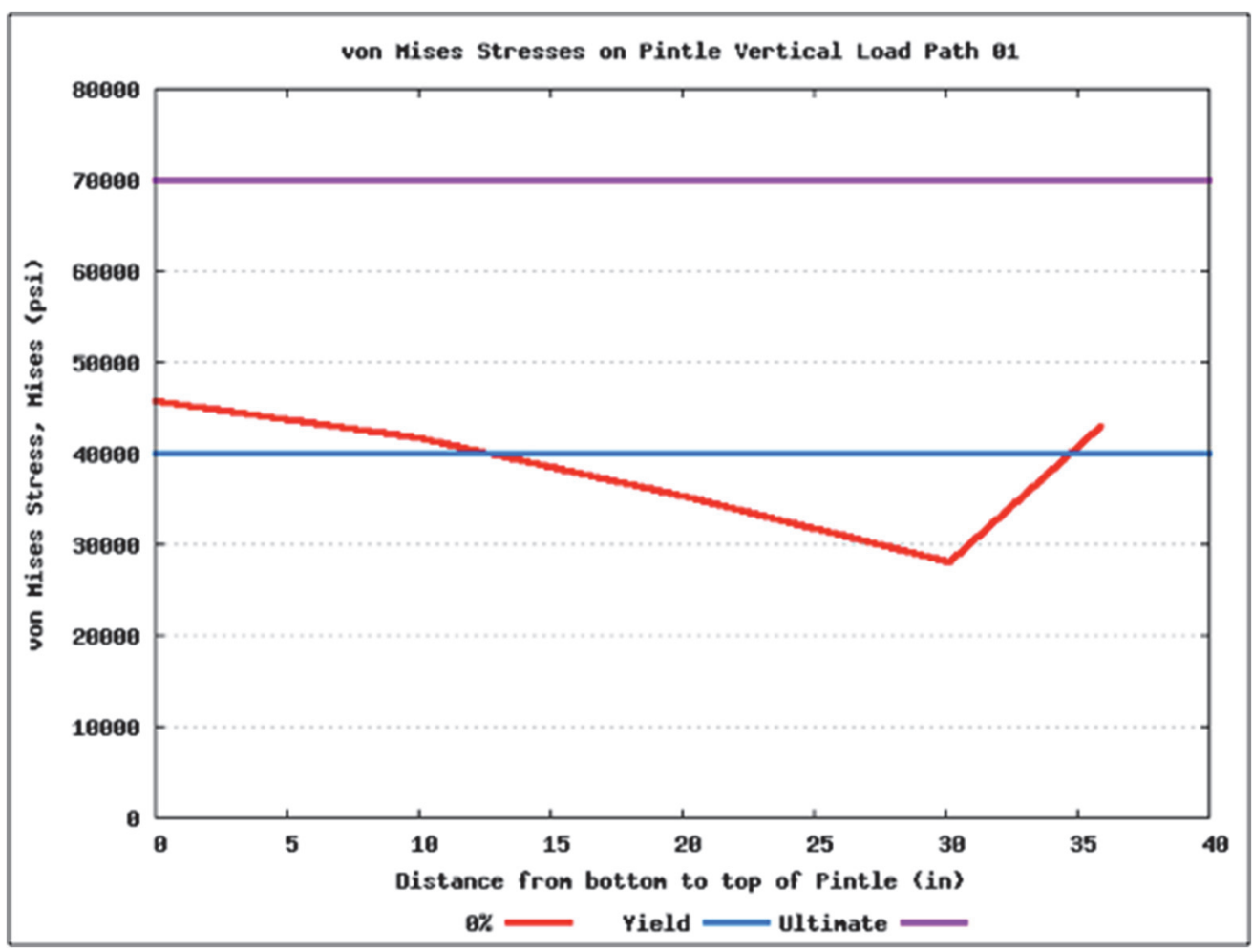

Figure 4-9. Stress plot showing von Mises stress along "Vertical Load Path 2" at 0\% deterioration.

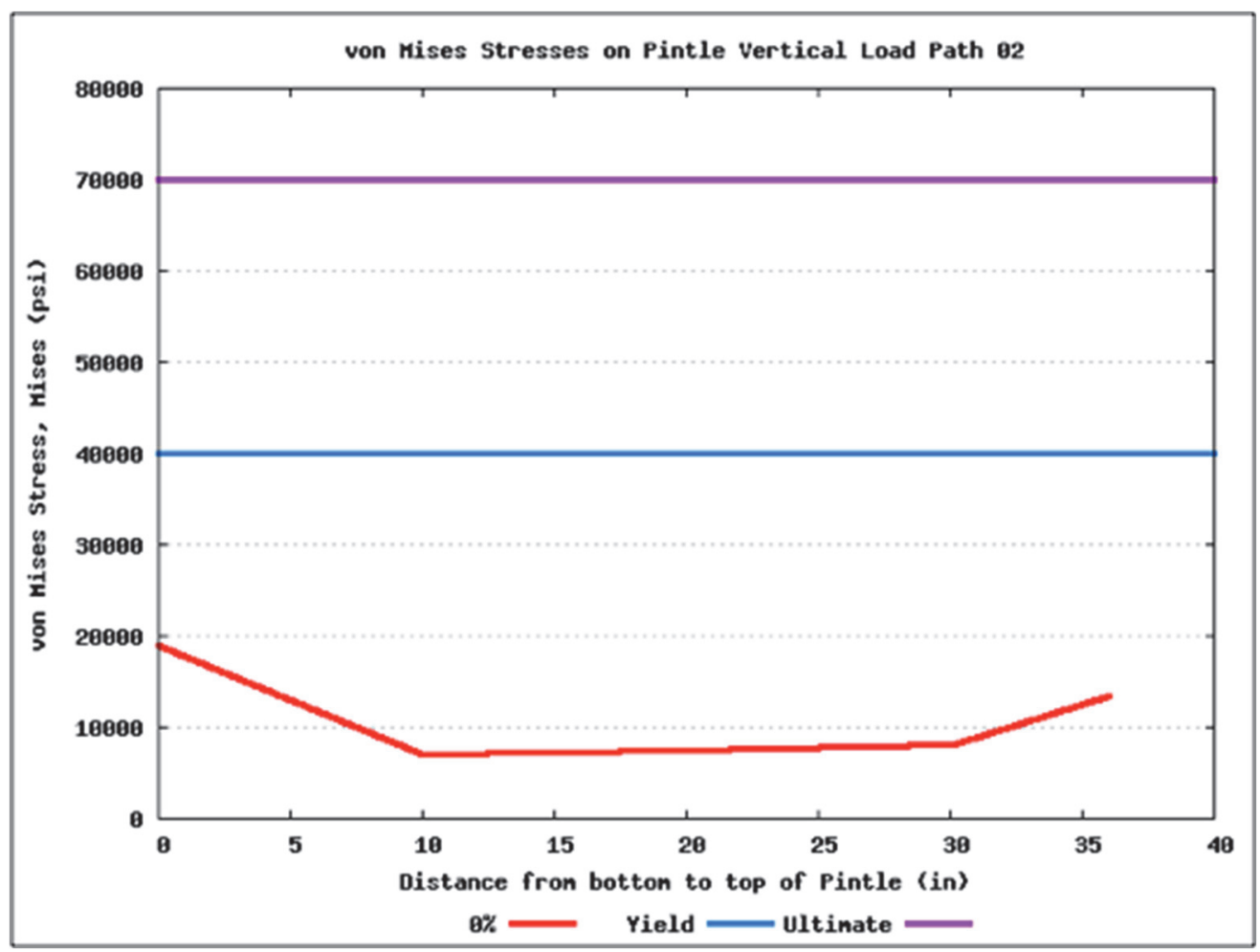


The stress path plotted in Figure 4-10 shows the von Mises stresses along the "Vertical Load Path 3" for o\% deterioration. Initially, the stresses start off high and decrease. The stresses remain consistent until 30 in. along the path; then, there is a slight increase. The stress increase is due to the path taken along the bolt-hole region from $\mathrm{o}$ and $30 \mathrm{in}$. The predicted von Mises stresses show from bottom to top [0-33) in. that yielding does not occur.

The stress path plotted in Figure 4-11 shows the von Mises stresses along the "Vertical Load Path 4" for o\% deterioration. The stresses are consistent until 22 in., then there is a slight increase. It is very likely the stress increase is due to the path taken near the bolt-hole region at $22 \mathrm{in.}$ The predicted von Mises stresses show from bottom to top [0-32) in. that yielding does not occur.

Figure 4-10. Stress plot showing von Mises stress along "Vertical Load Path 3" at $0 \%$ deterioration.

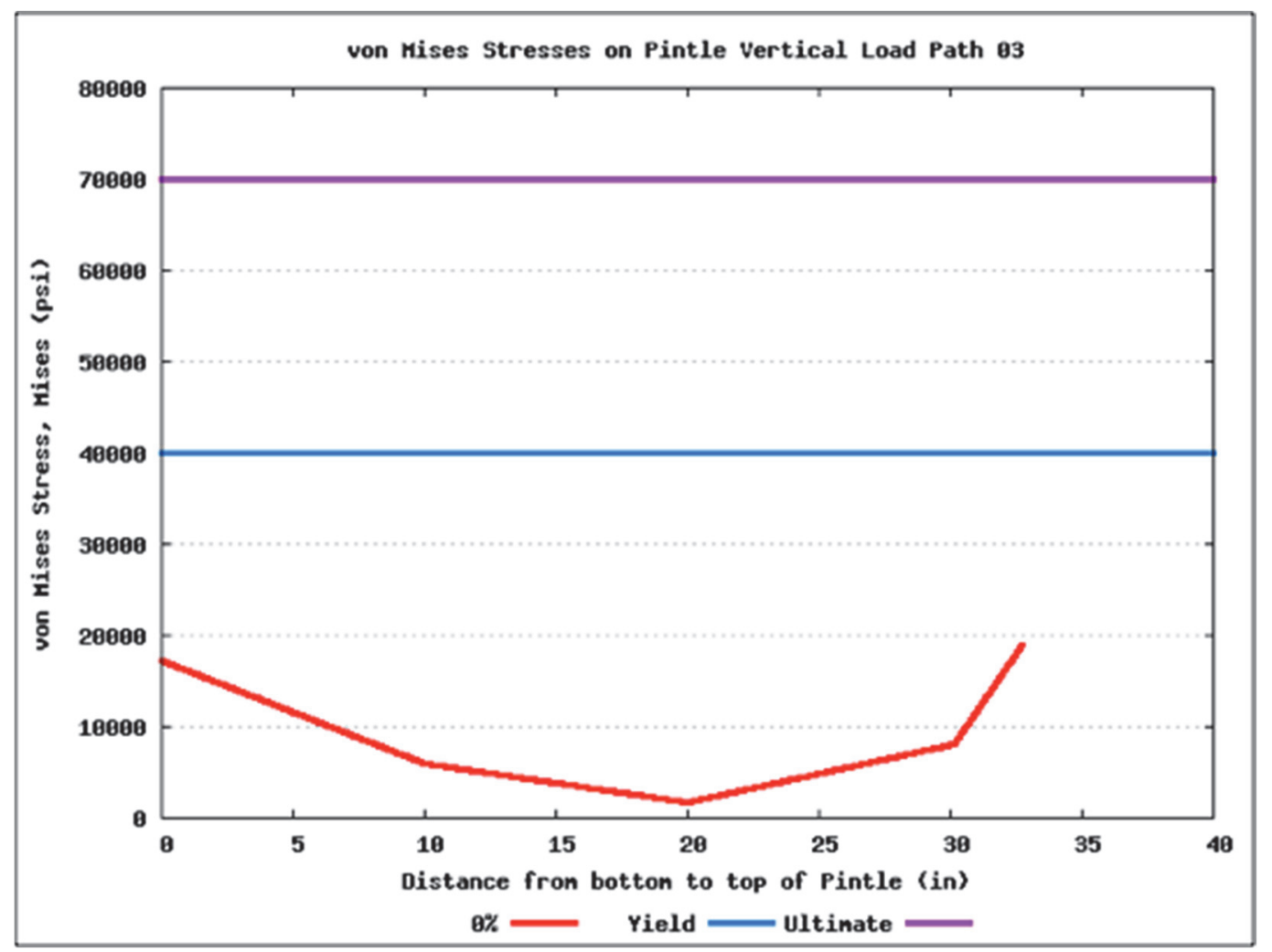


Figure 4-11. Stress plot showing von Mises stress along “Vertical Load Path 4" at 0\% deterioration.

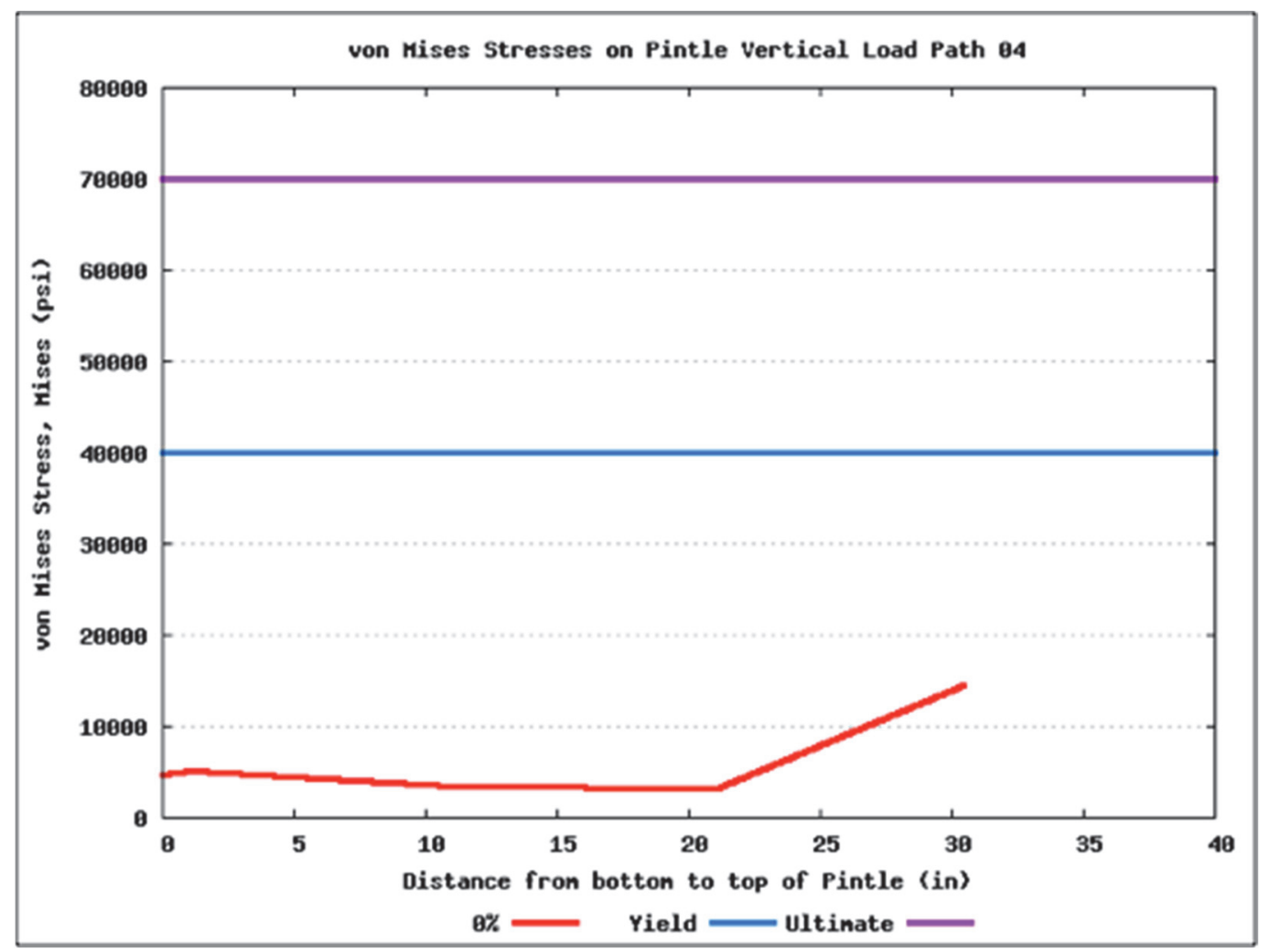

\subsubsection{5\% deterioration}

The contour and stress plotted in Figures 4-12 and 4-13, respectively, show the von Mises stresses along the "Horizontal-Load Path 1" when comparing o\% and 25\% deterioration levels. The observed increase seems to be occurring from left to right. A bolt-hole passes through the stress path at $10 \mathrm{in}$. and 30 in., likely causing a stress increase. The predicted von Mises stresses show from left to right [0-30) in. that yielding does not occur. However, from distances [30-32) in., yielding occurs. The maximum von Mises stress for $25 \%$ deterioration exceeds yield by $14 \%$ at 30 in. for the stress path.

The stress path plotted in Figure 4-14 shows the von Mises stresses along the "Horizontal-Load Path 2" when comparing $0 \%$ and 25\% deterioration levels. The observed increase seems to be occurring from left to right. It is very likely the stress increase along the path at 37 in. is due to crossing the bolt-hole region. The predicted von Mises stresses show from left to right [0-37) in. that yielding does not occur; however, at 38 in., yielding occurs. The von Mises stress for $25 \%$ deterioration exceeds yield by $26 \%$ at 38 in. for the stress path. 
Figure 4-12. Contour plot showing von Mises stress and critical stress region at (a) $0 \%$ and

(b) $25 \%$ deterioration levels (plane view).

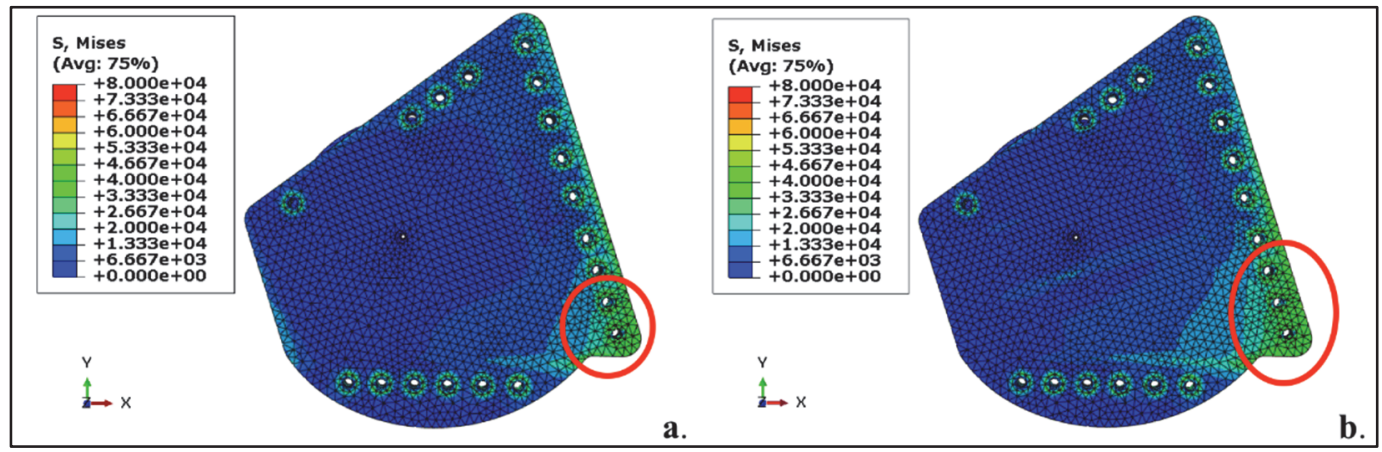

Figure 4-13. Stress plot showing von Mises stress along "Horizontal- Load Path 1" at $0 \%$ and $25 \%$ deterioration levels.

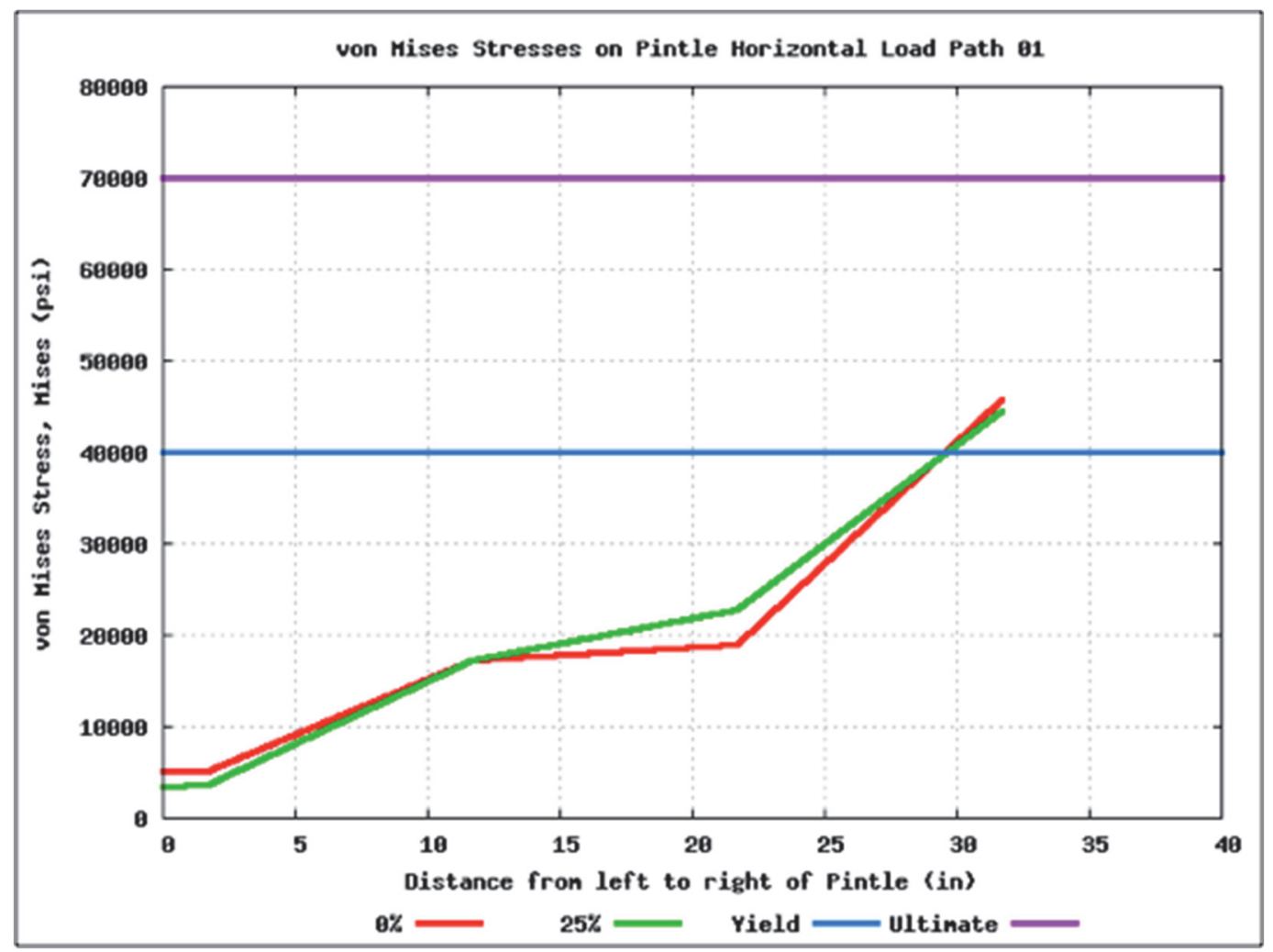


Figure 4-14. Stress plot showing von Mises stress along "Horizontal- Load Path 2" at 0\% and $25 \%$ deterioration levels.

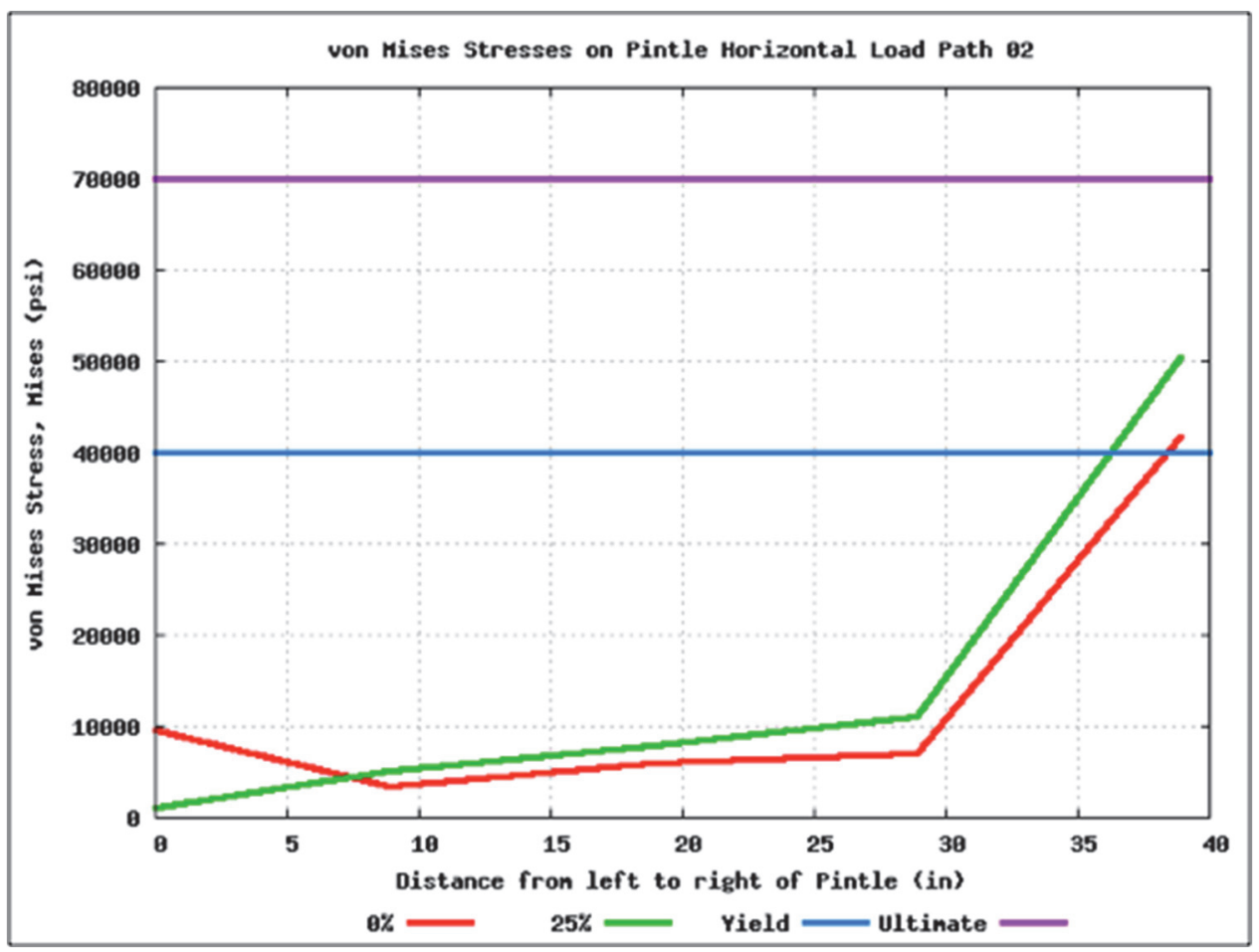

The stress path plotted in Figure 4-15 shows the von Mises stresses along the "Horizontal-Load Path 3" when comparing $0 \%$ and $25 \%$ deterioration levels. The observed increase seems to be occurring from left to right. A bolt-hole is near the stress path at 37 in., leading to the stress increase. The predicted von Mises stresses show yielding does not occur.

The stress path plotted in Figure 4-16 shows the von Mises stresses along the "Horizontal-Load Path 4" when comparing $0 \%$ and $25 \%$ deterioration levels. The observed increase seems to be occurring from left to right. It is very likely the stress increase is due to the path taken along the bolt-hole region. A bolt-hole passes through the stress path at $25 \mathrm{in}$. The predicted von Mises stresses show yielding does not occur.

The stress path plotted in Figure 4-17 shows the von Mises stresses along the "Vertical Load Path 1" when comparing $0 \%$ and $25 \%$ deterioration levels. The predicted von Mises stresses show from left to right [0-20) in. yielding does occur. However, from [20-36) in., yielding does not occur. More than likely the initial yielding at the location is due to the path taken along the bolt-hole region. The bolt-holes are near the entire length of the stress path. The maximum von Mises stress for $25 \%$ deterioration exceed yield by $26 \%$ at $10 \mathrm{in}$. for the stress path. 
Figure 4-15. Stress plot showing von Mises stress along "Horizontal- Load Path 3" at 0\% and $25 \%$ deterioration levels.

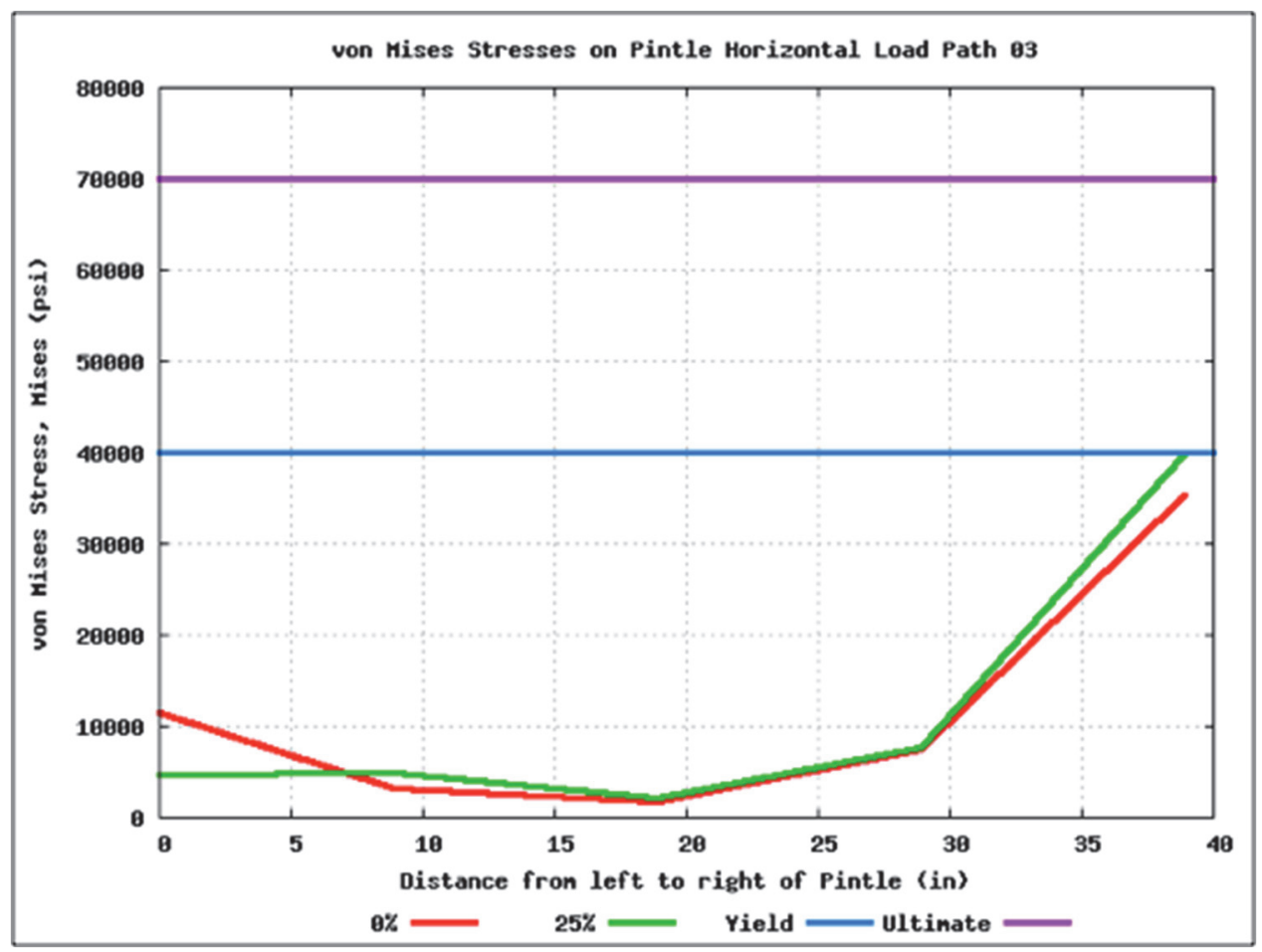

Figure 4-16. Stress plot showing von Mises stress along "Horizontal- Load Path 4" at $0 \%$ and $25 \%$ deterioration levels.

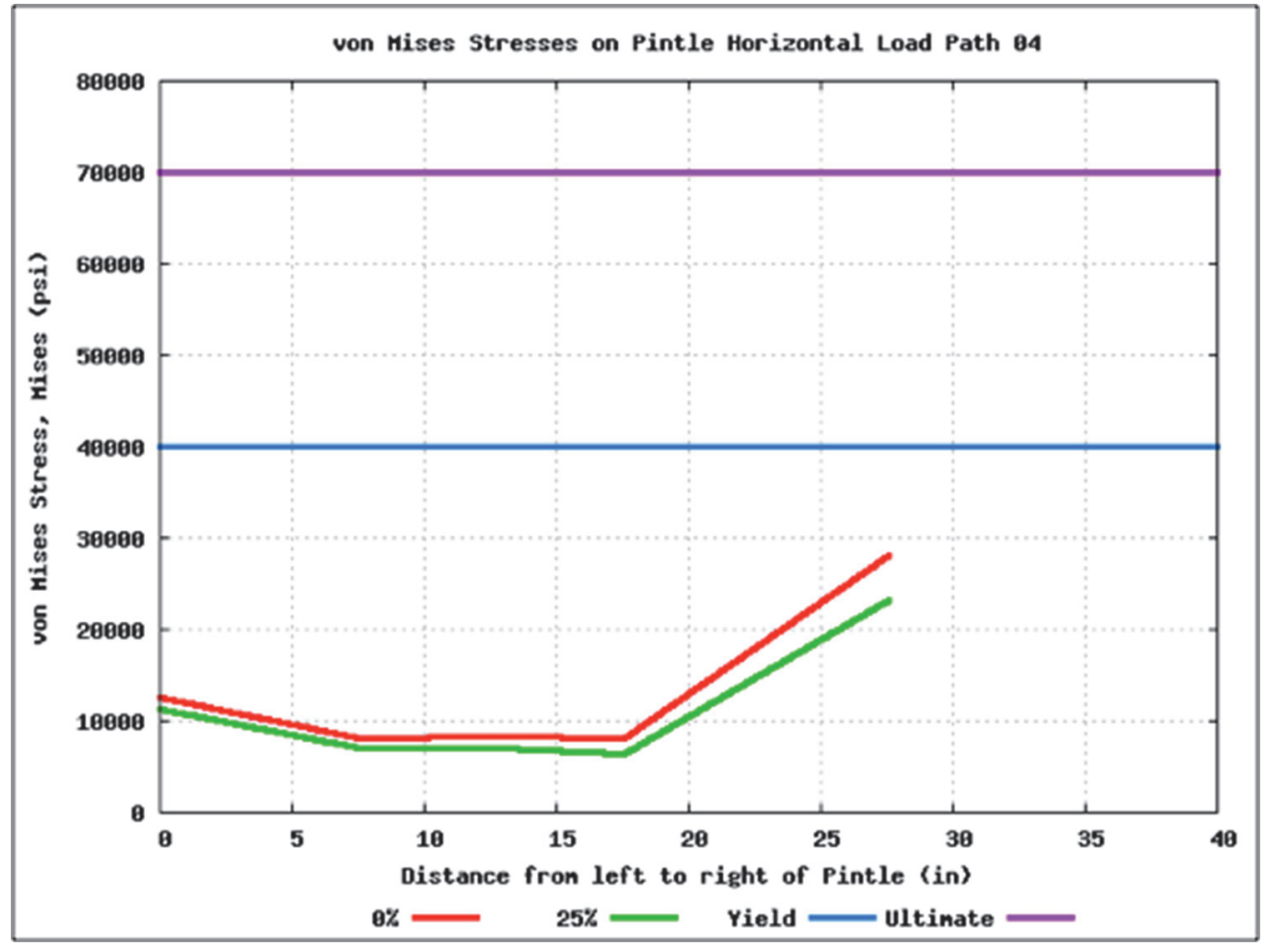


Figure 4-17. Stress plot showing von Mises stress along "Vertical- Load Path 1" at $0 \%$ and $25 \%$ deterioration levels.

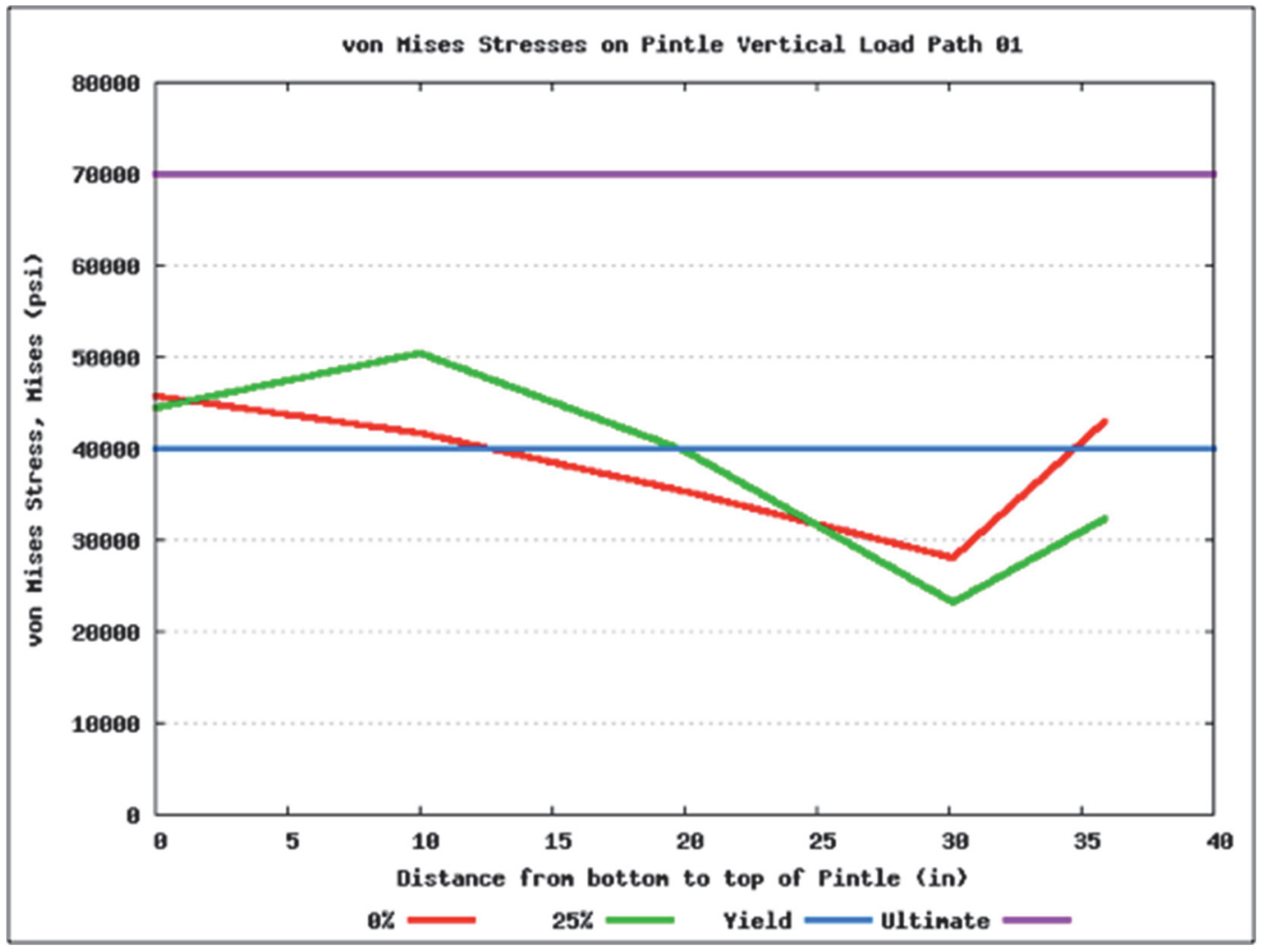

The stress path plotted in Figure 4-18 shows the von Mises stresses along the "Vertical Load Path 2" when comparing 0\% and 25\% deterioration levels. Initially, the stresses start above yield and decrease below the yield until 30 in. along the path. Then, there is a slight increase. It is very likely the stress increase at the location is due to the path taken along the bolt-hole region at $\mathrm{o}$ and $30 \mathrm{in}$. The predicted von Mises stresses show from bottom to top that yielding does not occur.

The stress path plotted in Figure 4-19 shows the von Mises stresses along the "Vertical Load Path 3 " when comparing 0\% and 25\% deterioration levels. Initially, the stresses start off high then decreases but never exceeds the materials yield strength. The stresses remain consistent until 30 in. along the path; then, there is a slight increase. More than likely, the stress decrease occurring at $\mathrm{O}$ and $20 \mathrm{in}$. is because the path is progressing away from the bolt-hole region. The stress again increases along the path between 20 and $25 \mathrm{in}$. when the path again approaches another bolt-hole region. The predicted von Mises stresses show from bottom to top that yielding does not occur. 
Figure 4-18. Stress plot showing von Mises stress along "Vertical- Load Path 2" at 0\% and $25 \%$ deterioration levels.

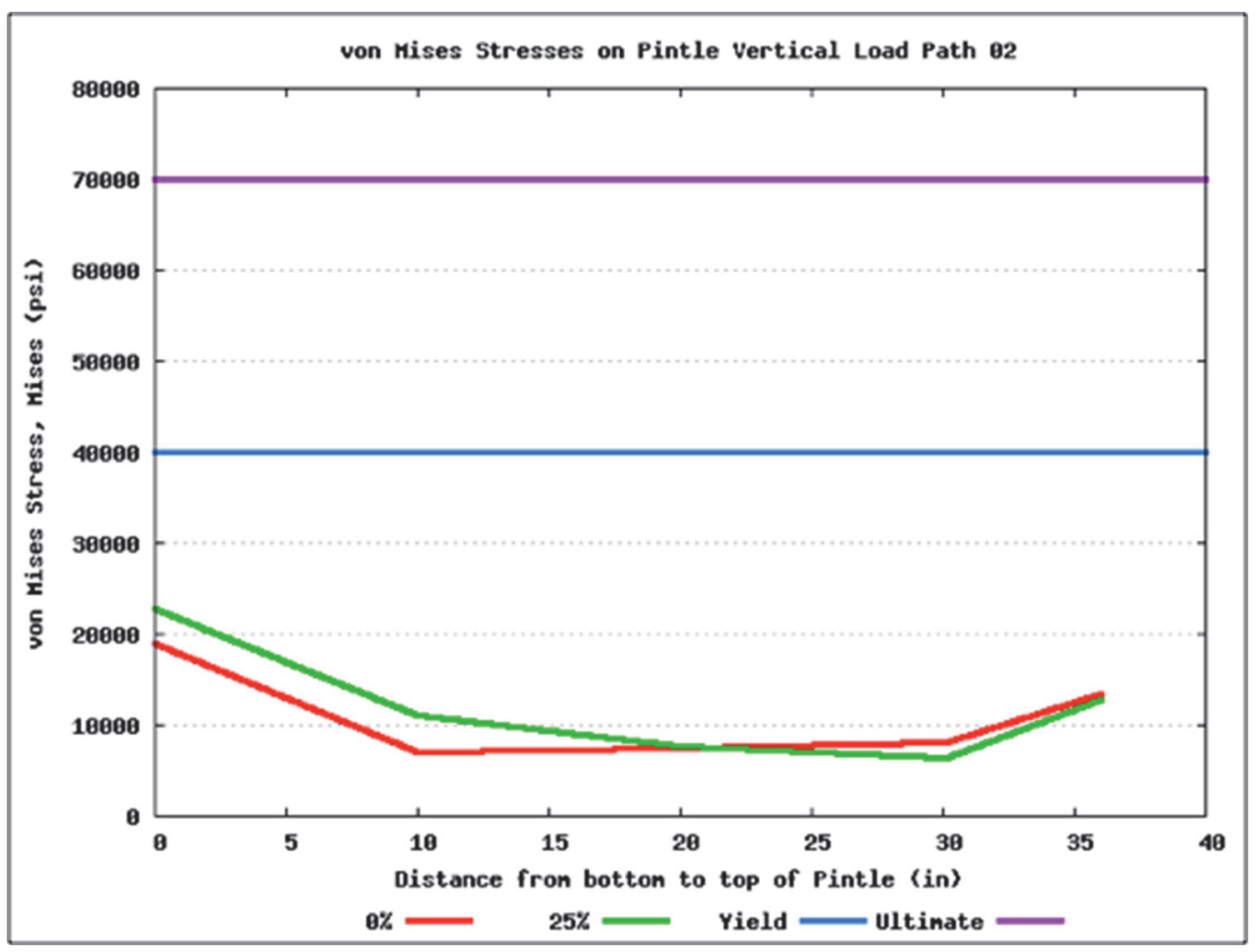

Figure 4-19. Stress plot showing von Mises stress along "Vertical- Load Path 3" at $0 \%$ and $25 \%$ deterioration levels.

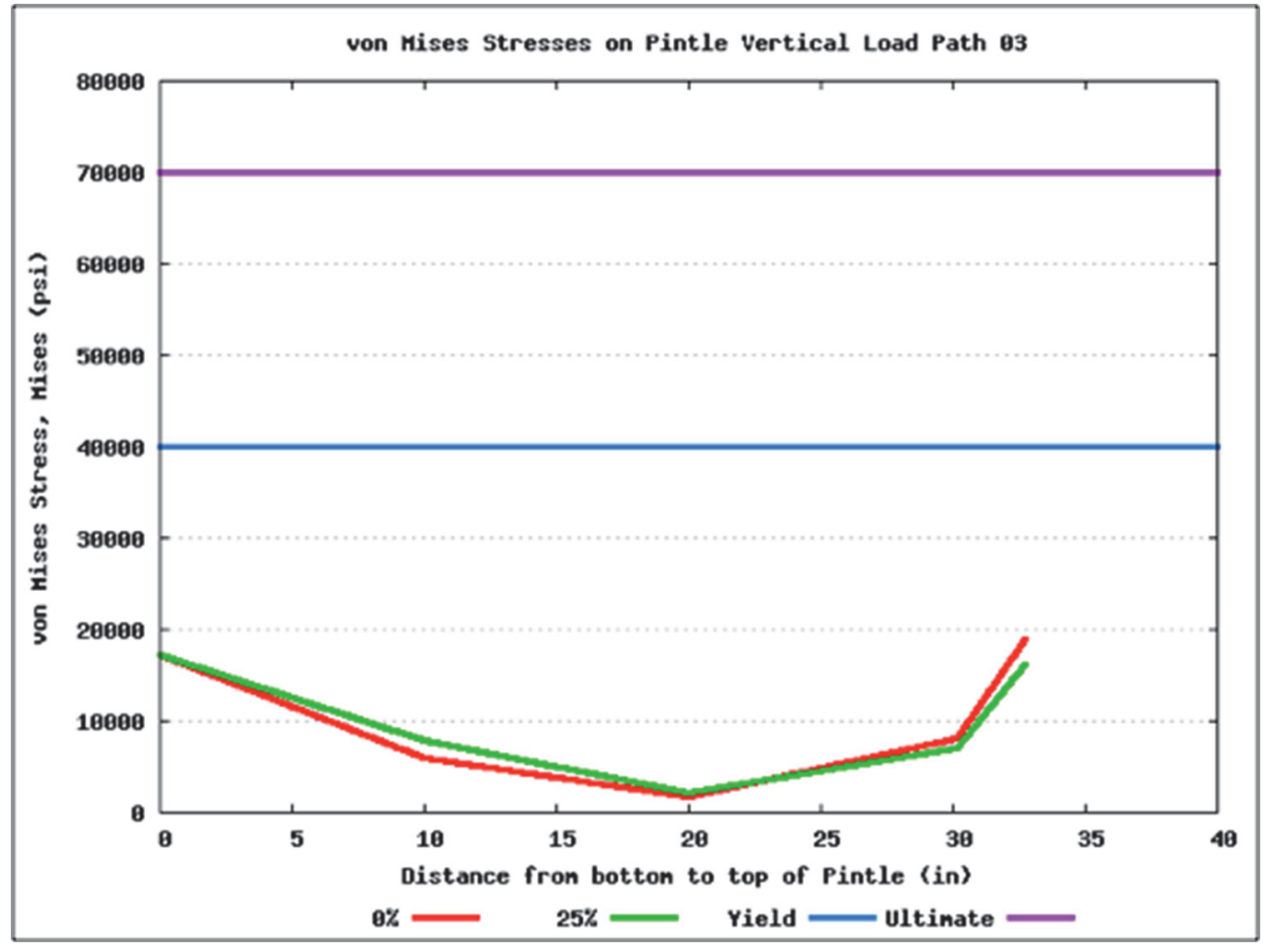


The stress path plotted in Figure 4-20 shows the von Mises stresses along the "Vertical Load Path 4" when comparing $0 \%$ and $25 \%$ deterioration levels. The stresses are consistent until 22 in.; then, there is a slight increase. It is very likely the stress increase is due to the path taken near the bolthole region at $22 \mathrm{in}$. The predicted von Mises stresses show from bottom to top that yielding does not occur.

\subsection{4 $50 \%$ deterioration}

The contour and stress plotted in Figures 4-21 and 4-22, respectively, show the von Mises stresses along the "Horizontal-Load Path 1" when comparing $0 \%$ and $50 \%$ deterioration levels. The observed increase seems to be occurring from left to right. It is very likely the stress increase at the location is due to the path taken along the bolt-hole region. A bolt-hole passes through the stress path at $10 \mathrm{in}$. and 30 in. The predicted von Mises stresses show from left to right [0-30) in. that yielding does not occur. However, from distances [30-32) in., yielding occurs. The maximum von Mises stress for 50\% deterioration exceed yield by $9 \%$ at 32 in. for the stress path.

Figure 4-20. Stress plot showing von Mises stress along "Vertical- Load Path 4" at $0 \%$ and $25 \%$ deterioration levels.

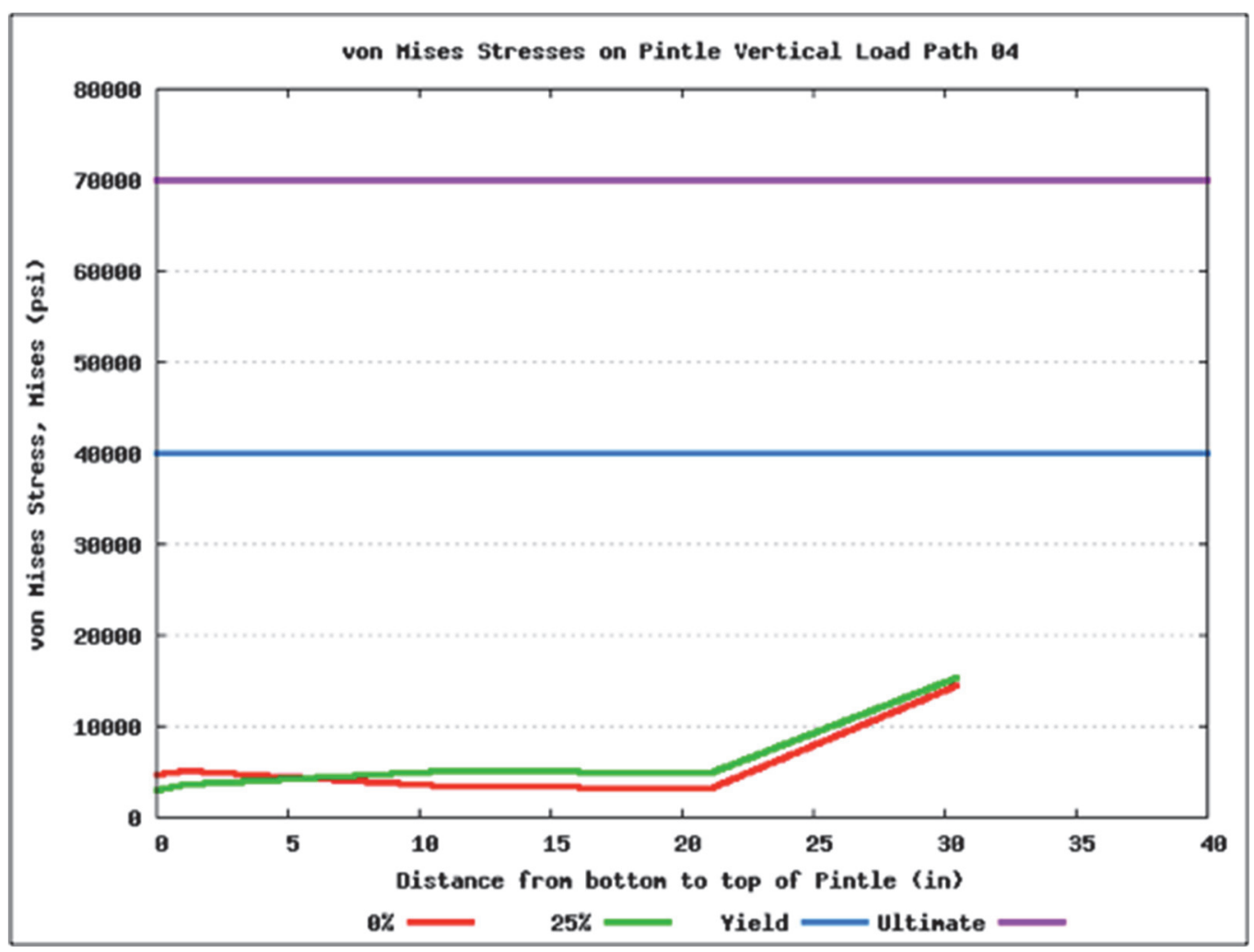


Figure 4-21. Contour plot showing von Mises stress and critical stress region at (a) $0 \%$ and (b) $50 \%$ deterioration levels (plane view).

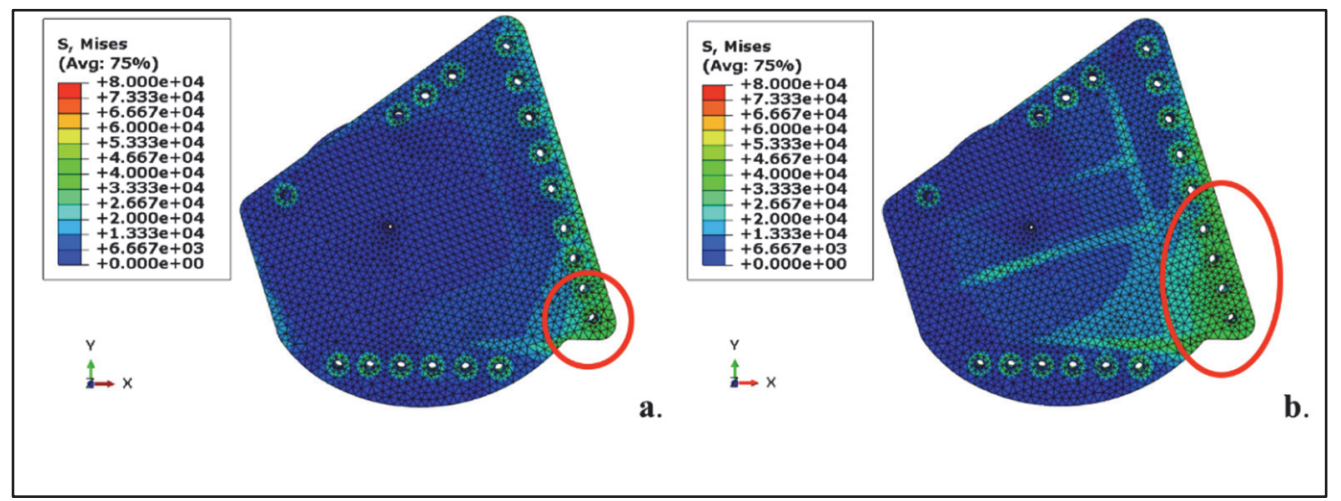

Figure 4-22. Stress plot showing von Mises stress along "Horizontal- Load Path 1" at $0 \%$ and $50 \%$ deterioration levels.

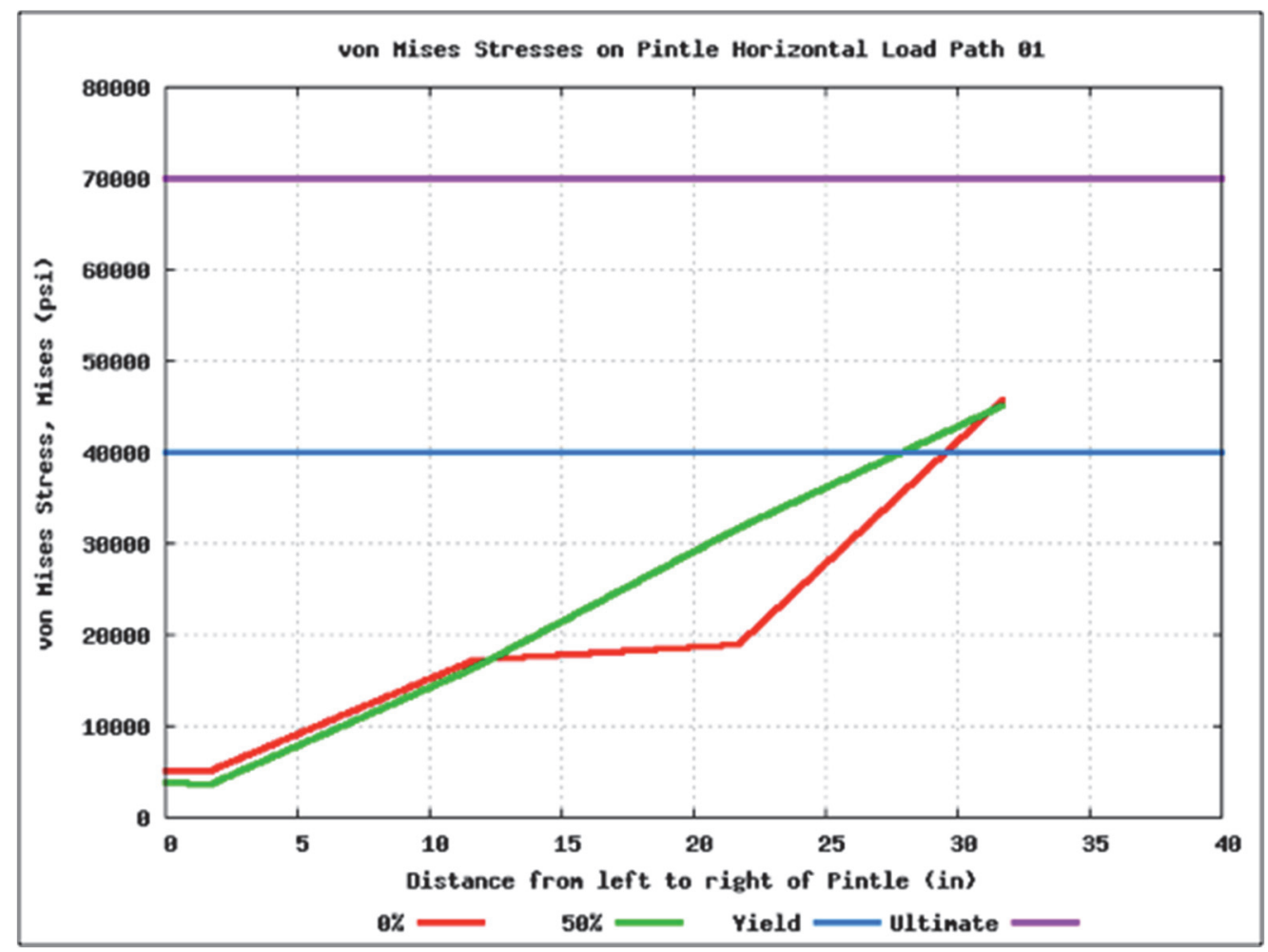

The stress path plotted in Figure 4-23 shows the von Mises stresses along the "Horizontal-Load Path 2" when comparing 0\% and 50\% deterioration levels. The observed increase seems to be occurring from left to right. The stress increase is likely due to the path taken along the bolt-hole region. There is a bolt-hole near the stress path at 37 in. The predicted von Mises stresses show from left to right [0-36) in. that yielding does not occur. However, from distances [36-38) in., yielding occurs. The maximum von Mises stress for 50\% deterioration exceed yield by $24 \%$ at 38 in. for the stress path. 
Figure 4-23. Stress plot showing von Mises stress along "Horizontal- Load Path 2" at $0 \%$ and $50 \%$ deterioration levels.

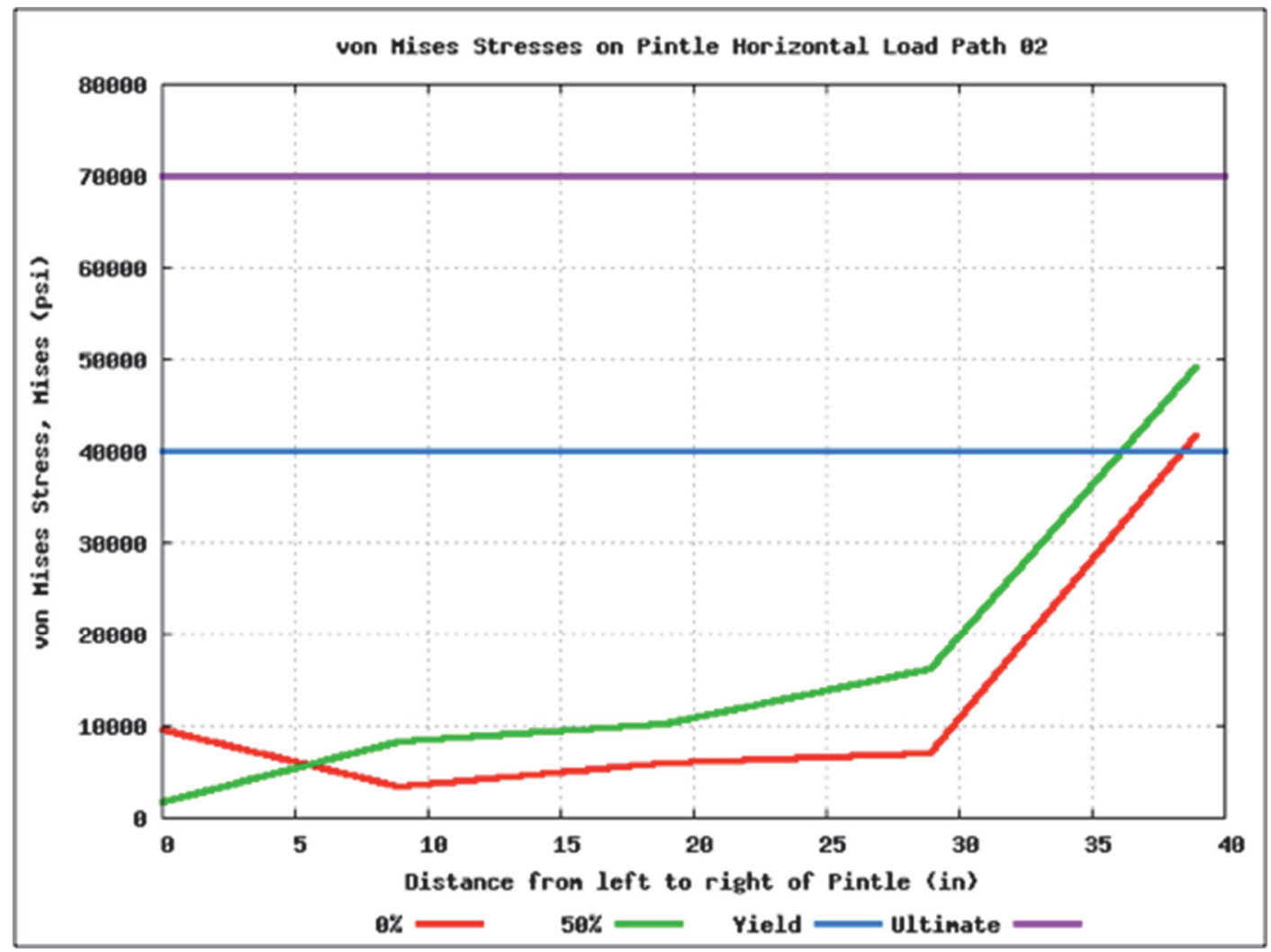

The stress path plotted in Figure 4-24 shows the von Mises stresses along the "Horizontal-Load Path 3" when comparing $0 \%$ and 50\% deterioration levels. The observed increase seems to be occurring from left to right. It is very likely the stress increase is due to the path taken along the bolt-hole region. There is a bolt-hole near the stress path at $37 \mathrm{in}$. The predicted von Mises stresses show from left to right [0-36) in. that yielding does not occur. However, from distances [36-38) in., yielding occurs. The maximum von Mises stress for $50 \%$ deterioration exceed yield by $20 \%$ at 38 in. for the stress path.

The stress path plotted in Figure 4-25 shows the von Mises stresses along the "Horizontal-Load Path 4" when comparing $0 \%$ and 50\% deterioration levels. The observed increase seems to be occurring from left to right. It is very likely the stress increase is due to the path taken along the bolt-hole region. A bolthole passes through the stress path at 25 in. The predicted von Mises stresses show from left to right that yielding does not occur. 
Figure 4-24. Stress plot showing von Mises stress along "Horizontal- Load Path 3" at 0\% and $50 \%$ deterioration levels.

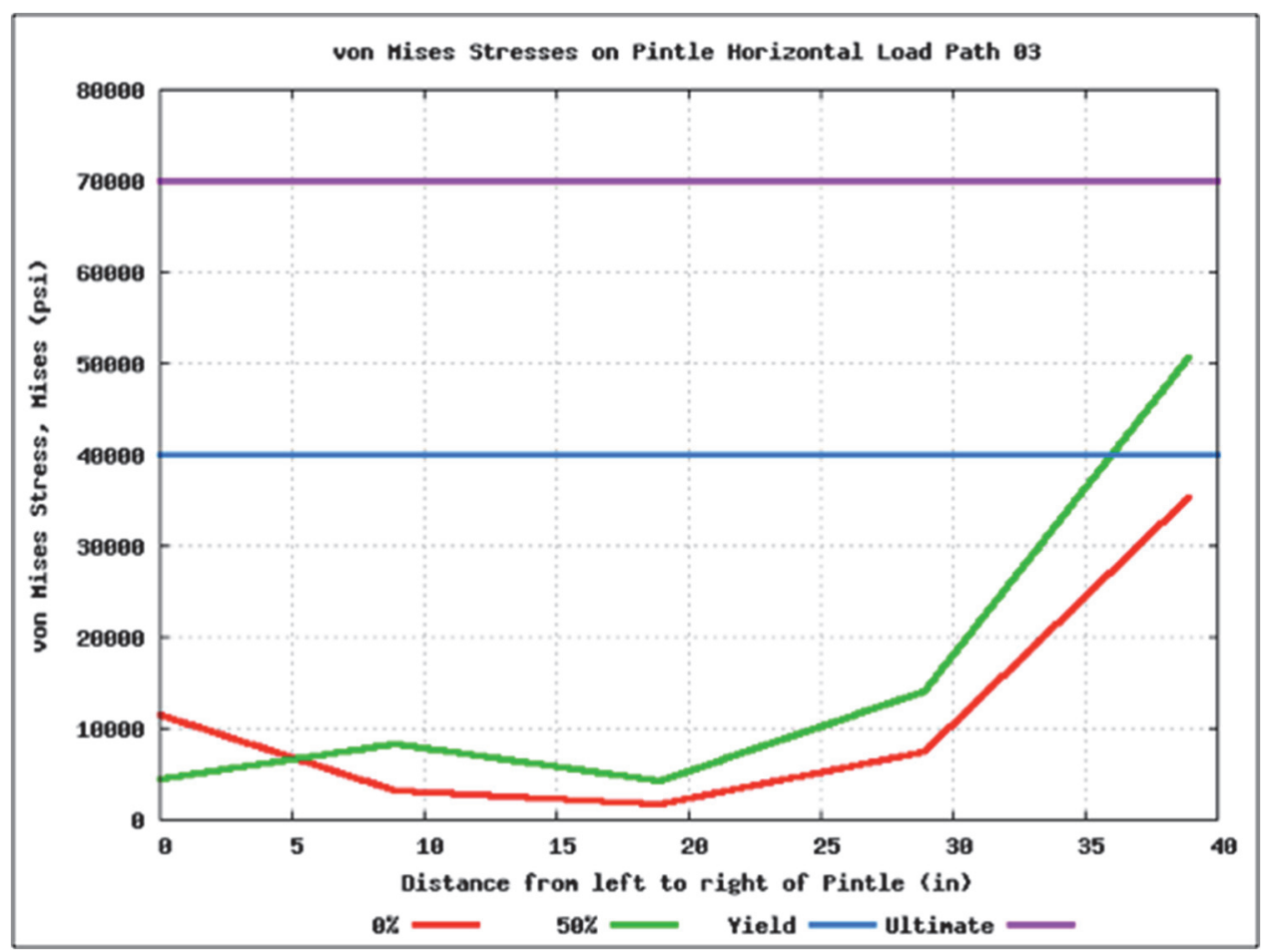

Figure 4-25. Stress plot showing von Mises stress along "Horizontal- Load Path 4" at 0\% and $50 \%$ deterioration levels.

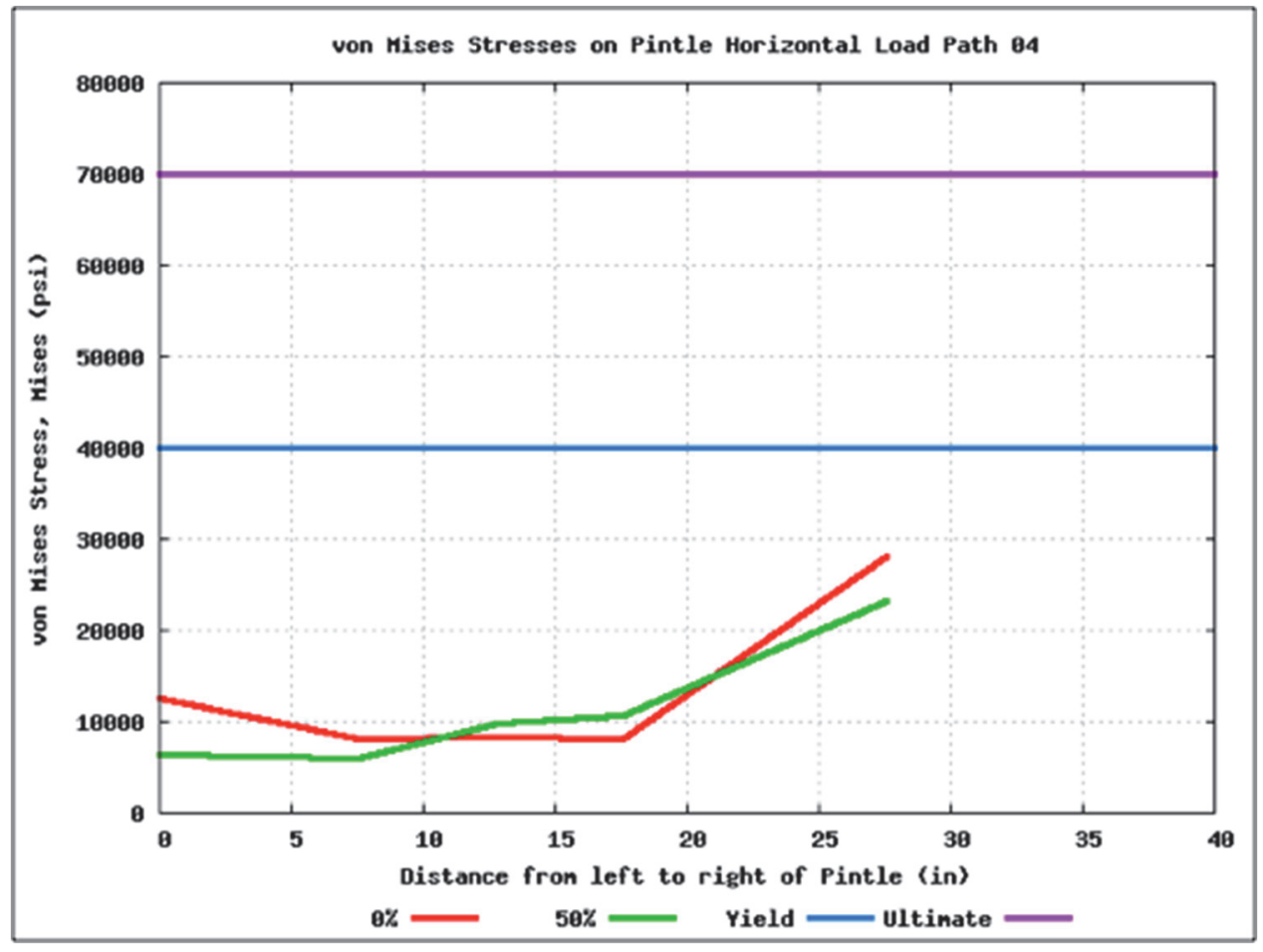


The stress path plotted in Figure 4-26 shows the von Mises stresses along the "Vertical Load Path 1" when comparing $0 \%$ and 50\% deterioration levels. The predicted von Mises stresses show from bottom to top [0-24) in. that yielding occurs. However, from distances [24-36) in., yielding does not occur. More than likely, the initial yielding at the location is due to the path taken along the bolt-hole region. The bolt-holes are near the entire length of the stress path. The maximum von Mises stress for $50 \%$ deterioration exceeds yield by $28 \%$ at 20 in. for the stress path.

The stress path plotted in Figure 4-27 shows the von Mises stresses along the "Vertical Load Path 2" when comparing o\% and 50\% deterioration levels. Initially, the stresses start off high and decrease with consistency until $30 \mathrm{in}$. along the path. Then, there is a slight increase. It is very likely the stress increase at the location is due to the path taken along the bolt-hole region at $\mathrm{o}$ and $30 \mathrm{in}$. The predicted von Mises stresses show yielding does not occur for the stress path.

The stress path plotted in Figure 4-28 shows the von Mises stresses along the "Vertical Load Path 3" when comparing 0 and 50 deterioration levels. Initially, the stresses start off high and decrease. The stresses remain consistent until $30 \mathrm{in}$. along the path; then, there is a slight increase. It is very likely the stress increase is due to the path taken along the bolt-hole region at $\mathrm{o}$ and $30 \mathrm{in}$. The predicted von Mises stresses show from bottom to top [o-32) in. that yielding does not occur; however, at 32 in., yielding does occur. The maximum von Mises stress for $50 \%$ deterioration exceed yield by $2.5 \%$ at 32 in. for the stress path.

The stress path plotted in Figure 4-29 shows the von Mises stresses along the "Vertical Load Path 4" when comparing o and 50\% deterioration levels. The stresses are consistent until 22 in.; then, there is a slight increase. It is very likely the stress increase is due to the path taken near the bolthole region at $22 \mathrm{in}$. The predicted von Mises stresses show that yielding does not occur for the stress path. 
Figure 4-26. Stress plot showing von Mises stress along "Vertical- Load Path 1" at 0\% and $50 \%$ deterioration levels.

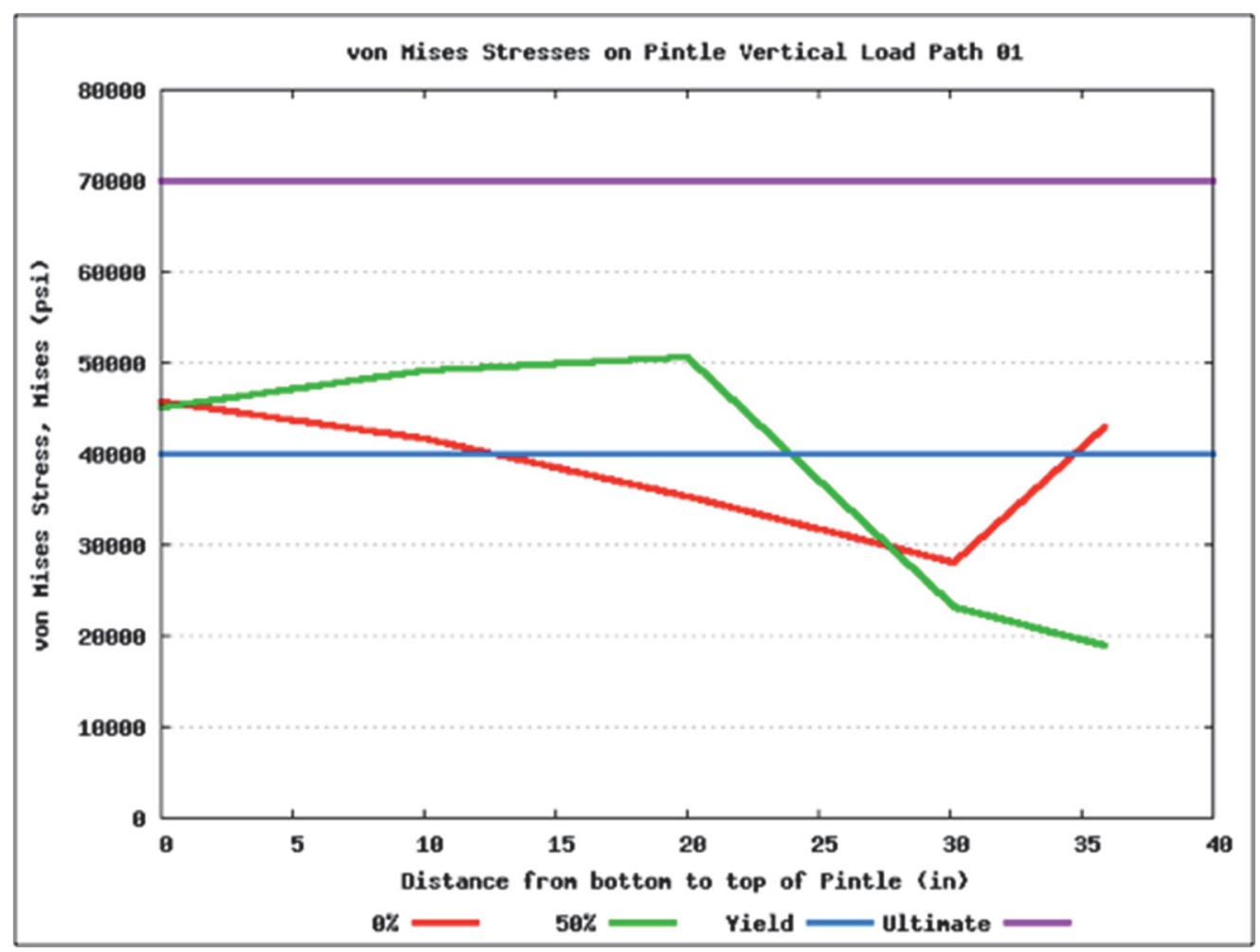

Figure 4-27. Stress plot showing von Mises stress along "Vertical- Load Path 2" at $0 \%$ and $50 \%$ deterioration levels.

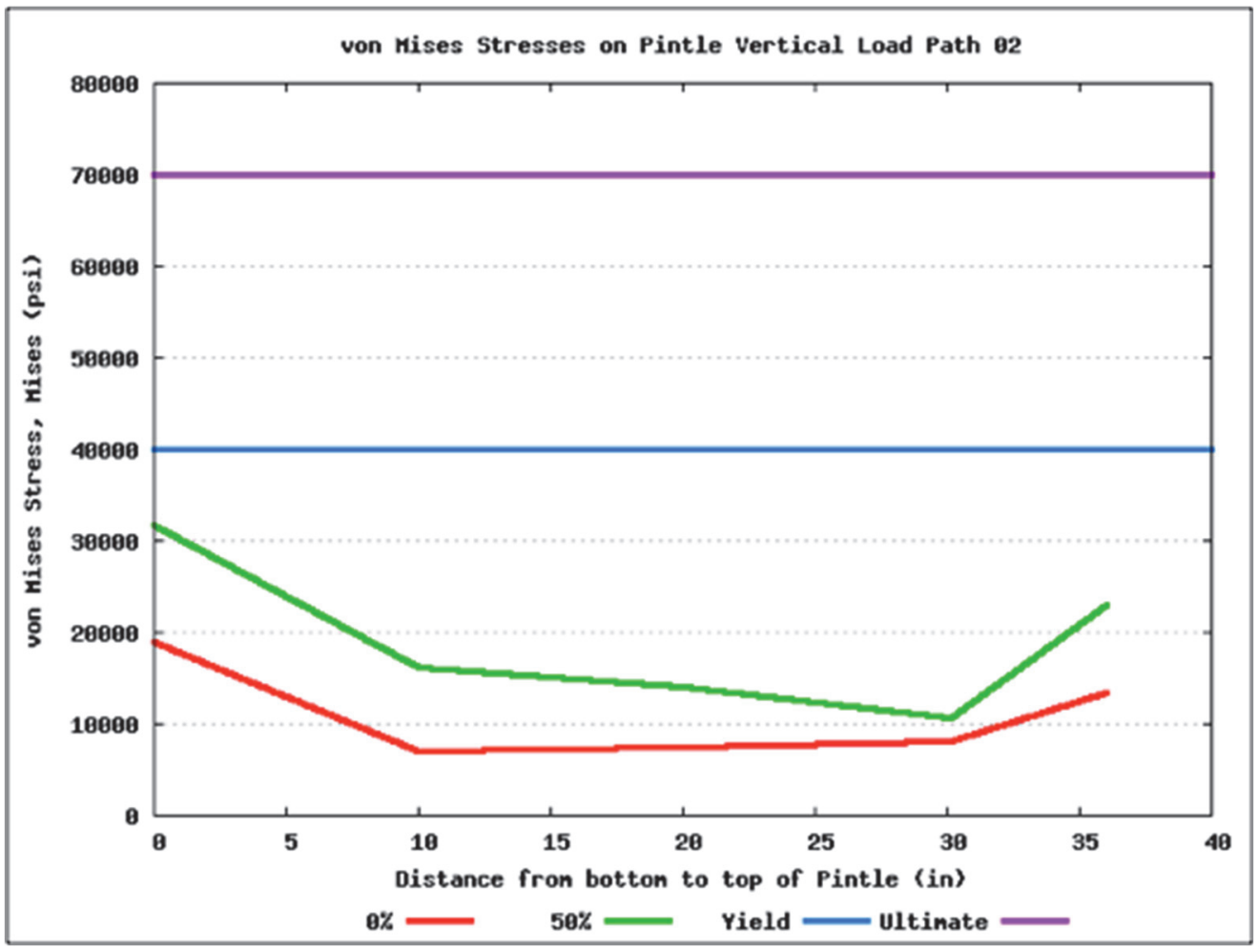


Figure 4-28. Stress plot showing von Mises stress along "Vertical- Load Path 3" at 0\% and $50 \%$ deterioration levels.

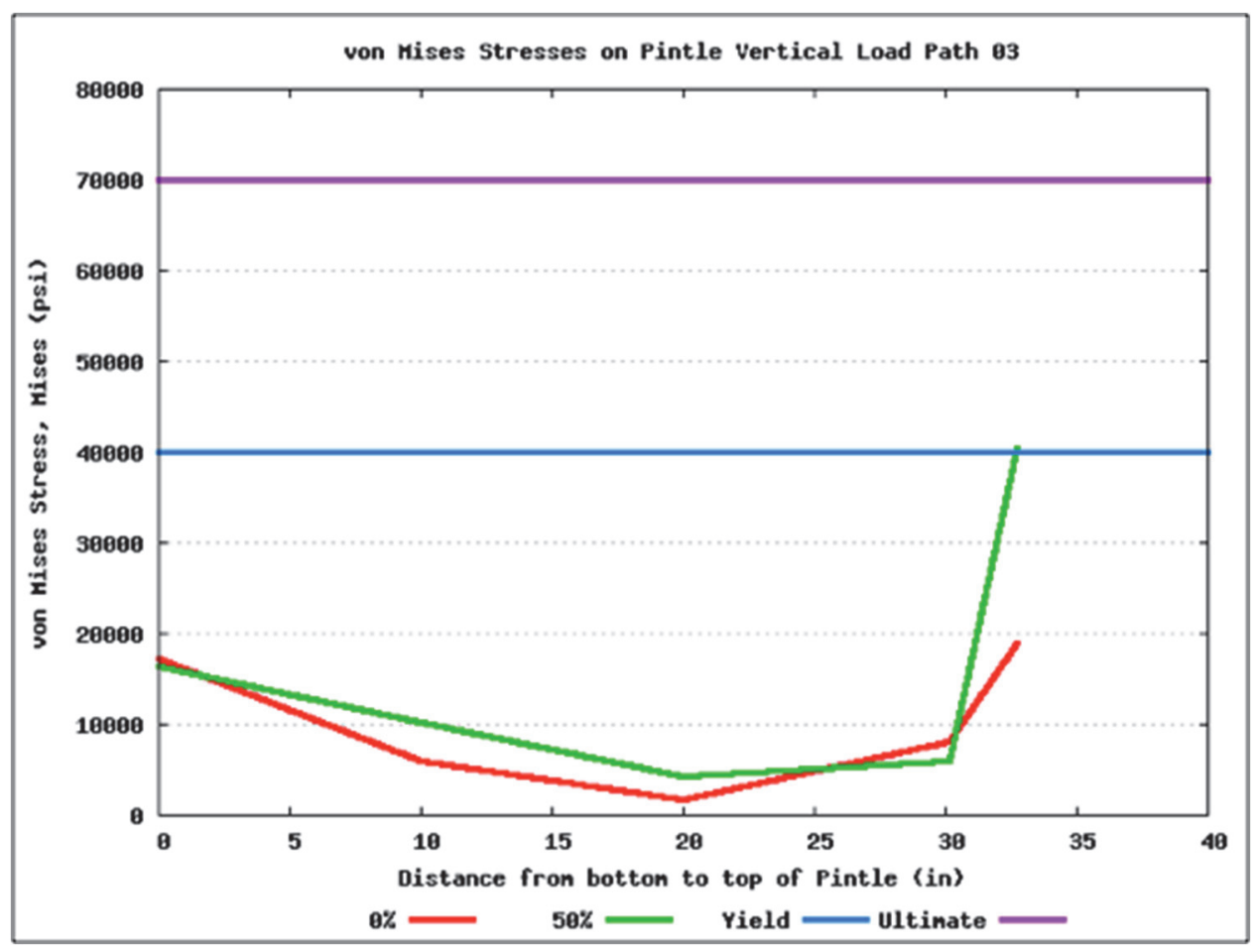

Figure 4-29. Stress plot showing von Mises stress along "Vertical- Load Path 4" at $0 \%$ and $50 \%$ deterioration levels.

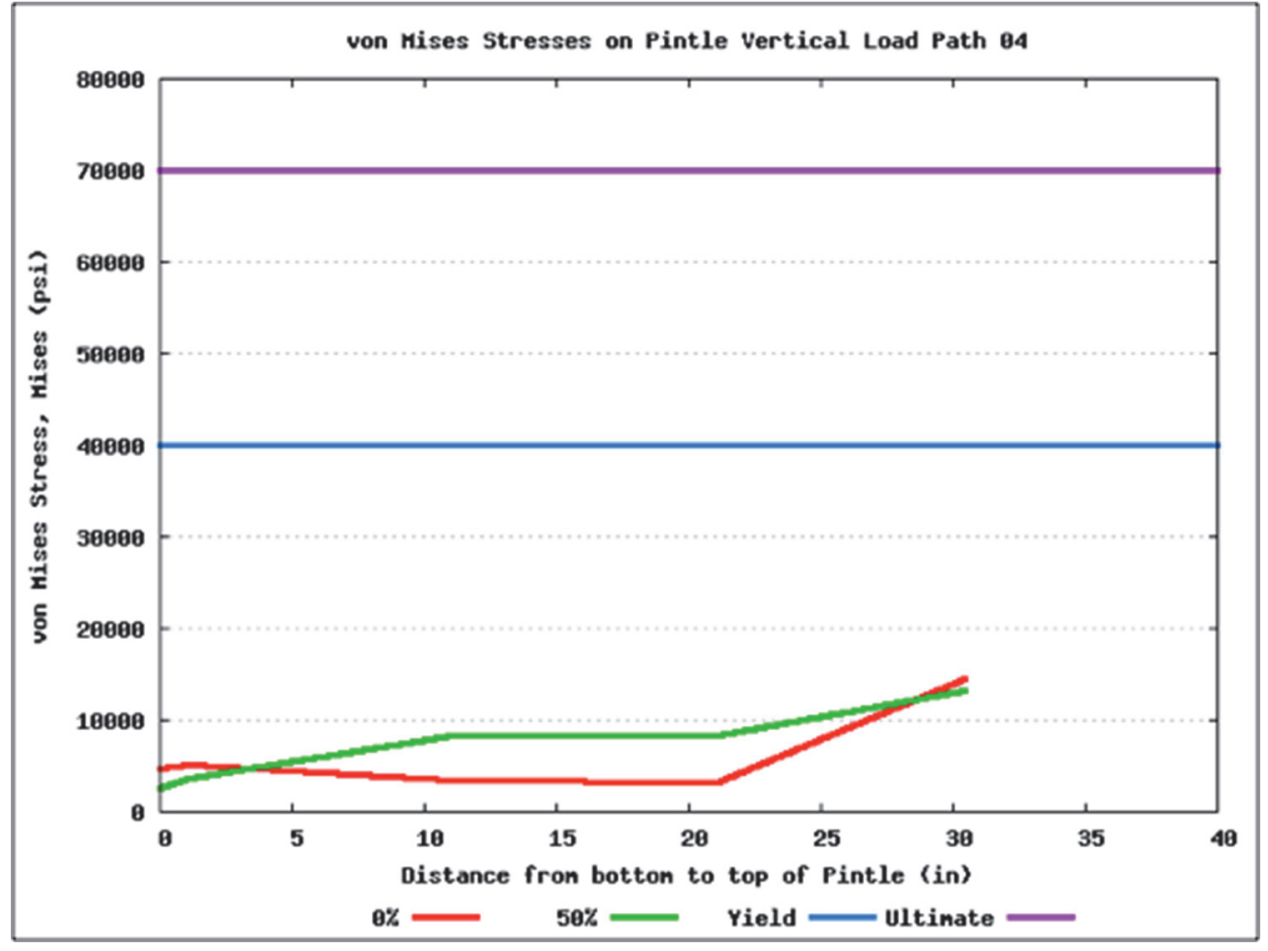




\subsection{5 $75 \%$ deterioration}

The contour and stress plotted in Figures 4-30 and 4-31, respectively, show the von Mises stresses along the "Horizontal-Load Path 1" when comparing $\mathrm{o}$ and $75 \%$ deterioration levels. The observed increase seems to be occurring from left to right. It is very likely the stress increase at the location is due to the path taken along the bolt-hole region. A bolt-hole passes through the stress path at $10 \mathrm{in}$. and 30 in. The predicted von Mises stresses show from left to right [0-22) in. that yielding does not occur. However, from distances [22-32) in., yielding occurs. The maximum von Mises stress for $75 \%$ deterioration exceed yield by $20 \%$ at 32 in. for the stress path.

Figure 4-30. Contour plot showing von Mises stress and critical stress region at (a) $0 \%$ and (b) 75 deterioration levels (plane view).

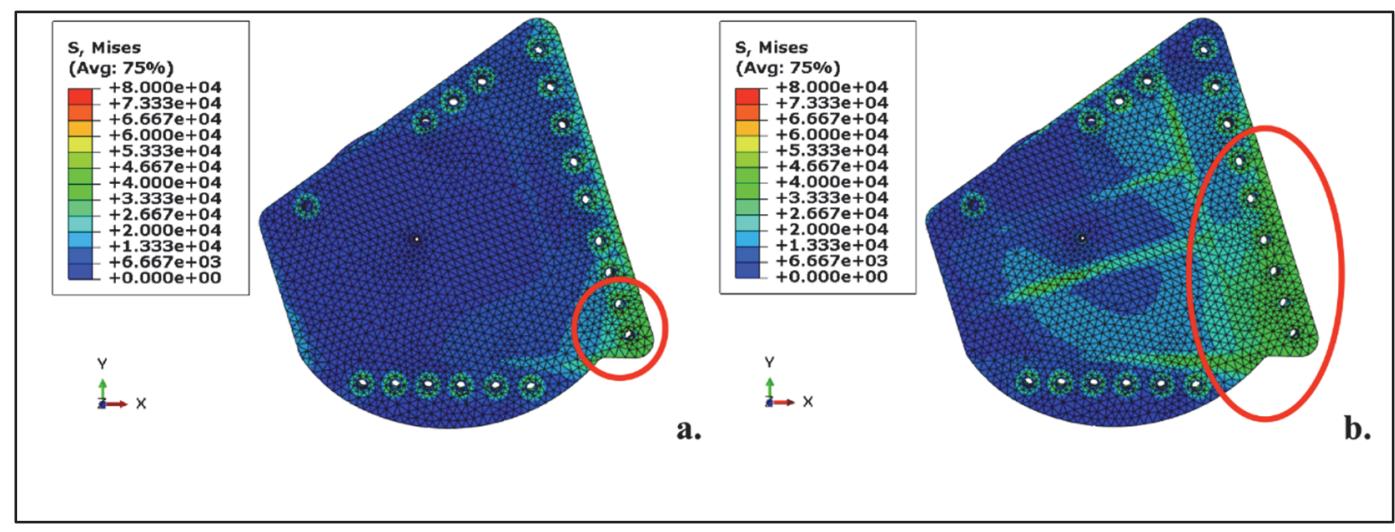

Figure 4-31. Stress plot showing von Mises stress along "Horizontal- Load Path 1" at $0 \%$ and $75 \%$ deterioration levels.

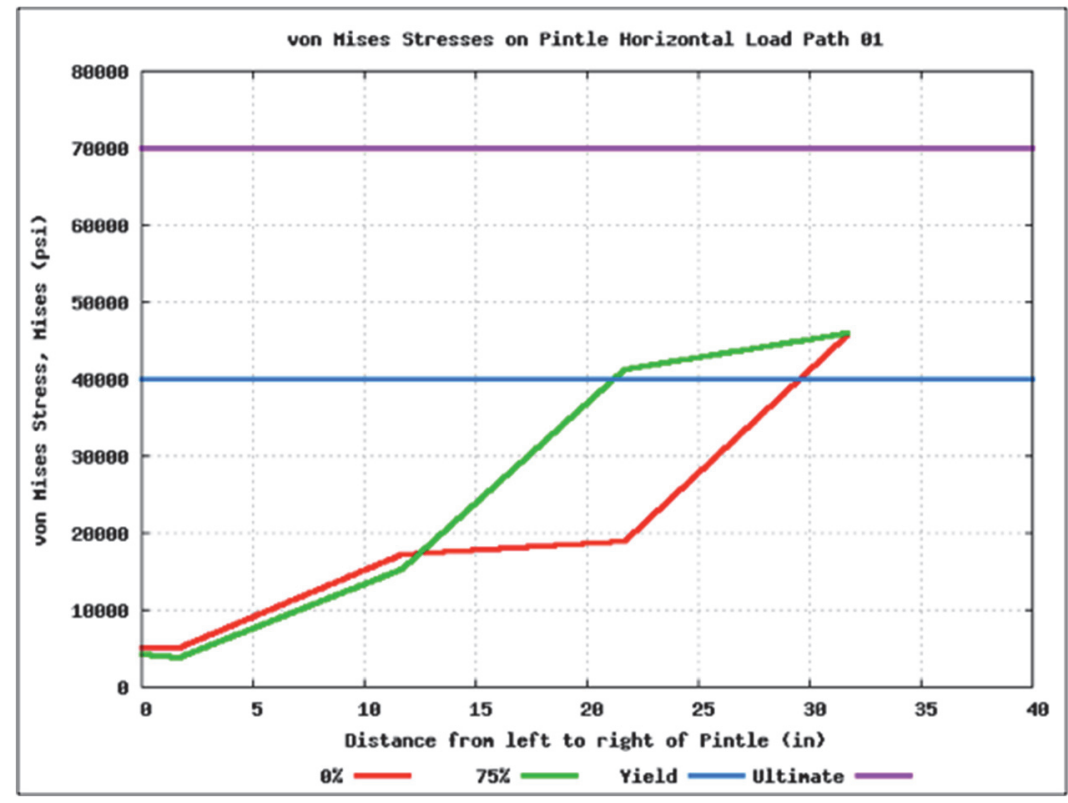


The stress path plotted in Figure 4-32 shows the von Mises stresses along the "Horizontal-Load Path 2" when comparing $0 \%$ and $75 \%$ deterioration levels. The observed increase seems to be occurring from left to right. It is very likely the stress increase at the location is due to the path taken along the bolt-hole region. A bolt-hole is near the stress path at $37 \mathrm{in}$. The predicted von Mises stresses show from left to right [0-36) in. that yielding does not occur. However, from distances [36-38) in., yielding occurs. The maximum von Mises stress for $75 \%$ deterioration exceed yield by $21 \%$ at 38 in. for the stress path.

The stress path plotted in Figure 4-33 shows the von Mises stresses along the "Horizontal-Load Path 3" when comparing $0 \%$ and $75 \%$ deterioration levels. The observed increase seems to be occurring from left to right. It is very likely the stress increase is due to the path taken along the bolt-hole region. A bolt-hole is near the stress path at 37 in. The predicted von Mises stresses show from left to right [0-35] in., that yielding does not occur. However, from distances [35-38) in., yielding occurs. The maximum von Mises stress for $75 \%$ deterioration exceeds yield by $29 \%$ at 38 in. for the stress path.

The stress path plotted in Figure 4-34 shows the von Mises stresses along the "Horizontal-Load Path 4" when comparing $0 \%$ and $75 \%$ deterioration levels. The observed increase seems to be occurring from left to right. It is very likely the stress increase is due to the path taken along the bolt-hole region. A bolthole passes through the stress path at $25 \mathrm{in}$. The predicted von Mises stresses show from left to right that yielding does not occur.

The stress path plotted in Figure 4-35 shows the von Mises stresses along the "Vertical Load Path 1" when comparing o\% and 75\% deterioration levels. The predicted von Mises stresses show from bottom to top [0-24) in. that yielding occurs. However, from distances [24-36) in., yielding does not occur. It is very likely the initial yielding at the location is due to the path taken along the bolt-hole region. The bolt-holes are near the entire length of the stress path. The maximum von Mises stress for $75 \%$ deterioration exceed yield by $29 \%$ at 20 in. for the stress path. 
Figure 4-32. Stress plot showing von Mises stress along "Horizontal- Load Path 2" at $0 \%$ and $75 \%$ deterioration levels.

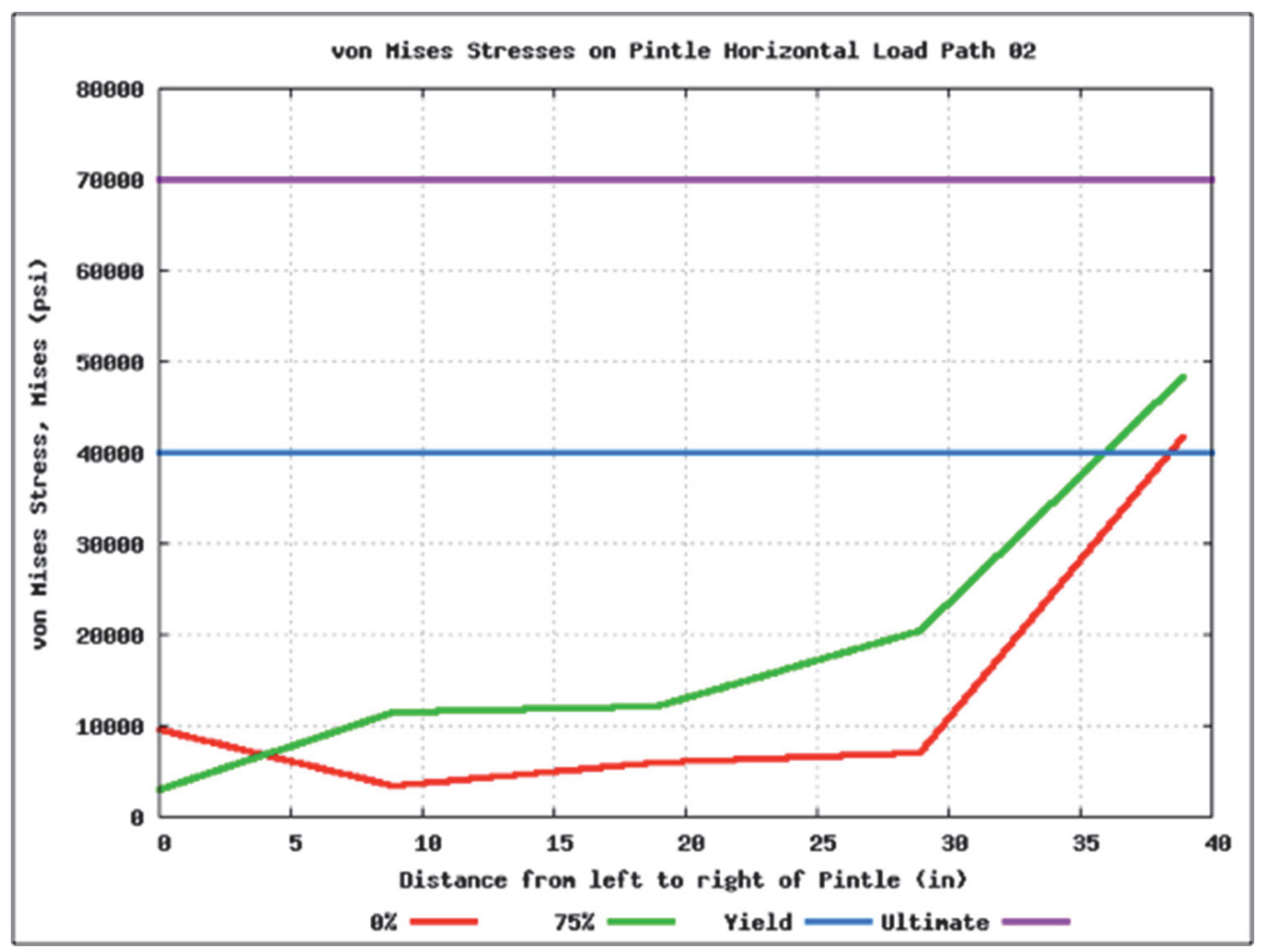

Figure 4-33. Stress plot showing von Mises stress along "Horizontal- Load Path 3" at $0 \%$ and $75 \%$ deterioration levels.

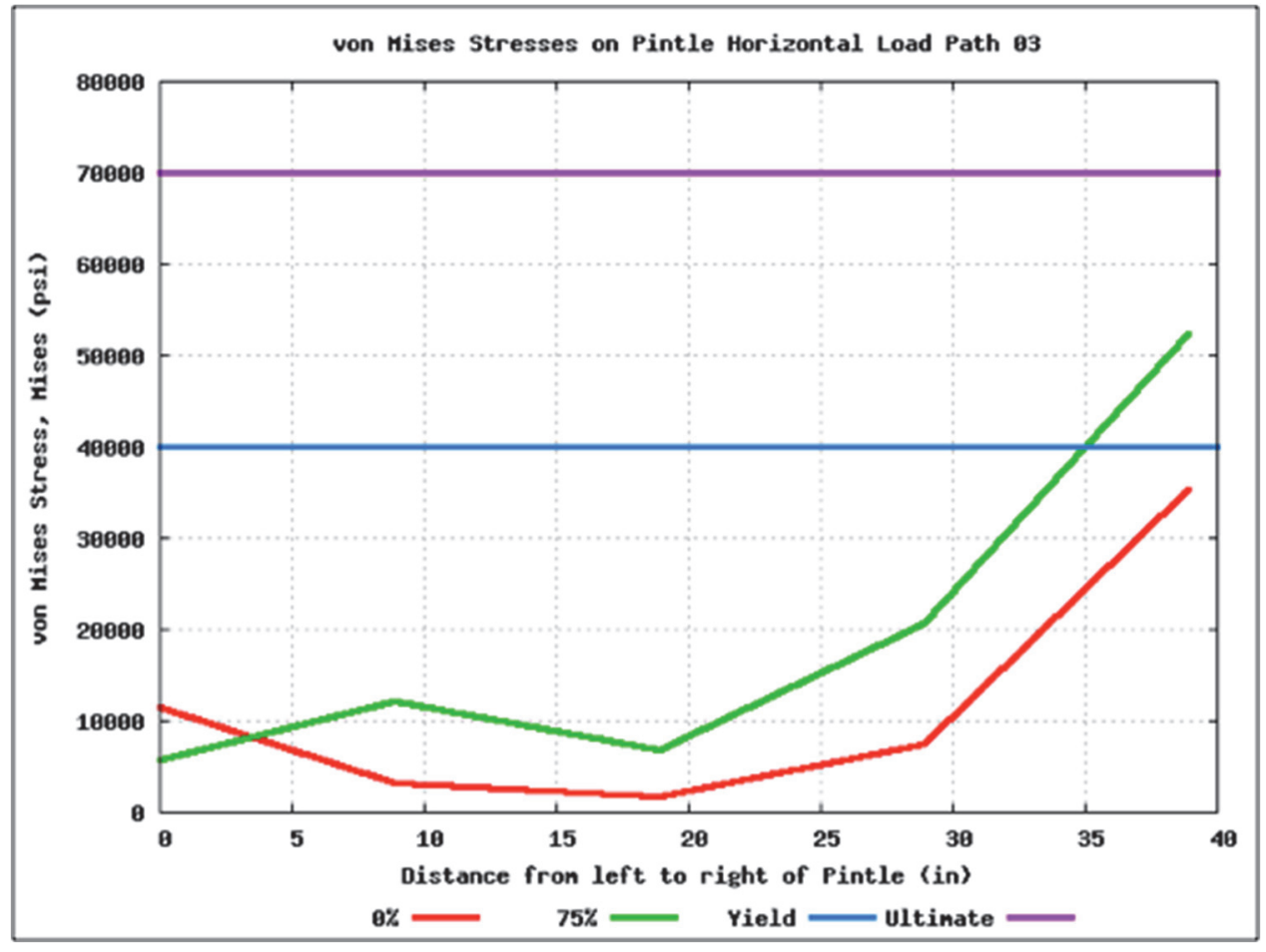


Figure 4-34. Stress plot showing von Mises stress along "Horizontal- Load Path 4" at $0 \%$ and $75 \%$ deterioration levels.

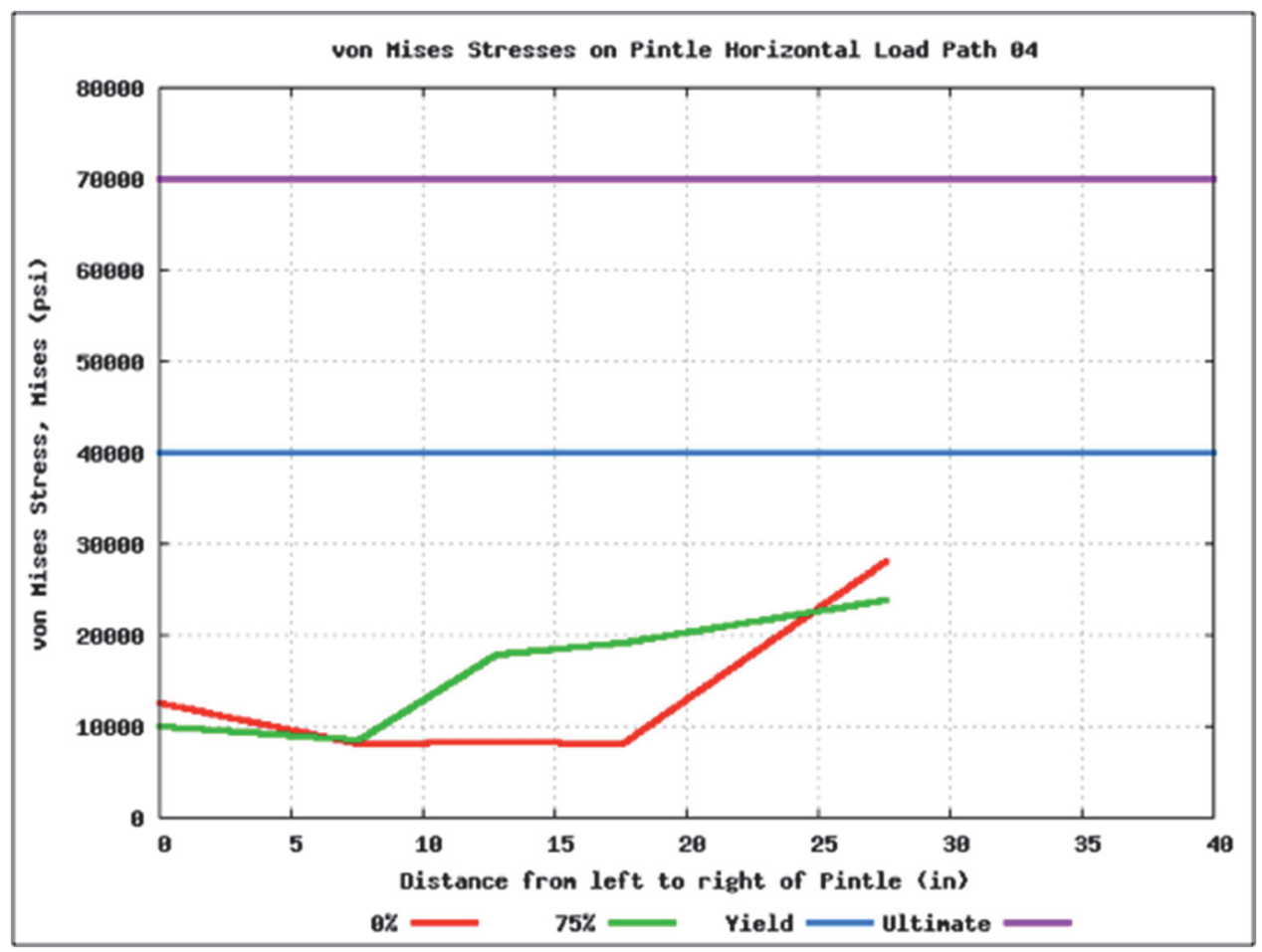

Figure 4-35. Stress plot showing von Mises stress along "Vertical- Load Path 1" at $0 \%$ and $75 \%$ deterioration levels.

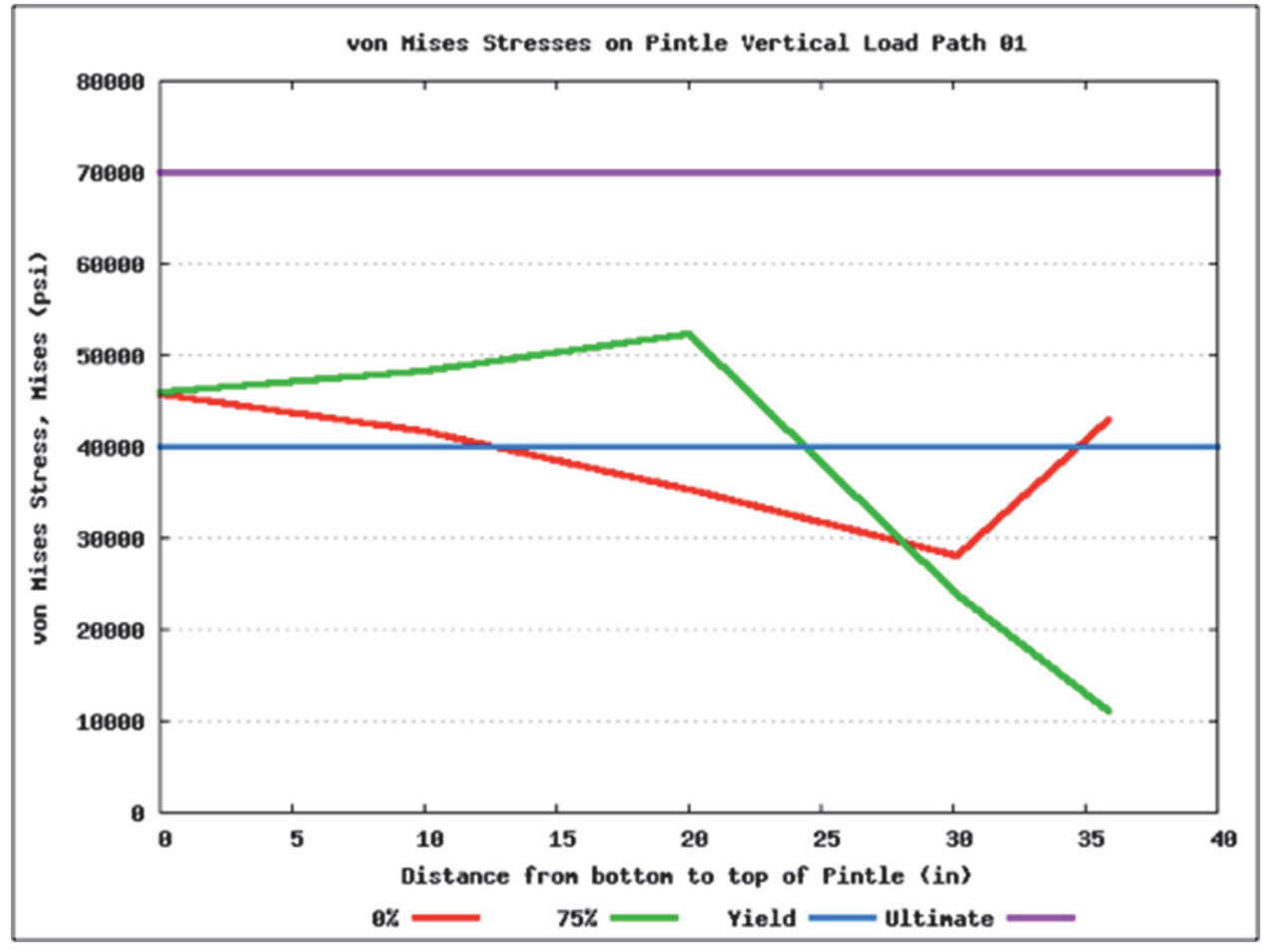


The stress path plotted in Figure 4-36 shows the von Mises stresses along the "Vertical Load Path 2" when comparing $0 \%$ and $75 \%$ deterioration levels. Initially, the stresses start off high and decrease with consistency until $30 \mathrm{in}$. along the path; then, there is a slight increase. It is very likely the stress increase at the location is due to the path taken along the bolt-hole region at $\mathrm{o}$ and $30 \mathrm{in}$. The predicted von Mises stresses show from bottom to top o in. that yielding occurs. However, from distances [1-36) in., yielding does not occur. The maximum von Mises stress for $75 \%$ deterioration exceed yields by $5 \%$ at $20 \mathrm{in}$. for the stress path.

The stress path plotted in Figure 4-37 shows the von Mises stresses along the "Vertical Load Path 3" when comparing $0 \%$ and $75 \%$ deterioration levels. Initially, the stresses start off high and decrease. The stresses remain consistent until $30 \mathrm{in}$. along the path; then, there is a slight increase. It is very likely the stress increase is due to the path taken along the bolt-hole region at $\mathrm{o}$ and $30 \mathrm{in}$. The predicted von Mises stresses show from bottom to top [0-30) in. that yielding does not occur. However, at 32 in., the ultimate strength has been reached. The maximum von Mises stress for $75 \%$ deterioration exceeds yield by $75 \%$ at 32 in. for the stress path.

The stress path plotted in Figure 4-38 shows the von Mises stresses along the "Vertical Load Path 4" when comparing $0 \%$ and $75 \%$ deterioration levels. The stresses are consistent until 22 in.; then, there is a slight increase. It is very likely the stress increase is due to the path taken near the bolthole region at $22 \mathrm{in}$. The predicted von Mises stresses show from bottom to top [0-32) in. that yielding does not occur. 
Figure 4-36. Stress plot showing von Mises stress along "Vertical- Load Path 2" at 0\% and $75 \%$ deterioration levels.

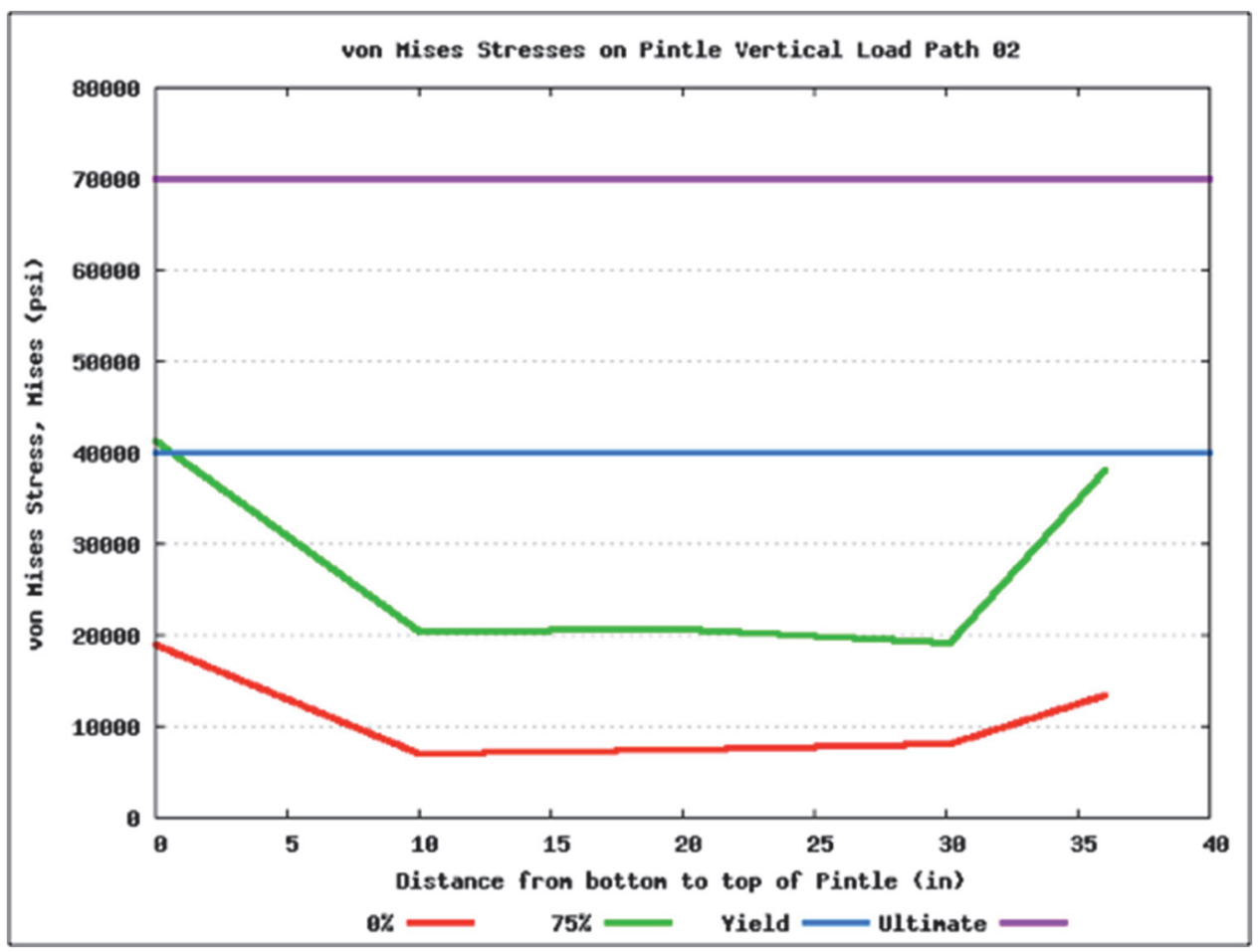

Figure 4-37. Stress plot showing von Mises stress along "Vertical- Load Path 3" at $0 \%$ and $75 \%$ deterioration levels.

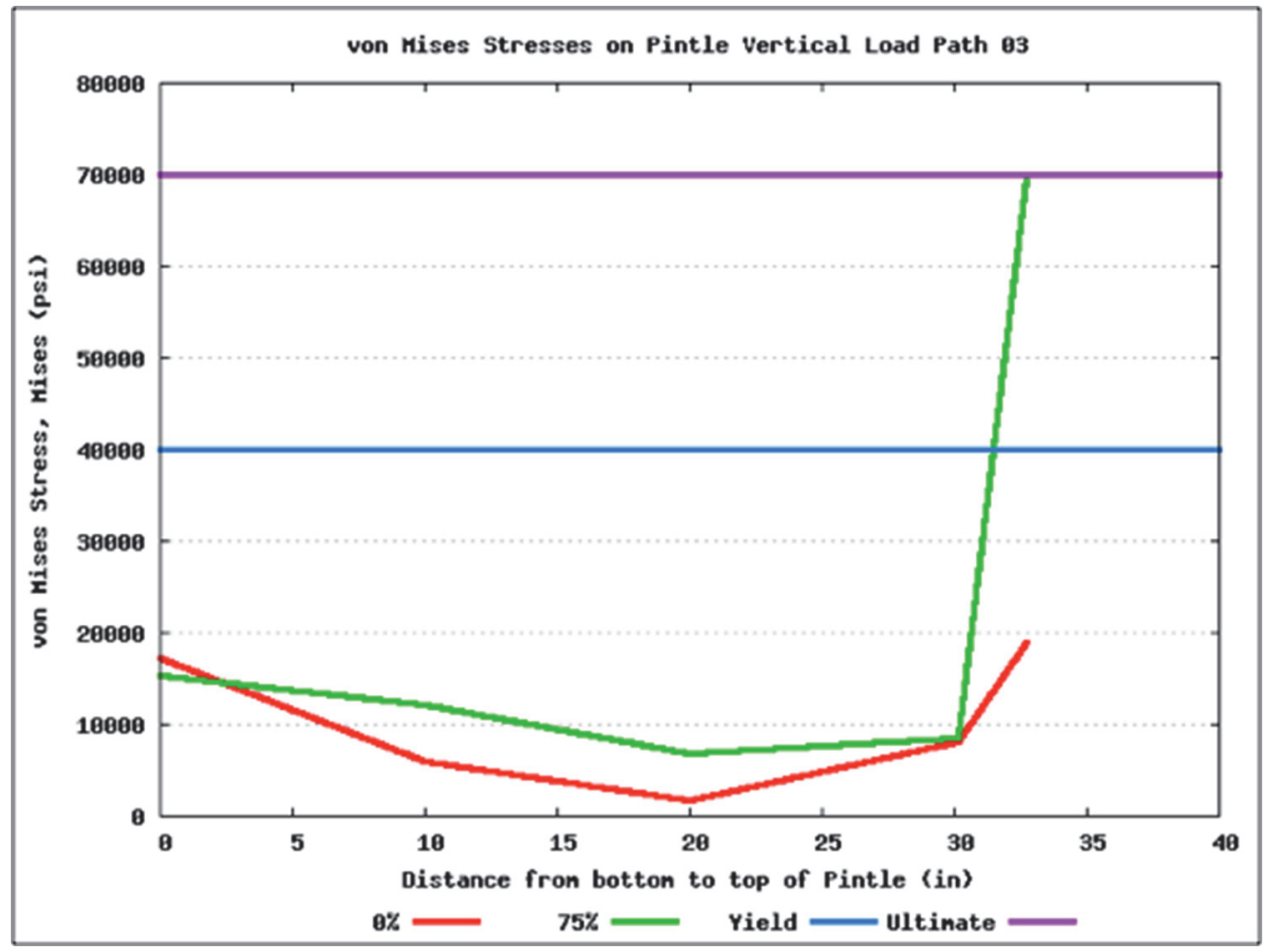


Figure 4-38. Stress plot showing von Mises stress along "Vertical- Load Path 4" at $0 \%$ and $75 \%$ deterioration levels.

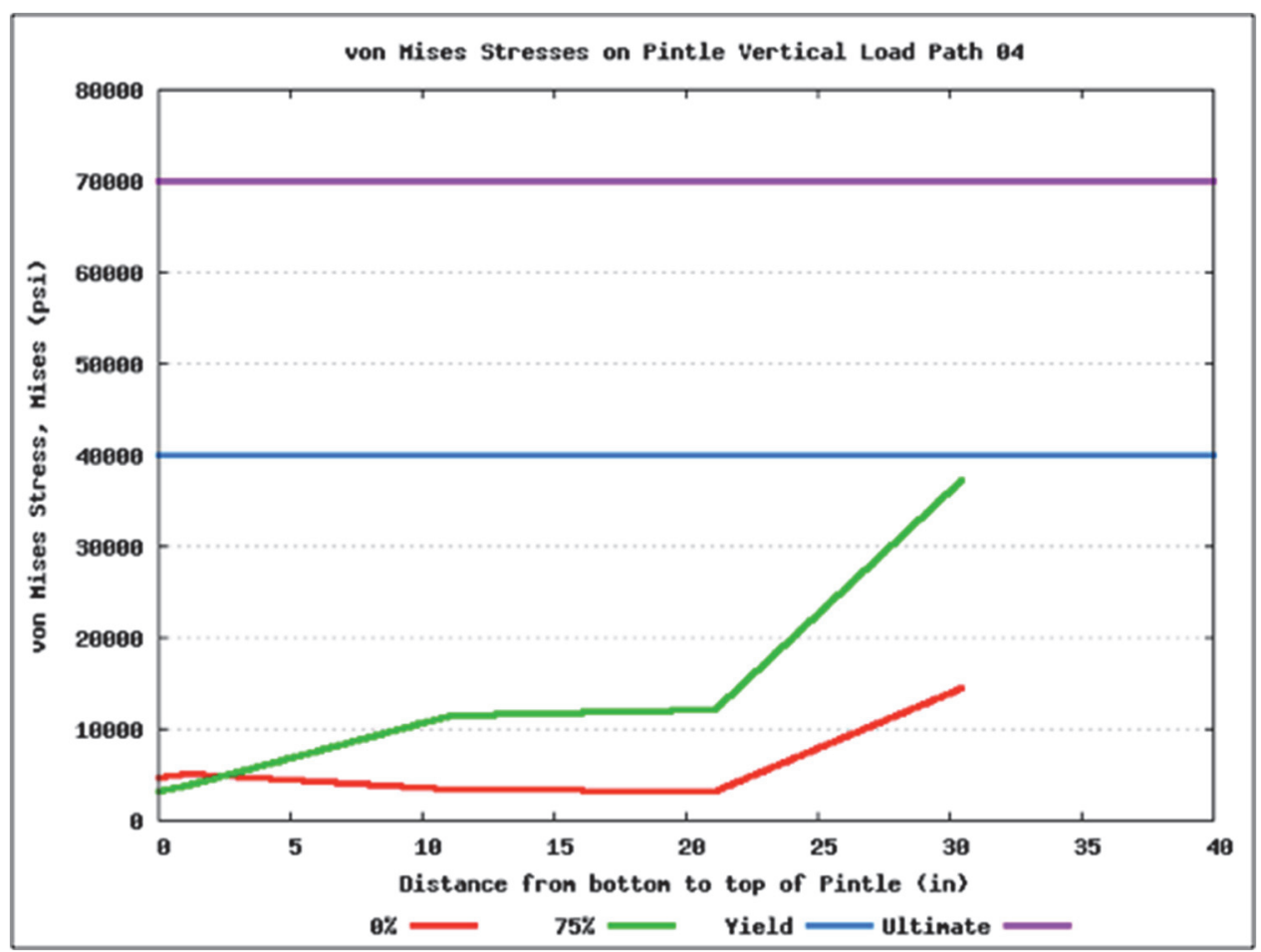

\subsection{Side view results of quoin block deterioration states}

Figure 4-39 (a-d) show "X-Z"-direction, side view contour plots for the pintle's von Mises stresses at o\%, 25\%, 50\%, and 75\% deterioration levels. At $0 \%$ deterioration the von Mises stresses are below the design yield stress limit. For 25\% deterioration, the von Mises stresses are increasing around the neck of the pintle; however, yielding is not observed. At 50\% deterioration, the contour plot shows a redistribution of stresses around the neck area. The von Mises stress reaches the materials yield stress limit around the pintle's neck for 50\% deterioration. Similarly, at 75\% deterioration, the contour plot shows a redistribution of stresses around the neck area. The von Mises stress reaches the materials yield stress limit but does not exceed the yield limit around the neck for $75 \%$ deterioration. 
Figure 4-39. Contour plot showing von Mises stress and stress distribution along the pintle's "X-Z" -direction at: (a) $0 \%$, (b) $25 \%$, (c) $50 \%$, and (d) $75 \%$ deterioration levels (side views).

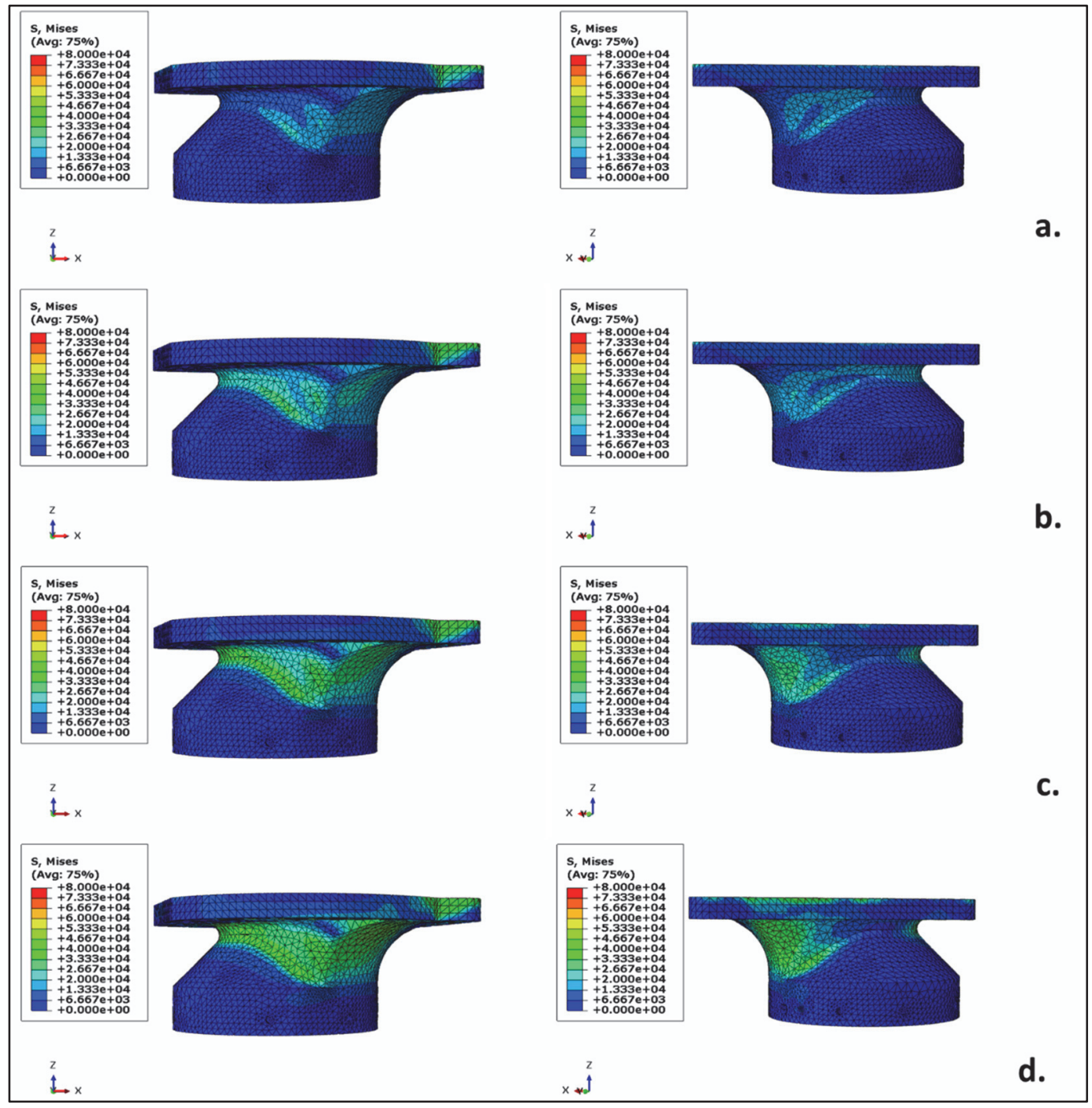

\subsection{Cut view results of quoin block deterioration states}

Figure 4-40 (a-d) show "Y-Z"-direction, cut view contour plots for the pintle's internal von Mises stress state at $0 \%, 25 \%, 50 \%$, and $75 \%$ deterioration levels. At $0 \%$ deterioration, the von Mises stresses are well below the yield stress limit. The von Mises stresses increase at 25\% deterioration, but deterioration has little effect on the pintle internally. At 50\% deterioration, the von Mises stresses increase even higher but are maintained below the design limit. Similarly, at $75 \%$ deterioration, the von Mises stresses have increased but have not exceeded the design limit. After observing the cut view, deterioration does not exceed the design limit at any of the deterioration states. 
Figure 4-40. Contour plot showing von Mises internal stress and stress distribution through the pintle's "Y-Z" -direction at: (a) 0\%, (b) 25\%, (c) 50\%, and (d) $75 \%$ deterioration levels (cut views).

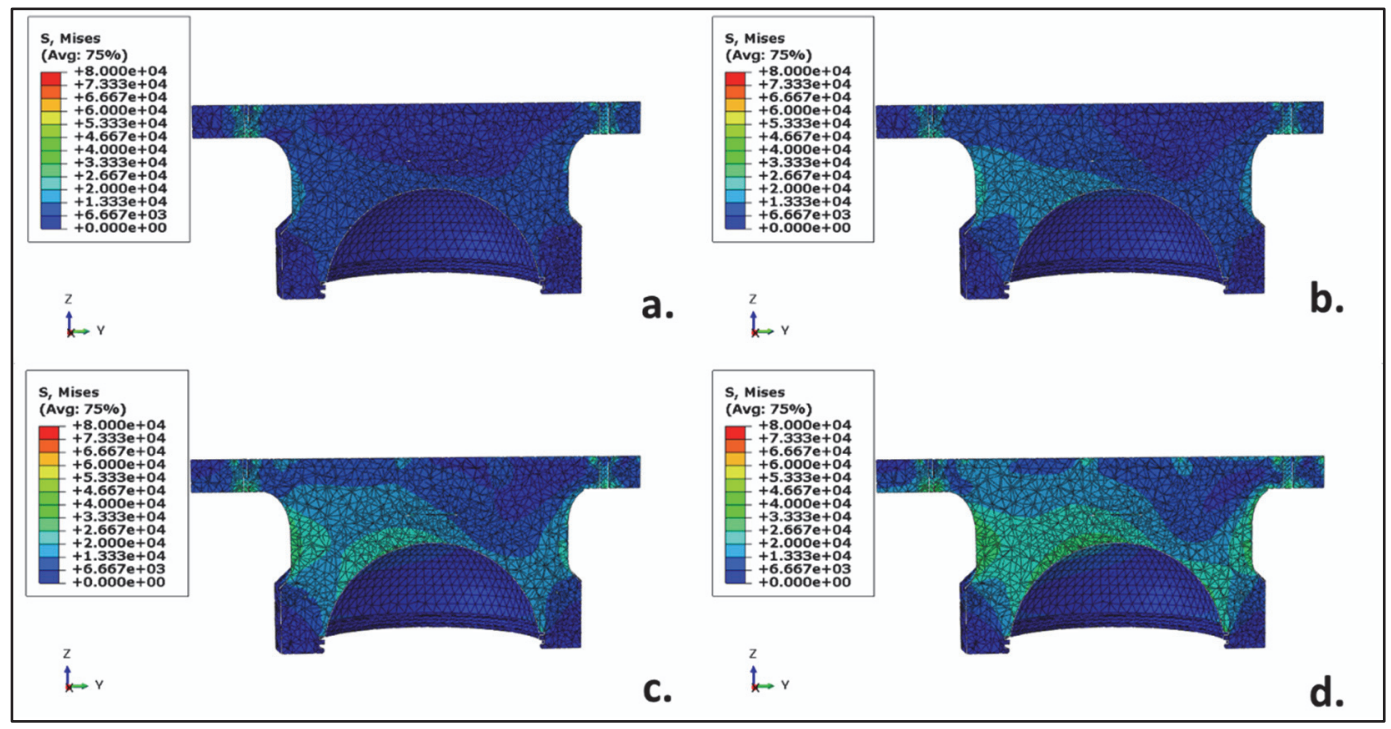

\subsection{Summary of findings}

A systematic detailed approach was used to determine the influence quoin block deterioration and loss of lock wall contact have on load transfer to the pintle and pintle connections. The simulations indicate the pintle is sufficiently designed at zero-percent deterioration. However, at the pintle connection locations, the stress levels are near or at the yield stress limit.

Additionally, when the quoin block is deteriorated and loses lock wall contact, the stress path and contour plot analysis show the loading is increasing in the pintle and pintle connections. Specifically, the analysis shows the exact locations where stresses are occurring, namely the pintle's surface, bolt-hole region and around the neck. In some instances, the yield stress limit has been exceeded on the surface and in the bolt-hole connection sites.

Although the results indicate the stress is increasing in the pintle structural member and its connection points, the yield states presented in this report are estimates only. As previously discussed in section 3.2.3 "Material properties" in Chapter 3, a bilinear elastic-plastic material (idealized) model was assigned to the pintle. As a result, the true stress-strain response predicted by the model will tend to be an underestimated material strength in the initial post-yield behavior for the pintle. Therefore, the findings of this report should be used to identify where stress concentrations and failure are likely to occur in the structural member. 
For clarity and conciseness, the results presented in Chapter 4 will be discussed in greater detail in Chapter 5 . Also addressed in Chapter 5 are discussions of how the predicted results compare to previous observations made during previous field inspections of miter gates located in the USACE Mobile District. Additionally, recommendations are provided for the pintle and pintle connection design modifications. 


\section{Discussion}

The results discussed in Chapter 4 provided sufficient evidence to test the hypothesis $(H)$. The hypothesis $(H)$ stated was the quoin block deteriorates and loses contact with the lock wall, and then the miter gate adds excessive loads to the pintle region, leading to accelerated cracking and failure of its components. The hypothesis is found to be consistent with the data, and results of the comprehensive parametric analysis verified that:

1. As the quoin block deteriorates and loses contact with the lock wall, the miter gate adds excessive loads to the pintle region

2. When the excessive loads are applied to the pintle region, the stresses in the structural component seem to exceed the design yield limit, leading to accelerated failure of the component in the connection points and neck region.

To further expand on how the results were used to test and prove the hypothesis to be true, the remainder of this chapter discusses how this work addressed the overall research objective, which used 3D-FEA to quantify the effects of quoin block deterioration between the lock wall and miter gate as a function of stress level changes occurring in the pintle region. Additionally, the results were used to determine the overstressed (a) areas in the pintle globally and (b) local critical regions and pintle connection points. The pertinent information gathered helped provide recommendations for the pintle and pintle connection design modifications.

\subsection{Discussion}

\subsubsection{Deterioration level}

The FEA simulated quoin block degradation by removing $0 \%, 25 \%, 50 \%$, and $75 \%$ of the boundary conditions along the lock wall's height so that the stress state in the pintle and pintle connectors could be analyzed. The stress redistribution in the pintle was analyzed internally and externally using cross-sectional contours and stress path analysis techniques, respectively. The results from the simulated parametric stress analysis compared 
von Mises yield stress criterion to the LRFD based design for LD27 pintle. The results of the stress analysis are as follows:

1. The stress path analysis conducted for the pintle's surface indicated the stress increased along both the horizontal and vertical paths as the quoin block degradation level increased from $0 \%$ to $75 \%$. Additionally, in some instances, stress reversals were shown to occur. Specifically, "Vertical Load Path 1" at 50\% to 75\% deterioration levels in Figure 4-26 and "HorizontalLoad Path 4" at 75\% deterioration level in Figure 4-34 indicated a stress reversal had taken place. Also, the overall stress level at the bolt-hole connection region was much higher than the rest of pintle. Furthermore, the predicted simulations consistently showed the high stress concentrations were occurring at the connection sites for all deterioration levels. Finally, the stress concentrations predominately occurring in the bolt-hole region are an indication the pintle is prone to crack and/or fail if the material's yield stress is exceeded.

2. The contour plot analysis conducted for the pintle member's cross-sectional view indicated the stress level increased consistently as the quoin block degradation level increased from $0 \%$ to $75 \%$. Furthermore, the pintle's cross-sectional view shows the stress is increasing through the thickness and in the neck region. Yet, the stress is below yielding even at the $75 \%$ deterioration level.

3. The contour plot analysis conducted for the pintle member's side view indicated the stress level increased consistently as the quoin block degradation level increased from $0 \%$ to $75 \%$. Additionally, the member's side view contour plots show higher stress levels are occurring around the pintle's neck. The stress is below yielding even at the $75 \%$ deterioration level. The stress concentrations predominately occurring in the neck region are an indication the pintle is prone to crack and/or fail if the material's yield stress is exceeded. Further investigation is needed to determine the cause of higher stress in the neck region.

\subsubsection{Predicted results versus field observations}

This study developed a 3D-FEM so that an in-service operating miter gate could be sufficiently represented. The development of the 3D-FEM also allowed for comparison of the predicted behavior to the field observations made during field inspection of the miter gates along the Mississippi River. The following comparisons were made: 
1. The model predicted the stress concentrations predominately occurring in the bolt-hole region are an indication the pintle is prone to crack and/or fail if the material's yield stress is exceeded. The inspection of Tom Bevill Lock and Dam, conducted by ERDC in conjunction with the USACE Mobile District, showed cracking and crack propagation in the bolt region of the pintle. The image shown in Figure 5-1 indicates the FEM can predict and determine the exact phenomena occurring in the pintle as observed during the field inspection.

Figure 5-1. The (a) 3D-FEM correctly predicting the exact (b) field observed cracking and crack propagating in the bolt-hole region of the pintle region for the Bevill Lock and Dam, located in the USACE Mobile District.

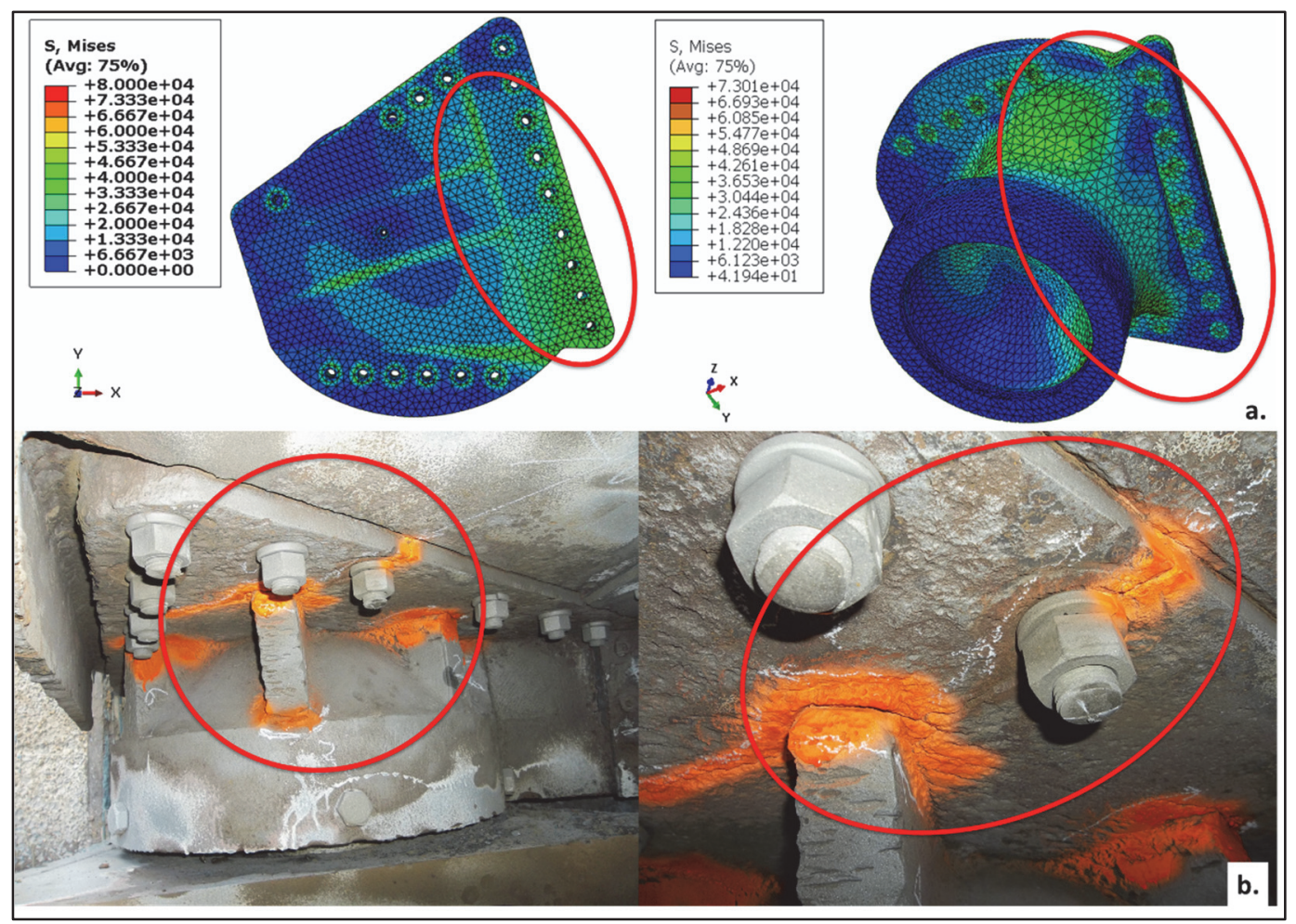

2. The model predicted the stress concentrations predominately occurring in the neck region are an indication the pintle is prone to crack and/or fail if the material's yield stress is exceeded. The inspection of John C. Stennis Lock and Dam, conducted by ERDC in conjunction with the USACE Mobile District, showed cracking in the neck region of the pintle. The image, shown by Figure 5-2, indicates the FEM can predict and determine the exact phenomena occurring in the pintle as observed during the field inspection. 
Figure 5-2. The (a) 3D-FEM correctly predicting the exact, and (b) field observed cracking in the neck region of the pintle region for the John C. Stennis Lock and Dam, located in the USACE Mobile District.

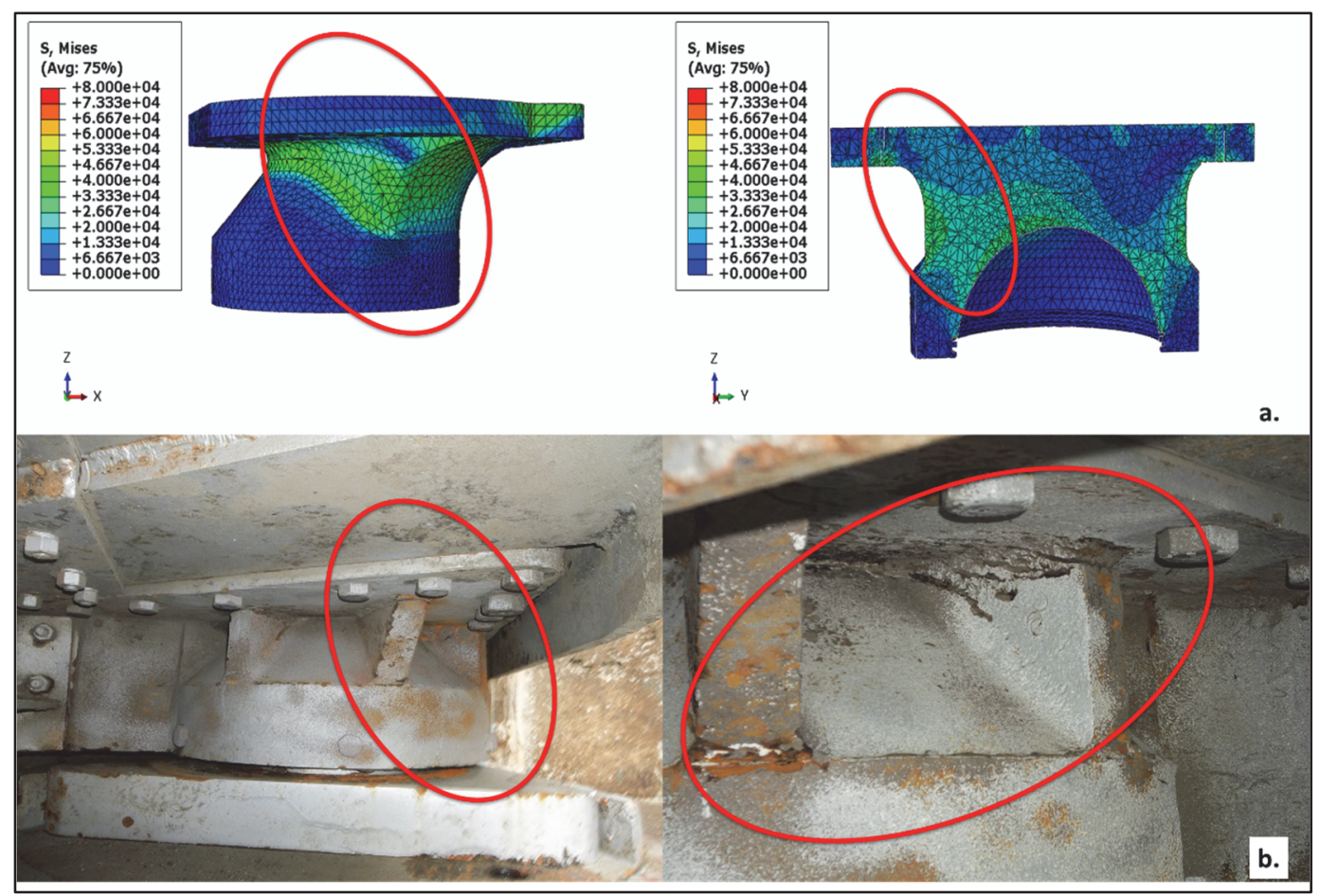

\subsubsection{Recommendations for pintle designs and retrofits}

This investigation has made new discoveries by showing how increasing load affects the loading capacity of the pintle and its connecting structural members. The findings of this study are essential for formulating recommendations for future pintle designs and retrofits that can better mitigate the detrimental deterioration effects:

1. The bolt region of the pintle needs to be redesigned so the stress is reduced. Currently, the bolts used in the design have a minimum tensile strength capacity of 75,000 psi and should not fail. However, the boltholes appear to be where cracking and/or failure will likely occur. Therefore, the recommendation is to increase the thickness of the connection site either during the steel casting process or by adding welded steel plating to the member during construction and/or assembly of the miter gate and pintle.

2. The neck region of the pintle needs to be redesigned so the stress is reduced. The current design does not use ribbing reinforcement retrofit. 
However, the previous design did make use of a ribbing reinforcement retrofit, and the technique should be reconsidered.

3. In 2013, the LD27 miter gate was replaced with a new pintle design. The new design was developed and/or used due to the cracks discovered in the ribbing retrofit of the pintle. The Jacobs Engineering Group firm hypothesized the ribs were susceptible to fatigue cracking, and they were therefore eliminated from the design of the LD27 replacement pintle (Jacobs Engineering Group 2010a,b,c). After ERDC conducted the FEA of the LD27 miter gate replacement pintle, the stresses are showing to be higher in the region (pintle necking) where the ribs were previously located. To better ascertain the cause of cracking, ERDC recommends a "Static" and "Computational Fluid Dynamics" finite element parametric analysis be performed on the pintle's with ribbing reinforcement and those that do not.

\subsection{Summary of discussion}

The research findings support the hypothesis $(H)$ the axial load is no longer applied to the gate's central axis when the quoin block deteriorates at the wall's boundaries. As a result of the eccentric loading condition, the load transfer that is intended to occur with the wall diminishes and may cause a stress increase in the pintle region. Excessive stress concentrations are occurring in both the bolt-hole and neck region of the pintle. Recommendations have been provided for reinforcing the regions. Additionally, "Static" and "Computational Fluid Dynamics" (finite element parametric) analyses are recommended so the cause of over stressing in the neck region can better be determined. The next chapter further explains the major conclusions and innovations produced from this comprehensive investigative effort. 


\section{Summary, Conclusions, and Future Work}

\subsection{Summary}

Operating and maintaining miter gates are important parts of the USACE mission. Maintaining the miter gates operation is vital for the trade industry, for port facilities, and for the safety of the adjacent river communities. Through the years there have been inspection, sensor-based health monitoring research programs implemented in support of the USACE mission. Still needed is a means to understand how deterioration affects the structural capacity of the gate while in service.

The focus of this study was to ascertain the influence quoin block deterioration and loss of lock wall contact has on load transfer to the pintle (component that the gate pivots on) and pintle connections. The investigation used a systematic detailed approach to examine the effects of quoin block degradation. A finite element parametric analysis was used to determine the influence quoin block deterioration and loss of lock wall contact has on load transfer to the pintle and pintle connections. The FEA was used to determine where the overstressed (a) areas in the pintle globally and (b) local critical regions and pintle connection points were occurring.

\subsection{Contributions and/or conclusions}

To the author's knowledge, this work has for the first time developed a $3 \mathrm{D}-\mathrm{FEM}$ that shows an in-service operating miter gate to be sufficiently represented. The simulated predictions indicated excessive stress concentrations are occurring in both the bolt-hole and neck region of the pintle. Additionally, the work contributed to determining where the overstressed area occurred in the pintle (a) globally-neck and (b) local critical regionsbolt-holes. Furthermore, the development of the $3 \mathrm{D}-\mathrm{FEM}$ made it possible to compare predicted behavior to field observations made during field inspection of the miter gates along the Mississippi River. The findings of the computational analysis support the field observations made during field inspection, conducted by ERDC in conjunction with USACE Mobile District, of the miter gates along the Mississippi River.

\subsection{Future work}

The results of this work can be used to help USACE administrators to better prioritize repair. It is very likely gates that have greater deterioration 
will require relatively frequent maintenance and repair. The effort provided pertinent findings that can be used to suggest recommendations for future pintle designs and retrofits that can better mitigate the detrimental deterioration effects:

1. The bolt region of the pintle needs to be redesigned so the stress is reduced. Currently, the bolts used in the design have a minimum tensile strength capacity of 75,000 psi and should not fail. However, the boltholes appear to be where cracking and/or failure will likely occur. Therefore, the recommendation is to increase the thickness of the connection site either during the steel casting process or by adding welded steel plating to the member during construction and/or assembly of the miter gate and pintle.

2. The neck region of the pintle needs to be redesigned so the stress is reduced. The current design does not use ribbing reinforcement retrofit. However, the previous design did make use of a ribbing reinforcement retrofit, and the technique should be reconsidered.

3. In 2013, the LD27 miter gate was replaced with a new pintle design. The new design was developed and/or used due to the cracks discovered in the ribbing retrofit of the pintle. The Jacobs Engineering Group firm hypothesized the ribs were susceptible to fatigue cracking, and they were, therefore, eliminated from the design of the $\mathrm{LD} 27$ replacement pintle (Jacobs Engineering Group 2010a,b,c). After ERDC conducted the FEA of the LD27 miter gate replacement pintle, the stresses are showing to be higher in the region (pintle necking) where the ribs were previously located. To better ascertain the cause of cracking, ERDC recommends that a "Static" and "Computational Fluid Dynamics" finite element parametric analysis be performed on the pintle's with ribbing reinforcement and those that do not.

4. To effectively use field instrumentation data for model comparisons, the structural members must be instrumented immediately after fabrication, and limited data collection must be acquired during the miter gate construction assembly phase so that the initial stress state can be determined. Quantifying the initial internal stress state of the gate allows the data to be normalized correctly, therefore, a reasonable comparisons can be made between the instrumentation data and model simulations. 


\section{Bibliography}

\section{Cited works}

AISC (American Institute of Steel Construction). 2001. Manual of Steel Construction, Load and Resistance Factor Design (LFRD). $3^{\text {rd }}$ ed. Chicago, IL.

ASTM (American Society for Testing and Materials). 2013. Specification for Steel Castings, Carbon, for General Application. Standard A27/A27M. West Conshohocken, PA: ASTM International. Doi 10.1520/A0027_A0027M-13.

2014. Standard Specification for Stainless Steel Bolts, Hex Cap Screws, and Studs. ASTM Standard F593 West Conshohocken, PA: ASTM International.

Barker, B. 2012. SMART Gate. USACE Fact Sheet.

Boresi, A., R. Schmidt, and O. Sidebottom. 2003. Advanced Mechanics of Materials. New York: Wiley 3.

Carriere, R., and R. L. Moses. 1992. "High Resolution Radar Target Modeling Using a Modified Prony Estimator." IEEE Transactions on Antennas and Propagation 40:13-18. doi:10.1109/8.123348.

Chang, F.-K., and F. Kopsaftopoulos. 2015. Structural Health Monitoring 2015: System Reliability for Verification and Implementation. Lancaster, PA: DESrech Publication, Inc.

Commander, B. C., J. X. Schulz, G. G. Goble, Bridge Diagnostics, Inc., and C. P. Chasten. 1992a. Computer-Aided, Field-Verified, Structural Evaluation: Report 2, Field Test and Analysis Correlation at John Hollis Bankhead Lock and Dam.

Technical Report ITL-92-12. Vicksburg, MS: U.S. Army Engineer Research and Development Center, Information Technology Laboratory (ERDC-ITL).

1992b. Computer-Aided, Field-Verified, Structural Evaluation: Report 3, Field Test and Analysis Correlation of a Vertically Framed Miter Gate at the Emsworth Lock and Dam. Technical Report ITL-92-12. Vicksburg, MS: U.S. Army Engineer Research and Development Center, Information Technology Laboratory (ERDC-ITL).

1993. Computer-Aided, Field-Verified, Structural Evaluation: Report 4, Field Test and Analysis Correlation at Red River Lock and Dam No. 1. Technical Report ITL-92-12. Vicksburg, MS: U.S. Army Engineer Research and Development Center, Information Technology Laboratory (ERDC-ITL).

. 1994a. Field Testing and Structural Analysis of Vertical Lift Lock Gates. Technical Report REMR-CS-44. Vicksburg, MS: U.S. Army Engineer Research and Development Center (ERDC).

1994b. Detection of Structural Damage on Miter Gates. ERDC/TR-REMR-CS-45. Vicksburg, MS: U.S. Army Engineer Research and Development Center (ERDC). 
Cullen, J. 2015. “Mississippi River Generates \$405,000,000,00o Annually.” Quad-City Times. http://qctimes.com/news/local/government-and-politics/mississippiriver-generates-annually/article_b1e73932-dbof-544d-86a5-3923c54fc5aa.html.

Dowling, N. E. 1999. Mechanical Behavior of Materials: Engineering Methods for Deformation, Fracture, and Fatigue. 2d ed. New Jersey: Prentice-Hall.

Estes, A. C., D. M. Frangopol, and S. D. Foltz. 2004. "Updating Reliability of Steel Miter Gates on Locks and Dams Using Visual Inspection Results.” Engineering Structures 26:319-333.

Fish, J., and T. Belytschko. 2008. A First Course in Finite Elements. Hoboken, NJ: John Wiley \& Sons.

Grier, D. V. 2009. "The Declining Reliability of the U.S. Inland Waterway System.” OnlinePubs. https://www.hsdl.org/?view\&did=743731.

Hite, Jr. J. E, J. E. Clausner, and D. N. McComas. 2006. Navigation Lock and Dam Inspection and Emergency Repairs Workshop Summary. ERDC/CHL-SR-06-2. Vicksburg, MS: U.S. Army Engineer Research and Development Center, Coastal and Hydraulics Laboratory (ERDC-CHL).

HQUSACE (Headquarters, U.S. Army Corps of Engineers). 1993. Design of Hydraulic Steel Structures. EM 1110-2-2105. Washington, DC: HQUSACE.

. 1994. Lock Gates And Operating Equipment. EM 1110-2-2703. Washington, DC: HQUSACE.

- 2001. Inspection, Evaluation and Repair of Hydraulic Steel Structures. EM 11102-6054. Washington, DC: HQUSACE.

- 2010. Advanced Reliability Analysis of Fatigue Cracking in Horizontally Framed Miter Gates. ETL 1110-2-566. Washington, DC: HQUSACE.

Jacobs Engineering Group. 2010a. LD 27 Miter Gate Design Report. USACE St. Louis District.

—. 2010b. LD 27 Miter Gate Replacement Drawings. USACE St. Louis District.

_. 2010c. LD 27 Miter Gate Technical Specifications. USACE St. Louis District.

Kulak, G. L., J. W. Fisher, and J. H. A. Struik. 2001. Guide to Design Criteria for Bolted and Riveted Joints. 2nd ed. Chicago, IL: John Wiley \& Sons.

McAllister, T. P., and B. R. Ellington. 2001. "Reliability-Based Condition Assessment of Welded Miter Gate Structures.” Journal of Infrastructure Systems 7:95-106.

McCleese, W. F. 2000. REMR Program Overview and Guide. Vicksburg, MS: U.S. Army Engineer Research and Development Center (ERDC).

NAVSIMS. Accessed. 25 January 2016. https://navsims.usace.army.mil/. 
Padula, J. A., D. D. Abraham, and K. L. Haskins. 2010. Emergency Gap Closures. ERDC/GSL-TR-10-44. Vicksburg, MS: U.S. Army Engineer Research and Development Center, Geotechnical and Structures Laboratory (ERDC-GSL).

Riveros, G. A. 1995. User's Guide: Computer Program for the Design and Investigation of Horizontally Framed Miter Gates Using the Load and Resistance Factor Design Criteria (CMITER-LRFD). ITL-95-1. Vicksburg, MS: U.S. Army Corps of Engineers, Waterways Experiment Station.

Riveros, G. A., J. L. Ayala-Burgos, and J. Perez. 2009. Numerical Investigation of Miter Gates. ERDC/ITL-TR-09-1. Vicksburg, MS: U.S. Army Engineer Research and Development Center, Information Technology Laboratory (ERDC-ITL).

Riveros, G. A., and E. Arredondo. 2014. "Predicting Future Deterioration of Hydraulic Steel Structures with Markov Chain and Multivariate Samples of Statistical Distributions.” Journal of Applied Mathematics Vol 2014, Article ID 360532.

Riveros, G., E. Arredondo, K. Walker, D. Dixon, V. Fermo, J. Davis, C. Boler, and L. Whitlow. 2014. A Procedure for Predicting the Deterioration of Steel Hydraulic Structures to Enhance Their Maintenance, Management, and Rehabilitation. ERDC/ITL-TR-14-1. Vicksburg, MS: ERDC-ITL

Sauser, P. W., and G. A. Riveros. 2009. A System for Collecting and Compiling Condition Data for Hydraulic Steel Structures for Use in the Assessment of Risk and Reliability and Prioritization of Maintenance and Repairs. ERDC/ITL-TR-09-4. Vicksburg, MS: ERDC-ITL.

Systèmes, D. 2013. ABAQUS User's \& theory manuals-Release 6.13-1. Providence, RI, USA.

USACE (United States Army Corps of Engineers). 2008a. "Closed Holding Water." Management Measures Digital Library Floodwalls, Levees, and Dams. Website. http://library.water-resources.us/docs/MMDL/FLD/Feature.cfm?ID=25 .

. 2008b. "Open and Operating." Management Measures Digital Library Floodwalls, Levees, and Dams. Website. http:// library.waterresources.us/docs/MMDL/FLD/Feature.cfm?ID=25, posted on 14 May 2008, accessed 26 January 2014).

2013. Navigation Data Center. The U.S. Waterway System-Transportation Facts. Alexandria, VA.

\section{Uncited works}

Anderson, T. L. 2006. Fracture Mechanics - Fundamentals and Applications. $3^{\text {rd }}$ ed. Boca Raton, FL: CRC Press.

Ayyub, Bilal, M. Kaminskiy, R. C. Patev, and M. A. Leggett. 1995. Loading Cycles for the Fatigue Reliability Analysis of Miter Gates. ERDC/ITL TR-95-12. Vicksburg, MS: Engineer Research and Development Center, Information Technology Laboratory (ERDC-ITL).

Callister, W. D., Jr., and D. G. Rethwisch. 2014. Materials Science and Engineering: An Introduction. $9^{\text {th }}$ ed. New Jersey. 
Cherng, M. D., M. K. Phang, and C. H. Chang. 1983. "Miter-Type Navigation Lock Gates." Journal of Structural Engineering 109(10):2235-2247.

Dexter, R. J., M. N. Hussam, J. A. Padula, and R. Guillermo. 2007. Fitness-for-Purpose Evaluation of Hydraulics Steel Structures. ERDC/ITL-TR-07-15. Vicksburg, MS: U.S. Army Engineer Research and Development Center, Information Technology Laboratory (ERDC-ITL).

Eick, Brian A., Z. A. Treece, B. F. Spencer, M. D. Smith, S. C. Sweeney, Q. G. Alexander, and S. D. Foltz. 2018. Miter Gate Gap Detection Using Principal Component Analysis. ERDC TR-18-2. Vicksburg, MS: U.S. Army Research and Development Center (ERDC).

Ellingwood, B. R. 1993. Load and Resistance Factor Design for Steel Miter Gates. ITL93-4. Vicksburg, MS: U.S. Army Engineer Research and Development Center, Information Technology Laboratory (ERDC-ITL).

Engineers Edge, LLC. Undated. "Von Mises Criterion (Maximum Distortion Energy Criterion) - Strength (Mechanics) of Materials. Engineers Edge. Web. 16 March 2017.

Evans, James A., J. R. Tallent, R. D. Brown, A. D. Netchaev, and C. R. Thurmer. 2019. Determining Miter Gate Plate Corrosion and Thickness of Anti-Corrosion Coatings and Development of a Mobile Sensor Inspection Platform. ERDC/ITL TR-19-2. Vicksburg, MS: Engineer Research and Development Center, Information Technology Laboratory (ERDC-ITL).

Fehl, Barry D., G. A. Riveros, and Sharon Garner. 1997. Nonlinear Incremental Structural Analysis of Mcalpine Lock Replacement for Chamber, Miter Gate, and Culvert Valve Monoliths. ERDC/ITL TR-97-4. Engineer Research and Development Center, Information Technology Laboratory (ERDC-ITL).

Hartman, Joseph P., J. D. Gibson, and M. D. Nelson. 1987. Finite Element Studies of a Horizontally Framed Miter Gate, Report 7: Application and Summary. ERDC/ITL TR-87-4. Engineer Research and Development Center, Information Technology Laboratory (ERDC-ITL).

HQUSACE (Headquarters, U.S. Army Corps of Engineers). 2014. Design of Hydraulic Steel Structures. ETL 1110-2-584. Washington, DC: HQUSACE.

Hibbeler, R. C. 2009. Structural Analysis. $7^{\text {th }}$ ed. New Jersey: Pearson Prentice Hall.

Hinton, Jackson D. 2018. Corrosion of Hydraulic Steel Structures and Preventive Measures. Publication No. 10978643. Master's thesis. Mississippi State, MS: Mississippi State University, ProQuest Dissertations Publishing.

Lopez, Santiago R. 2018. Multi-Axial Fatigue Strength of Structural Bolts in Slip-Critical Connections under Combined Cyclic Axial and Shear Demands. Publication No. 10786222. Master's thesis. Fort Collins, CO: Colorado State University, ProQuest Dissertations Publishing.

Lozano, Christine. 2018. Development of Pre-Stressed Retrofit Strategies for Mitigating Fatigue Cracking in Steel Waterway Lock Gate Components. Publication No. 10681068. Master's thesis. Fayetteville, AR: University of Arkansas, ProQuest Dissertations Publishing. 
Lozano, Christine. 2019. "Effects of Adhesive Bond-Slip Behavior on the Capacity of Innovative FRP Retrofits for Fatigue and Fracture Repair of Hydraulic Steel Structures." Materials (Basel, Switzerland), 12(9). http://dx.doi.org.erdclibrary.idm.oclc.org/10.3390/ma12091495.

Lu, Yingxiang. 2018. Composites for Hydraulic Structures: A Review. Publication No. 27527171. Master's thesis. Morgantown, WV: West Virginia University, ProQuest Dissertations Publishing.

Mahmoud, Hussam, A. Como, and G. A. Riveros. 2014. Fatigue Assessment of Underwater CFRP-Repaired Steel Panels Using Finite Element Analysis. ERDC/ITL TR-14-3. Vicksburg, MS: Engineer Research and Development Center, Information Technology Laboratory (ERDC-ITL).

Padula, Joseph A. 1997. Flaw Detection Practices for Steel Hydraulic Structures. ERDC/ITL TR-91-1. Vicksburg, MS: Engineer Research and Development Center, Information Technology Laboratory (ERDC-ITL).

Ren, Kevin L. 1994. An Ultrasonic Approach for Nondestructive Testing of Deteriorating Infrastructure: Use of Direct Sequence Spread Spectrum Ultrasonic Evaluation. Publication No. 9424256. Doctoral Dissertation. Morgantown, WV: West Virginia University, ProQuest Dissertations Publishing.

Riveros, G. A. 1997. User's Guide: Computer Aided Inspection Forms for Hydraulic Steel Structures (CAIF-HSS), Windows Version. ERDC/ITL IR-97-1. Vicksburg, MS: Engineer Research and Development Center, Information Technology Laboratory (ERDC-ITL).

Riveros, G. A., and Christine A. Lozano. 2019. "Blind Prediction of FRP Repairs for Multiaxial Fatigue Cracks on Hydraulic Steel Structures.” MATEC Web of Conferences. Vol. 300.

http://dx.doi.org.erdclibrary.idm.oclc.org/10.1051/matecconf/201930005002.

Salmon, C. G., and J. E. Johnson. 1990. Steel Structures: Emphasizing Load and Resistance Factor Design. 3d ed. New York: Harper and Row.

Salmon, C., J. E. Johnson, and F. A. Malhas. 2009. Steel Structures: Design and Behavior Emphasizing Load and Resistance Factor Design. 5th ed. New Jersey: Pearson Prentice Hall.

USAWES (U.S. Army Engineer Waterways Experiment Station). 1950. Study of Butterfly Valves for Pearl River Locks. TM-2-313. Vicksburg, MS: U.S. Army Engineer Waterways Experiment Station. https://hdl.handle.net/11681/21221.

-1964. Operating Forces on Miter-Type Lock Gates. TR-2-651. Vicksburg, MS: U.S. Army Engineer Waterways Experiment Station.

Valsangkar, Anuj. 2015. Fatigue Crack Propagation in Underwater Carbon Fiber Reinforced Polymer (CFRP)-Retrofitted Steel Panels. Publication No. 1606578. Master's thesis. Fort Collins, CO: Colorado State University, ProQuest Dissertations Publishing. 
Will, Kenneth M. 1995. Comparison Of Barge Impact Experimental and Finite Element Results for the Lower Miter Gate of Lock and Dam 26. ITL-95-1. Vicksburg, MS: Engineer Research and Development Center, Information Technology Laboratory (ERDC-ITL).

Xiang, Li, T. Guan, and Zhou Youhui. 2015. "The Lightweight Design and Simulation of Hydraulic Steel Gate with Metal Sandwich and Construction.” Advanced Materials Research. 1095:539-544.

https://doi.org/10.4028/www.scientific.net/AMR.1095.539 


\section{Acronyms and Abbreviations}

\begin{tabular}{|c|c|}
\hline Abbreviation & Full Term \\
\hline 3D & Three Dimensional \\
\hline AISC & American Institute of Steel Construction \\
\hline ASD & Allowable Stress Design \\
\hline ASTM & American Society for Testing and Materials \\
\hline C & Ice Load \\
\hline $\mathrm{Cl}$ & Condition Index \\
\hline $\mathrm{D}$ & Dead Load \\
\hline $\mathrm{E}$ & Earthquake Loads \\
\hline ERDC & Engineer Research and Development Center \\
\hline FEA & Finite Element Analysis \\
\hline FEM & Finite Element Model \\
\hline FY & Fiscal Year \\
\hline $\mathrm{H}$ & Hypothesis \\
\hline$H_{s}$ & Hydraulic \\
\hline HSS & Hydraulic Steel Structures \\
\hline I & Barge Impact \\
\hline LD27 & Lock and Dam 27 \\
\hline LFRD & Load and Resistance Factor Design \\
\hline M & Mud Load \\
\hline NAVSIMS & Navigation Structures Inventory Management System \\
\hline NAVSYS & Navigation Systems Research Program \\
\hline NYDoT & New York State Department of Transportation \\
\hline Q & Operating \\
\hline QC/QA & Quality Control and Quality Assurance \\
\hline REMR & Repair, Evaluation, Maintenance, and Rehabilitation \\
\hline SHM & Structural health monitoring \\
\hline SMART & Structural health Monitoring and Analysis in Real Time \\
\hline USACE & U.S. Army Corps of Engineers \\
\hline W & Gravity \\
\hline
\end{tabular}




\section{Unit Conversion Factors}

\begin{tabular}{|l|l|l|}
\hline Multiply & By & To Obtain \\
\hline ic kh & 0.02831685 & cubic meters \\
\hline cubic inches (cu in.) & $1.6387064 \mathrm{E}-05$ & cubic meters \\
\hline degrees (angle) (deg) & 0.01745329 & radians \\
\hline degrees Fahrenheit $\left({ }^{\circ}\right.$ F) or (deg F) & $(\mathrm{F}-32) / 1.8$ & degrees Celsius \\
\hline feet (ft) & 0.3048 & meters \\
\hline inches (in.) & 0.0254 & meters \\
\hline pounds (force) (lb) & 4.448222 & newtons \\
\hline pounds (force) per foot (lb/ft) & 14.59390 & newtons per meter \\
\hline pounds (force) per inch (lb/in.) & 175.1268 & newtons per meter \\
\hline pounds (force) per square foot (lb/sq ft) & 47.88026 & pascals \\
\hline pounds (force) per square inch (lb/sq in.) & 6.894757 & kilopascals \\
\hline pounds (mass) (lb) & 0.45359237 & kilograms \\
\hline pounds (mass) per cubic foot (lb/cu ft) & 16.01846 & kilograms per cubic meter \\
\hline pounds (mass) per cubic inch (lb/cu in.) & $2.757990 \mathrm{E}+04$ & kilograms per cubic meter \\
\hline pounds (mass) per square foot (lb/sq ft) & 4.882428 & kilograms per square meter \\
\hline pounds (mass) per square yard (lb/sq yd) & 0.542492 & kilograms per square meter \\
\hline square feet (sq ft) & 0.09290304 & square meters \\
\hline square inches (sq in.) & $6.4516 \mathrm{E}-04$ & square meters \\
\hline
\end{tabular}




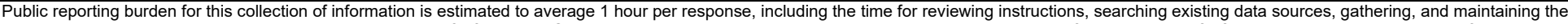

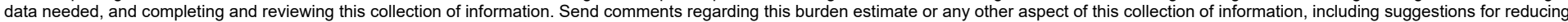

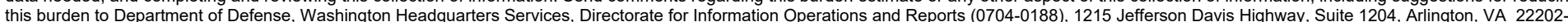

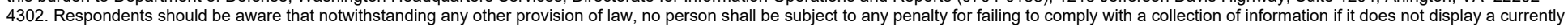
valid OMB control number. PLEASE DO NOT RETURN YOUR FORM TO THE ABOVE ADDRESS.
1. REPORT DATE (DD-MM-YYYY)
May 2021
2. REPORT TYPE
Technical Report (TR)

\section{TITLE AND SUBTITLE}

Finite Element Analysis of Quoin Block Deterioration and Load Transfer Mechanisms in Miter Gates:

Pintle and Pintle Connections
3. DATES COVERED (From - To)

5a. CONTRACT NUMBER

5b. GRANT NUMBER

5c. PROGRAM ELEMENT

5d. PROJECT NUMBER

6. AUTHOR(S)

DeAnna L. Dixon and Wayne D. Hodo 5e. TASK NUMBER

5f. WORK UNIT NUMBER

8. PERFORMING ORGANIZATION REPORT NUMBER

ERDC TR-21-9
U.S. Army Engineer Research and Development Center (ERDC)

Information Technology Laboratory (ITL)

3909 Halls Ferry Road

Vicksburg, MS 39180-6199
U.S. Army Engineer Research and Development Center (ERDC) Geotechnical and Structures Laboratory (GSL) 3909 Halls Ferry Road, Vicksburg, MS 39180-6199

\section{SPONSORING / MONITORING AGENCY NAME(S) AND ADDRESS(ES)}

10. SPONSOR/MONITOR'S ACRONYM(S)

\section{SPONSOR/MONITOR'S REPORT NUMBER(S)}

\section{DISTRIBUTION / AVAILABILITY STATEMENT}

Approved for public release; distribution is unlimited.

\section{SUPPLEMENTARY NOTES}

This effort was partially funded under the ERDC Information Technology Laboratory Training Program. This report was used to meet my Master's degree program requirements. The research topic was developed under the purview of the USACE- Mobile District.

\section{ABSTRACT}

The U.S. Army Corps of Engineers (USACE) currently operates and maintains approximately 193 commercially active lock sites with 239 locks and dams spanning nearly 12,000 miles. These networks of water channels are used to transport 600 million tons of domestic cargo, generating $\$ 405$ billion in revenue annually. Nearly $60 \%$ of these structures in operation are over 50 years old and have reached design life. A failure of the miter gates could result in a major negative impact on the economy and on the ability to maintain flood control. Administrators need recommendations to better prioritize maintenance and repair of the USACE miter gates. This work investigated the influence of miter gate's quoin block degradation on load transfer to the pintle and/or pintle connections. Results of finite element analysis are reported for the quoin block degradation simulated levels of $0 \%, 25 \%, 50 \%$, and $75 \%$. The parametric study shows the overstressed regions are the pintle neck and bolt-hole regions. To improve pintle designs so they may better mitigate detrimental environmental based deterioration effects, this work recommends (1) increasing the thickness of the bolt-hole connection region and (2) adding ribbing reinforcement around the neck area of the pintle.

\section{SUBJECT TERMS}

Locks (Hydraulic engineering)--Maintenance and repair Hydraulic structures Hydraulic gates--Structural failures Finite Element Method

\begin{tabular}{|c|c|c|c|c|c|}
\hline 16. SECURITY C & IFICATION OF: & & 17. LIMITATION & 18. NUMBER & 19a. NAME OF RESPONSIBLE PERSON \\
\hline $\begin{array}{l}\text { a. REPORT } \\
\text { Unclassified }\end{array}$ & $\begin{array}{r}\text { b. ABSTRACT } \\
\text { Unclassified }\end{array}$ & $\begin{array}{l}\text { c. THIS PAGE } \\
\text { Unclassified }\end{array}$ & SAR & 98 & $\begin{array}{l}\text { 19b. TELEPHONE NUMBER } \\
\text { (include area code) }\end{array}$ \\
\hline
\end{tabular}

